Florida International University FIU Digital Commons

\title{
Concurrent Participation in Federally-Funded Welfare Programs and Empowerment toward Economic Self-Sufficiency
}

Rigaud Joseph

Florida International University, rjose019@fiu.edu

DOI: 10.25148 /etd.FIDC001929

Follow this and additional works at: https:// digitalcommons.fiu.edu/etd

Part of the Social Welfare Commons, and the Social Work Commons

\section{Recommended Citation}

Joseph, Rigaud, "Concurrent Participation in Federally-Funded Welfare Programs and Empowerment toward Economic SelfSufficiency" (2017). FIU Electronic Theses and Dissertations. 3363.

https://digitalcommons.fiu.edu/etd/3363 


\section{FLORIDA INTERNATIONAL UNIVERSITY}

Miami, Florida

\section{CONCURRENT PARTICIPATION IN FEDERALLY-FUNDED \\ WELFARE PROGRAMS AND EMPOWERMENT \\ TOWARD ECONOMIC SELF-SUFFICIENCY}

A dissertation submitted in partial fulfillment of the

requirements for the degree of

DOCTOR OF PHILOSOPHY

in

SOCIAL WELFARE

by

Rigaud Joseph

2017 
To: Dean Tomás R. Guilarte

College of Public Health and Social Work

This dissertation, written by Rigaud Joseph, and entitled Concurrent Participation in Federally-Funded Welfare Programs and Empowerment toward Economic SelfSufficiency, having been approved in respect to style and intellectual content, is referred to you for judgment.

We have read this dissertation and recommend that it be approved.

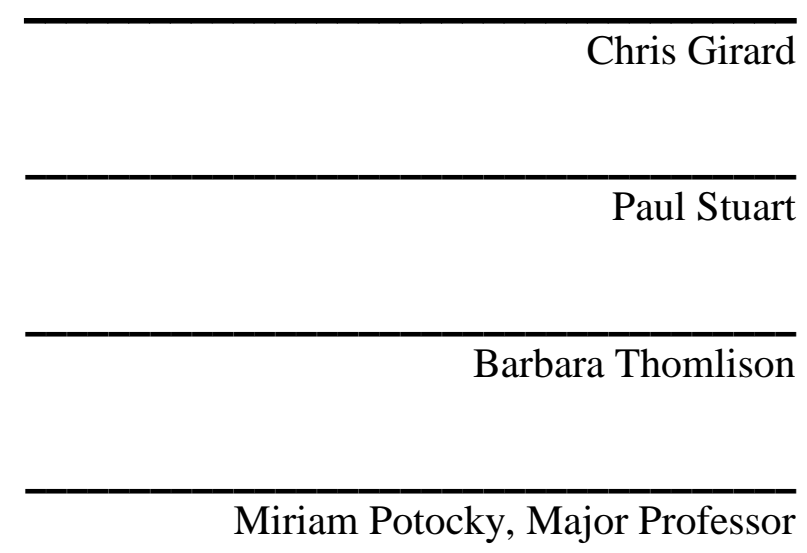

Date of Defense: June 19, 2017

The Dissertation of Rigaud Joseph is approved.

Dean Tomás R. Guilarte
College of Public Health and Social Work

College of Public Health and Social Work

Florida International University, 2017 
C Copyright 2017 by Rigaud Joseph

All rights reserved. 


\section{ACKNOWLEDGMENTS}

I hereby thank the members of my committee for their support, patience, and guidance, all of which were essential to achieving this work. I have been appreciative of their gentle but firm direction throughout the realization of the comprehensive papers, the dissertation proposal, and the dissertation itself. Dr. Barbara Thomlison contributed significantly to the development of this dissertation, mainly in terms of the research rationale, selection of relevant theories and critical analysis of the literature. Dr. Paul H. Stuart was instrumental in identifying poverty as a social problem and tracing the historical development of relevant U.S. social welfare policies put forth to address the problem. Dr. Chris Girard brought a critical perspective in the refinement of the theoretical perspectives, the hypotheses, and the methodology used in this project. Finally, I would like to thank my major professor, Dr. Miriam Potocky, who overviewed all aspects of this work. Dr. Miriam Potocky's specific contributions were in the areas of research design and methodology, data analysis, and interpretation of results. I am particularly thankful to them for sending feedback in a timely manner, allowing me to complete this degree within just three years. Besides, the aforementioned committee members played a tremendous role in making me aware of my abilities to fulfill this highest degree with excellence. I forever am indebted to them for boosting my selfconfidence toward the accomplishment of this dissertation. It would be ungrateful on my part not to acknowledge the academic and financial support received from the Florida International University School of Social Work. The social welfare coursework provided me with vital insights on how to identify a significant social issue, as well as develop an intervention and design a research methodology to address the issue. The School of 
Social Work was also helpful from a financial viewpoint. By extending assistantships to me for three successive years, the School of Social Work allowed me to concentrate solely on completing the coursework and developing my research. Such a crucial contribution will forever be appreciated. 


\author{
ABSTRACT OF THE DISSERTATION \\ CONCURRENT PARTICIPATION IN FEDERALLY-FUNDED \\ WELFARE PROGRAMS AND EMPOWERMENT \\ TOWARD ECONOMIC SELF-SUFFICIENCY \\ by
}

Rigaud Joseph

Florida International University, 2017

Miami, Florida

Professor Miriam Potocky, Major Professor

The purpose of this research was to determine the odds for low-income households to become and remain economically self-sufficient as a result of participating in federallyfunded welfare programs. An evaluation in nature, this study assessed the merits and shortcomings of federally-funded welfare programs. Using the public-use version of the 2008 Survey of Income and Program Participation (SIPP) Panel, this quasi-experimental investigation compartmentalized 4,216 low-income households into two groups: an intervention group $(n=2,436)$ and a comparison group $(n=1,780)$. Households in the intervention group received one or more federal means-tested welfare benefits for the most part of the 2008-2013 quinquennium. By contrast, those in the comparison groupalthough eligible for these benefits - did not receive them. Based on the premises of the theory of policy design and social construction, the culture of poverty theory, the racial classification model, and the social control thesis, the following two hypotheses were formulated: (1) Low-income households who receive one or more lower-tier federal means-tested benefits will be less likely to attain and maintain economic self-sufficiency 
than their counterparts who do not participate in federal welfare programs and (2) Lowincome households that enroll in more welfare programs will have worse self-sufficiency outcomes than their counterparts that participate in fewer programs. The survey respondents were measured repeatedly over a 56-month period to assess whether welfare receipt impacts their household income steadily beyond 150 percent of the federal poverty level, after controlling for known predictors. Findings from binomial logistic regression displayed medium effect sizes indicating that participation in public assistance did decrease the likelihood of attainment and maintenance of economic self-sufficiency among low-income American households. These findings were interpreted within the context of pre-existing differences that may have existed between the intervention group and the comparison group which were not accounted for in the multivariate analysis. Macro-implications of these findings for poverty and social welfare stakeholders were discussed. 


\section{DEDICATION}

I dedicate this thesis to my wife Nadia Germain. Without her support, love,

patience, and understanding, even the most reasonable efforts toward the completion of this work would have been in vain. 


\section{TABLE OF CONTENTS}

CHAPTER

PAGE

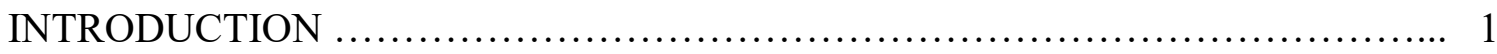

I. THE PARADOX OF POVERTY PERSISTENCE IN AMERICA ................. 4

Scope of Poverty in America .......................................... 4

Multifaceted Impact of Poverty on Children............................ 12

II. HISTORICAL DEVELOPMENT OF THE AMERICAN SOCIAL

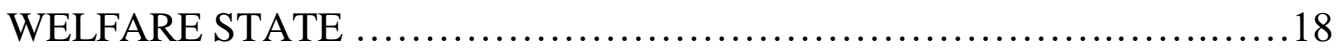

The Social Security Act of 1935 and the New Deal ........................... 19

The Economic Opportunity Act of 1964 and the War on Poverty ............ 23

The Omnibus Budget Reconciliation Act of 1981 and Neoliberalism,

Austerity, and Devolution Revolution ................................. 27

The Personal Responsibility and Work Opportunity Reconciliation Act

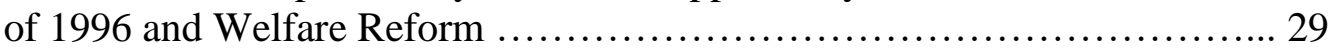

The Stimulus Package ............................................ 33

Today’s Safety Net Programs .......................................... 34

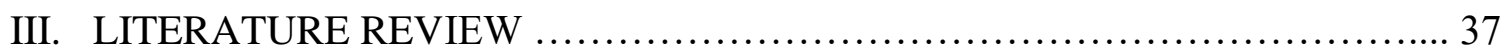

Toward Concurrent Participation ......................................... 37

Toward Self-Sufficiency ....................................... 45

Limitations of Previous Research and Rationale for the Current Study ...... 50

Significance of Current Study ..................................... 51

IV. PERSPECTIVES, THESES, THEORIES, AND MODELS ABOUT POVERTY

AND SOCIAL WELFARE IN AMERICA .......................... 58

Theoretical Perspectives on the Etiology of Poverty.................... 58

Theses of Welfare Expansion................................................................... 62

Theories of Devolution and Racial Disparities in Social Welfare........... 69

Theories of Savings and Economic Self-Sufficiency. .................. 75

Limitations of Theories ......................................... 80

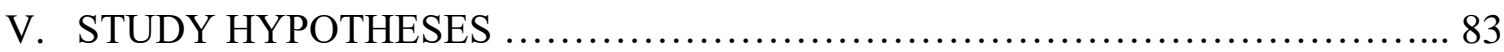

Linking Study Hypotheses with the Theory of Policy Design and

Social Construction .................................................. 84

Linking Study Hypotheses with the Culture of Poverty Theory............. 86

Linking Study Hypotheses with the Racial Classification Model ........... 87

Linking Study Hypotheses with the Social Control Thesis ................ 88

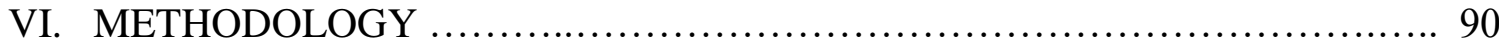

Research Design .................................................. 90 


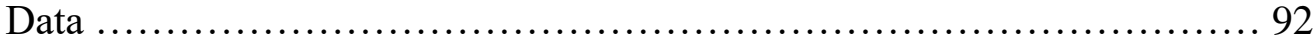

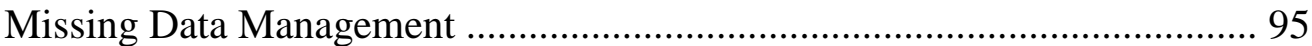

Sample ......................................................... 101

Study Variables .............................................. 103

VII. DATA ANALYSIS ................................................ 115

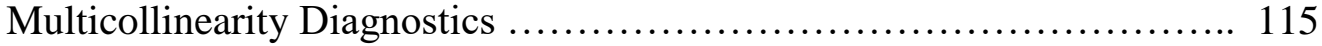

Binomial Logistic Regression ....................................... 117

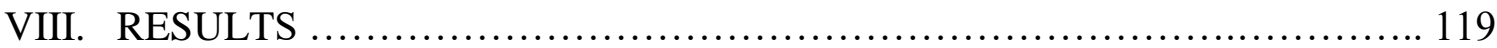

Descriptive Statistics ........................................... 119

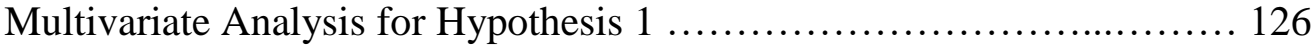

Multivariate Analysis for Hypothesis 2 ............................... 133

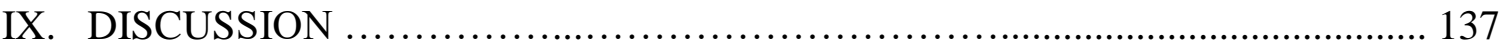

Interpretation of Results ........................................ 137

Theoretical Inferences .......................................... 140

Consistency with Prior Research......................................................... 141

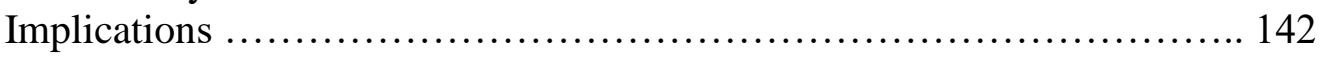

Limitations ..................................................... 154

Recommendations for Future Research ......................... 157

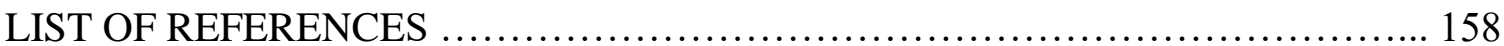

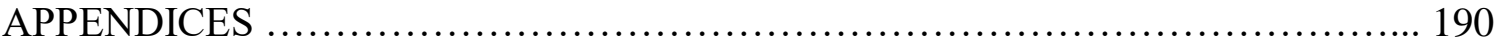

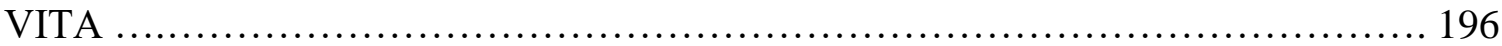




\section{LIST OF TABLES}

TABLE

PAGE

1. Federal Expenditures on Safety Net Programs for Fiscal Year 2012 ............... 54

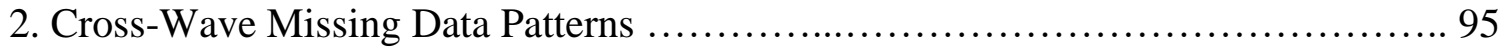

3. Attrition Rates Comparison for Full 2008 SIPP Panel and Study Sample ............ 97

4. Diagnosis of Missing Data Randomness .................................. 99

5. Case Inclusion/Exclusion Comparison in Initial Sample ......................102

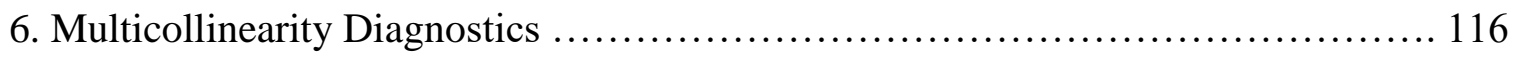

7. Frequency Distributions of Variables for Full Sample ....................... 121

8. Frequency Distributions of Variables for Intervention Group and

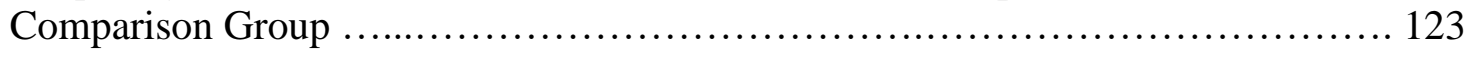

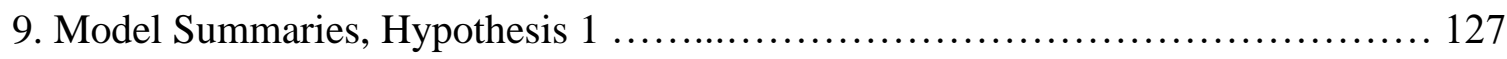

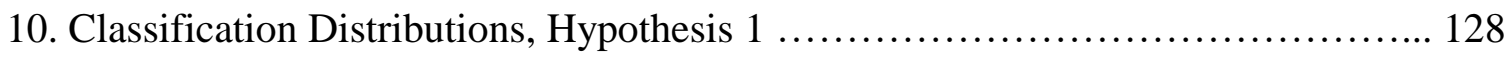

11. Logistic Regression of Self-Sufficiency: Variables in the Equation,

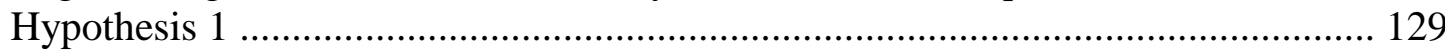

12. Model Summaries, Hypothesis 1, Households with Children Only ............... 131

13. Classification Distributions, Hypothesis 1, Households with Children Only ....... 131

14. Logistic Regression of Self-Sufficiency: Variables in the Equation, Hypothesis 1, Households with Children Only ............................... 132

15. Model Summaries, Hypothesis 2 ..................................... 134

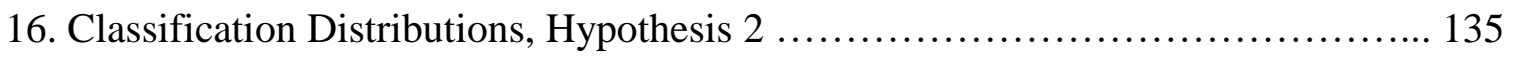

17. Logistic Regression of Self-Sufficiency: Variables in the Equation, Hypothesis 2 


\section{LIST OF FIGURES}

FIGURE

PAGE

1. Poverty Rates in the United States during the 2005-2015 Decade .................. 5

2. Poverty Rates in America by Region during the 2005-2015 Decade ................. 6

3. Deep Poverty Rates in the United States during the 2005-2015 Decade ............. 7

4. Poverty Rates in America by Age during the 2005-2015 Decade .................. 9

5. Deep Poverty Rates in America by Age during the 2005-2015 Decade .............. 9

6. Poverty Rates in America by Race during the 2005-2015 Decade .................. 10

7. Deep Poverty Rates in America by Race during the 2005-2015 Decade ............. 11

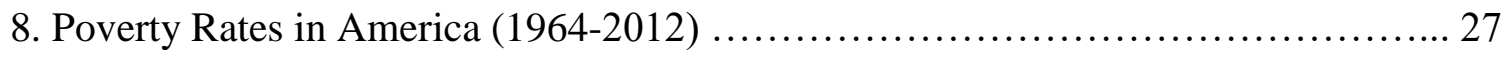

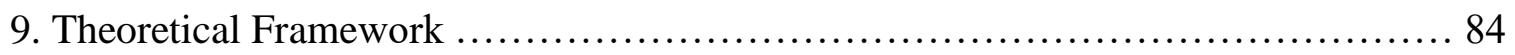

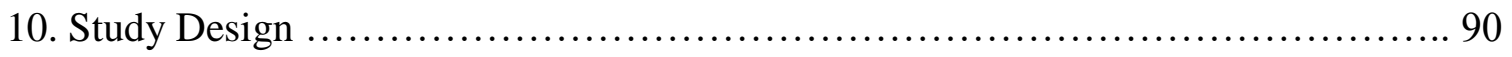




\section{ABREVIATIONS AND ACRONYMS}

$\mathrm{ACF}$

AFDC

AOTC

ARC

ARRA

CACFP

CBPP

CHIP

CNCS

CSOSADC

CTC

EITC

FCC

FPL

GDP

GED

$\mathrm{HCV}$

HUD

IHS

IPR

LIHEAP
Administration for Children and Families

Aid to Families with Dependent Children

American Opportunity Tax Credit

Appalachian Regional Commission

American Recovery and Reinvestment Act

Child and Adult Care Food Program

Center on Budget and Policy Priorities

Children's Health Insurance Program

Corporation for National and Community Service

Court Services and Offender Supervision Agency for the District of Columbia

Child Tax Credit

Earned Income Tax Credit

Federal Communications Commission

Federal Poverty Level

Gross Domestic Product

General Education Diploma

Housing Choice Voucher

Department of Housing and Urban Development

Indian Health Service

Income to Poverty Ratio

Low-Income Home Energy Assistance Program 


\begin{tabular}{|c|c|}
\hline MAR & Missing at Random \\
\hline MCAR & Missing Completely at Random \\
\hline MI & Multiple Imputation \\
\hline MNAR & Missing Not at Random \\
\hline NLSY & National Longitudinal Survey of Youth \\
\hline NSLP & National School Lunch Program \\
\hline OPRE & Office of Planning, Research, and Evaluation \\
\hline PRWORA & Personal Responsibility and Work Opportunity Reconciliation Act \\
\hline PSM & Propensity Score Matching \\
\hline $\mathrm{RCM}$ & Racial Classification Model \\
\hline RECS & Research and Evaluation Conference on Self-Sufficiency \\
\hline SBP & School Breakfast Program \\
\hline SIPP & Survey of Income and Program Participation \\
\hline SNAP & Supplemental Nutritional Assistance Program \\
\hline SSBG & Social Services Block Grants \\
\hline SSDI & Social Security Disability Insurance \\
\hline SSI & Supplemental Security Income \\
\hline SSM & Self-Sufficiency Matrix \\
\hline TANF & Temporary Assistance to Needy Families \\
\hline UI & Unemployment Insurance \\
\hline USDA & United States Department of Agriculture \\
\hline USDHHS & United States Department of Health and Human Services \\
\hline USHBCMS & United States House Budget Committee Majority Staff \\
\hline
\end{tabular}




$\begin{array}{ll}\text { VA } & \text { Veterans Affairs } \\ \text { WES } & \text { Women's Employment Survey } \\ \text { WIA } & \text { Workforce Investment Act } \\ \text { WIC } & \begin{array}{l}\text { Special Supplemental Nutrition Program for Women, Infants, and } \\ \text { Children }\end{array} \\ \text { WIN } & \text { Work Incentive Program } \\ \text { WOP } & \text { War on Poverty }\end{array}$




\section{INTRODUCTION}

The primary goal of this study is to contribute to the literature by expanding the body of research on poverty, welfare, and economic self-sufficiency. An evaluation in nature, this research sought to examine the impact of participation in federal means-tested welfare programs on the attainment and maintenance of economic self-sufficiency among low-income households. Embracing Schneider and Ingram's theory of policy design and social construction, Lewis' culture of poverty theory, Soss, Fording, and Schram's racial classification model, and Piven and Cloward's social control thesis, this investigation tested two welfare-related hypotheses: (1) low-income households who receive one or more lower-tier federal means-tested benefits will be less likely to attain and maintain economic self-sufficiency than their counterparts who do not participate in federal welfare programs and (2) low-income households that enroll in more welfare programs will have worse self-sufficiency outcomes than their counterparts that participate in fewer services.

The current study includes eight interrelated chapters. Chapter One-The Paradox of Poverty Persistence in America - introduces readers to poverty as a social and public health problem across the United States (US). The chapter particularly provides compelling statistics with respect to the scope of poverty, including its incidence and prevalence across the country. Also included in this chapter are graphical estimates about populations living below the federal poverty level. This chapter concludes with a descriptive assessment of the multifaceted impact of poverty on children.

Chapter Two entitled Historical Development of the American Welfare State presents a panoramic glimpse of America's most prominent antipoverty policies at the 
federal level since the 1930s. More specifically, this chapter highlights the New Deal programs implemented in the 1930s in response to the Great Depression; covers the War on Poverty policies pushed through by the Johnson administration in the 1960s; explains the devolution revolution agenda promoted by the Reagan administration in the 1980s; dives into the welfare reform enacted by Congressional Republicans and accepted by President Clinton in the 1990s; and reviews the Stimulus Package implemented under the Obama administration. Chapter Two ends with a synopsis of the current American welfare state with a special focus on the means-tested programs targeted on persons in the lower-tier.

Chapter Three is a thorough review of the body of literature on concurrent program participation and economic self-sufficiency among welfare beneficiaries. This chapter also identifies gaps in the existing scholarship, lays down the rationale for this project, and describes its significance in light of the economic costs of antipoverty policies in the United States.

Chapter Four contains a critical analysis of the most common theoretical perspectives pertaining to poverty and social welfare. This chapter - the longest in this current research project—critically reviews as many as eleven theoretical perspectives on poverty and social welfare. These theories take center stage in explaining the etiology of poverty, the expansion of welfare, the transfer of administrative power and racial disparities in the implementation of welfare policies, and the acquisition of savings and accumulation of assets among low-income households.

Chapter Five elaborates on the study hypotheses. This chapter presents proposed connections between the study hypotheses and the theory of policy design and social 
construction, the culture of poverty theory, the racial classification model, and the social control thesis.

The methodology is presented in Chapter Six. This section starts with a synthesis of the research design followed by a complete description of the longitudinal dataset used in the current investigation. Besides providing an in-depth description of the sample, this chapter explores methods of missing data management. All of the study variablesindependent, dependent, and confounding variables—are also discussed in this section.

While Chapter Seven details the statistical software and procedure employed in the analysis of the data, Chapter Eight explains the findings of this investigation. The final chapter of this research project—Chapter Nine — presents a thorough discussion and interpretation of the findings. In addition, this chapter appraises the merits and shortcomings of the research by analyzing both the implications and the limitations of the results. Finally, this chapter proposes directions for future research. 


\section{CHAPTER I. THE PARADOX OF POVERTY PERSISTENCE IN AMERICA}

\section{Scope of Poverty in America}

Poverty poses a serious threat to the nation's well-being and has become a recurring social and public health phenomenon in the United States of America (US) since at least the late nineteenth century (Bremner, 1956; Patterson, 2000). Using data from the Current Population Survey (CPS), Proctor, Semega, and Kollar (2016) found that 43.1 million Americans were poor in 2015. This number represented 13.5 percent of the total US population. This number also constituted a slight improvement in the fight against poverty from the 2014 figure where 46.7 million people across America were poor. In other words, there was a 1.3 percentage point decrease in poverty estimates between 2014 and 2015 (Proctor et al., 2016).

However, a close look at the poverty data reported for the 2005-2015 decade indicated that the 2015 poverty estimates remain higher than the pre-Great Recession poverty rates in a statistically significant way (DeNavas-Walt, Proctor, \& Smith, 2008, 2009, 2010, 2011, 2012, 2013; DeNavas-Walt \& Proctor, 2014, 2015; Proctor et al., 2016). Indeed, for the fiscal year 2007 - the year that marked the beginning of the latest recession - the national poverty rate was 12.5 percent, a 1.0 percentage point poverty change in comparison with the fiscal year 2015 (DeNavas-Walt et al., 2008; Proctor et al., 2016). Figure 1 below presents a panoramic glimpse of poverty rates in the US between 2005 and 2015. This figure is based on estimates reported by the US Census Bureau for the aforementioned years. As evidenced in this figure, the fiscal year 2006 witnessed the lowest rate of poverty over the decade (12.3 percent). On the other hand, the highest poverty rate for the same period of time was recorded in 2010 . 


\section{Figure 1. Poverty Rates in the United States during the 2005-2015 Decade (Source: US Census Bureau)}

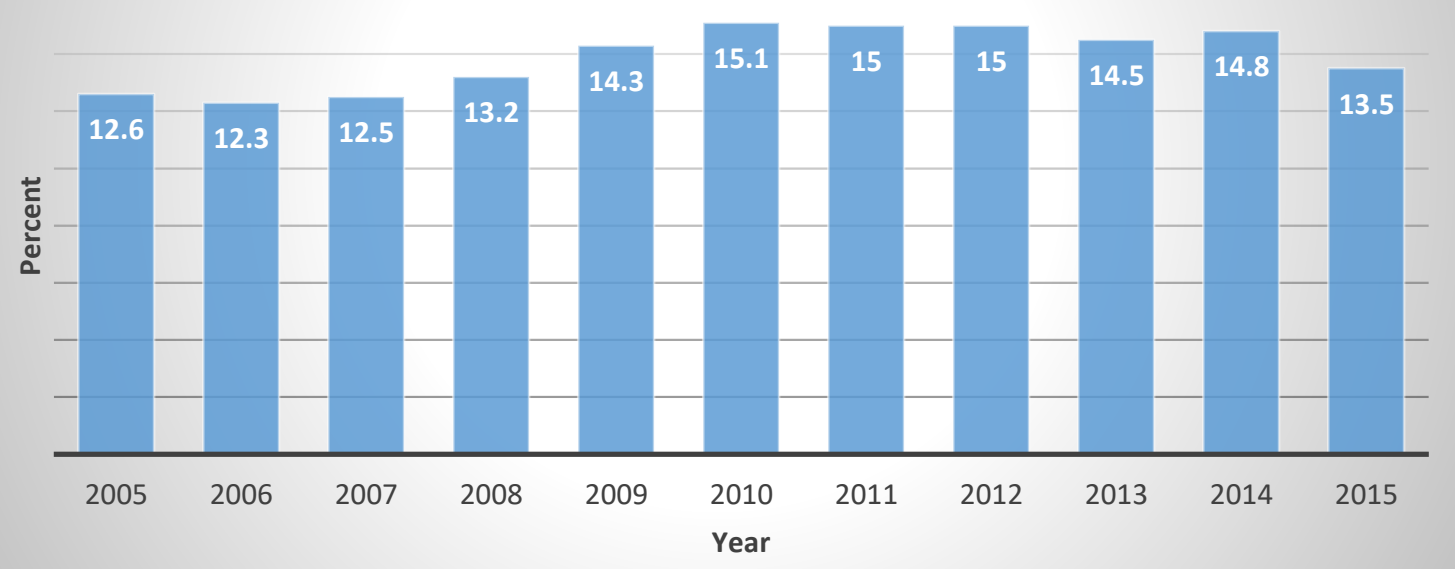

National data tend to mask the scope of the problem at lower levels of jurisdiction such as region, state, county, city, and zip code. According to Bishaw and Glassman (2016), some states have a history of having significantly higher poverty rates than the national average. As of the fiscal year 2015, this list includes Mississippi (22.0 percent), New Mexico (20.4 percent), Louisiana (19.6 percent), Arkansas (19.1 percent), Alabama and Kentucky (18.5 percent). By contrast, states such as New Hampshire, Maryland, Vermont, Minnesota, and Connecticut have been historically known for registering lower rates of poverty than the national average. In 2015, the poverty levels for these states were 8.2 percent, 9.7 percent, 10.2 percent, 10.2 percent, and 10.5 percent, respectively (Bishaw \& Glassman, 2016).

From a regional perspective, over the past decade most of the states with high rates of poverty were located in the South, while the Northeast was home to states with low rates of poverty (DeNavas-Walt et al., 2008, 2009, 2010, 2011, 2012, 2013; 
DeNavas-Walt \& Proctor, 2014, 2015; Proctor et al., 2016). Figure 2 below displays decade-long poverty estimates for the US regions.

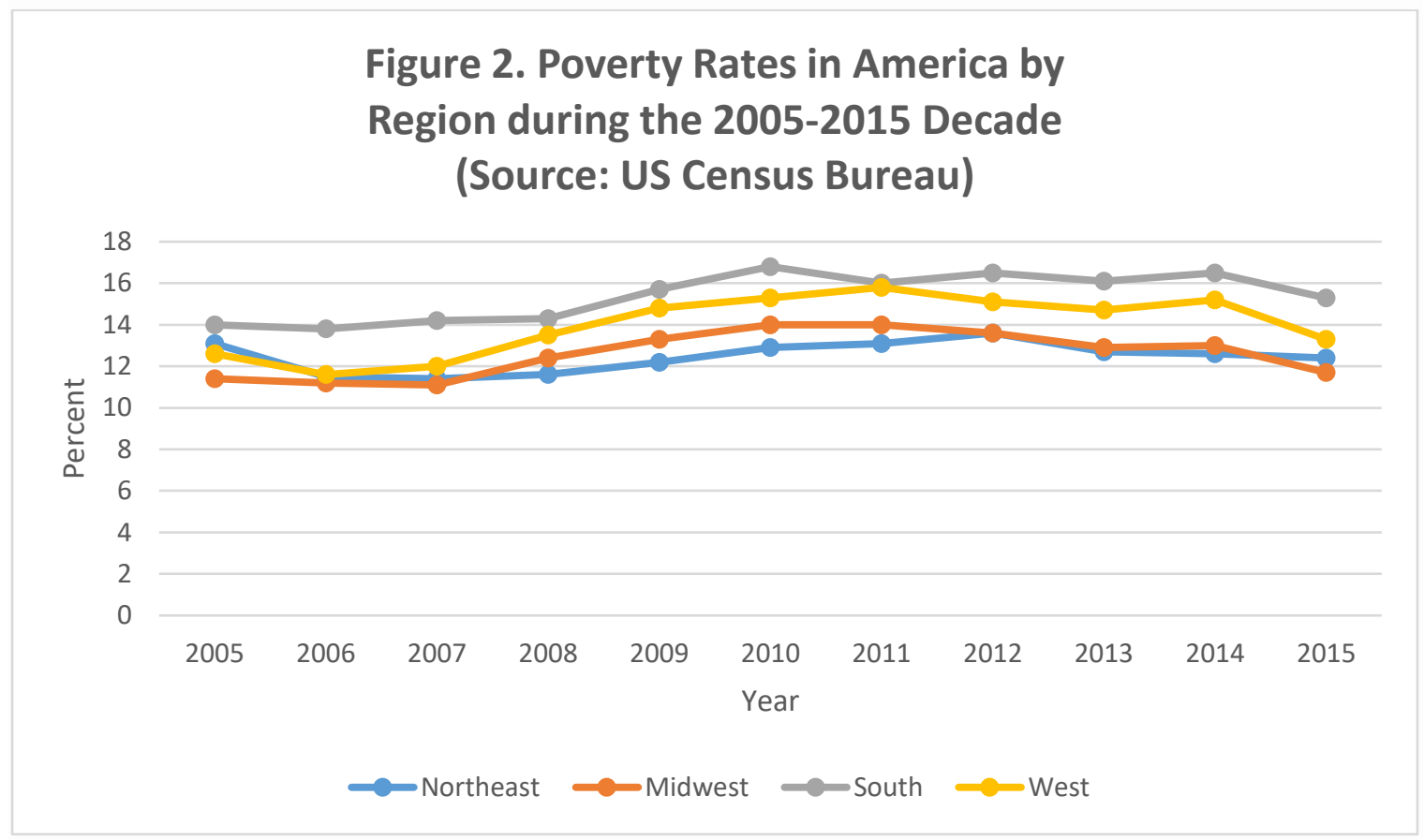

According to US Census Bureau (2015a), the United States of America is divided into four regions: Northeast, Midwest, South, and West. The Northeast encompasses 9 states: Connecticut, Maine, Massachusetts, New Hampshire, Rhode Island, Vermont, New Jersey, New York, and Pennsylvania. The Midwest englobes 12 states which are Illinois, Indiana, Michigan, Ohio, Wisconsin, Iowa, Kansas, Minnesota, Missouri, Nebraska, North Dakota, and South Dakota. The South is the largest region with 17 states: Delaware, District of Columbia, Florida, Georgia, Maryland, North Carolina, South Carolina, Virginia, West Virginia, Alabama, Kentucky, Mississippi, Tennessee, Arkansas, Louisiana, Oklahoma, and Texas. Finally, the West contains the remaining 13 states identified as Arizona, Colorado, Idaho, Montana, Nevada, New Mexico, Utah, Wyoming, Alaska, California, Hawaii, Oregon, and Washington. 
Deep poverty is another way to unmask national data and assess the severity of poverty among American households. Long dismissed as a developing-country issue, deep poverty has been a real concern in American society. Deep poverty is operationally defined as the state in which a household annual income falls under 50 percent of the federal poverty level (FPL) (Proctor et al., 2016). There had been an increase in deep poverty across America from 5.2 percent in 2006 to 6.6 percent in 2014 (DeNavas-Walt et al., 2008, 2009, 2010, 2011, 2012, 2013; DeNavas-Walt \& Proctor, 2014). Not until 2015 did the country experience a .5 percentage point decrease in the deep poverty rate to 6.1 percent in 2015 from 6.6 percent one year earlier. The trajectory of deep poverty in America over the past decade is demonstrated in Figure 3. As seen in this figure, it is evident that the nation has not made enough progress toward reducing this social problem (DeNavas-Walt et al., 2008, 2009, 2010, 2011, 2012, 2013; DeNavas-Walt \& Proctor, 2014, 2015; Proctor et al., 2016).

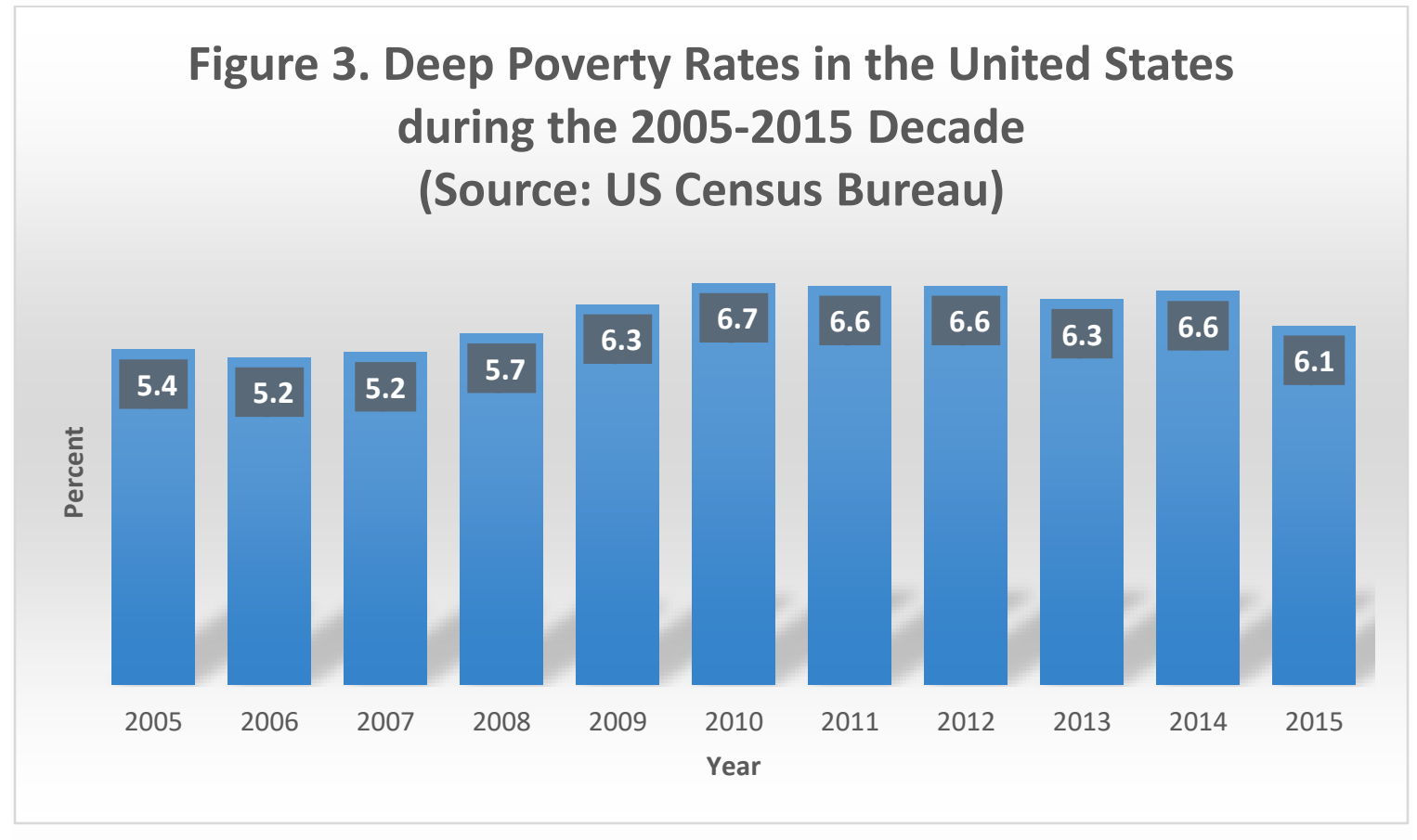


Children as poorest citizens. Children continued to be overrepresented among the poor, as child poverty rates are historically higher than the poverty rates for adults age 18-64 and older people age 65 and above. In 2015, 19.7 percent of children under age 18 lived in poverty, as opposed to just 12.4 percent of adults in the 18 to 65 age range, and 8.8 percent of citizens who were 65 years old and over (Proctor et al., 2016). This trend of higher child poverty rates has been consistent throughout the 2005-2015 decade (DeNavas-Walt et al., 2008, 2009, 2010, 2011, 2012, 2013; DeNavas-Walt \& Proctor, 2014, 2015; Proctor et al., 2016).

Children also had the highest rate of deep poverty, as 8.9 percent of them lived in households with income less than 50 percent of the FPL in 2015. For the same year, the deep poverty rate was 5.9 percent (for age 18-64) and 2.8 percent (for age 65 and over) (Proctor et al., 2016). Comparative displays of poverty and deep poverty rates per age are presented in Figures 4 and Figure 5, respectively. The estimates in the graphs were collected for the 2005-2015 decade (DeNavas-Walt et al., 2008, 2009, 2010, 2011, 2012, 2013; DeNavas-Walt \& Proctor, 2014, 2015; Proctor et al., 2016). 

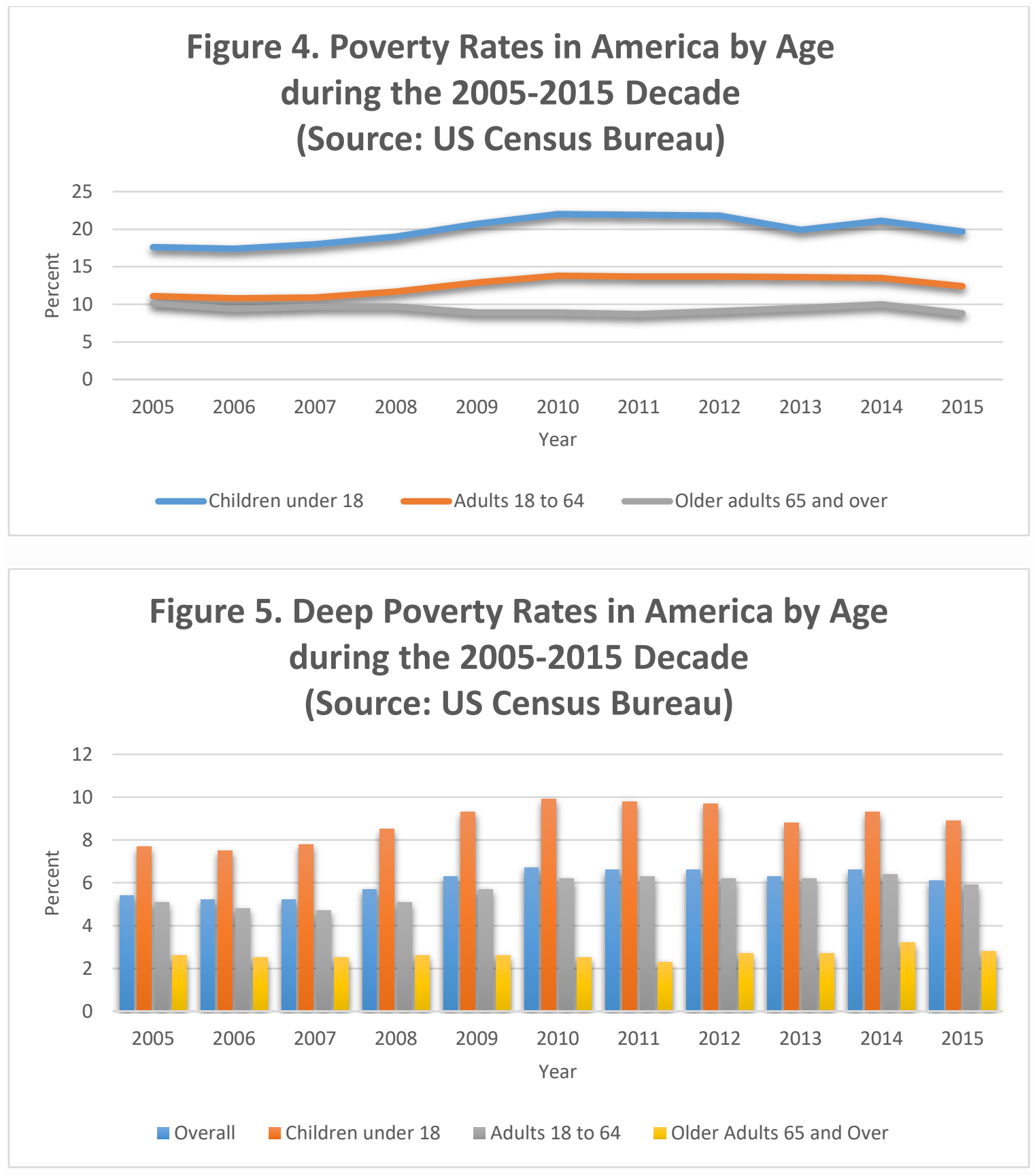

African Americans as poorest racial group. The incidence and prevalence of poverty among the African American population has been historically remarkable. Although poverty affects all racial and ethnic backgrounds, its impact has historically been the greatest on African Americans (DeNavas-Walt et al., 2008, 2009, 2010, 2011, 2012, 2013; DeNavas-Walt \& Proctor, 2014, 2015; Proctor et al., 2016). As shown in 
Figures 6 and Figure 7 below, the rates of poverty and deep poverty for African Americans were almost three times higher than poverty rates for non-Hispanic Whites. Compared to Asian Americans, African Americans were on average twice poorer between 2005 and 2015. Meanwhile, Hispanics had lower rates of poverty and deep poverty than African Americans, but significantly higher levels of poverty than nonHispanic Whites and Asian-Americans (see Figure 6 and Figure 7). It is worth mentioning that all racial groups experienced a decrease in poverty rates for the fiscal year 2015. The same applied for deep poverty, except for Asian-Americans (Proctor et al., 2016).

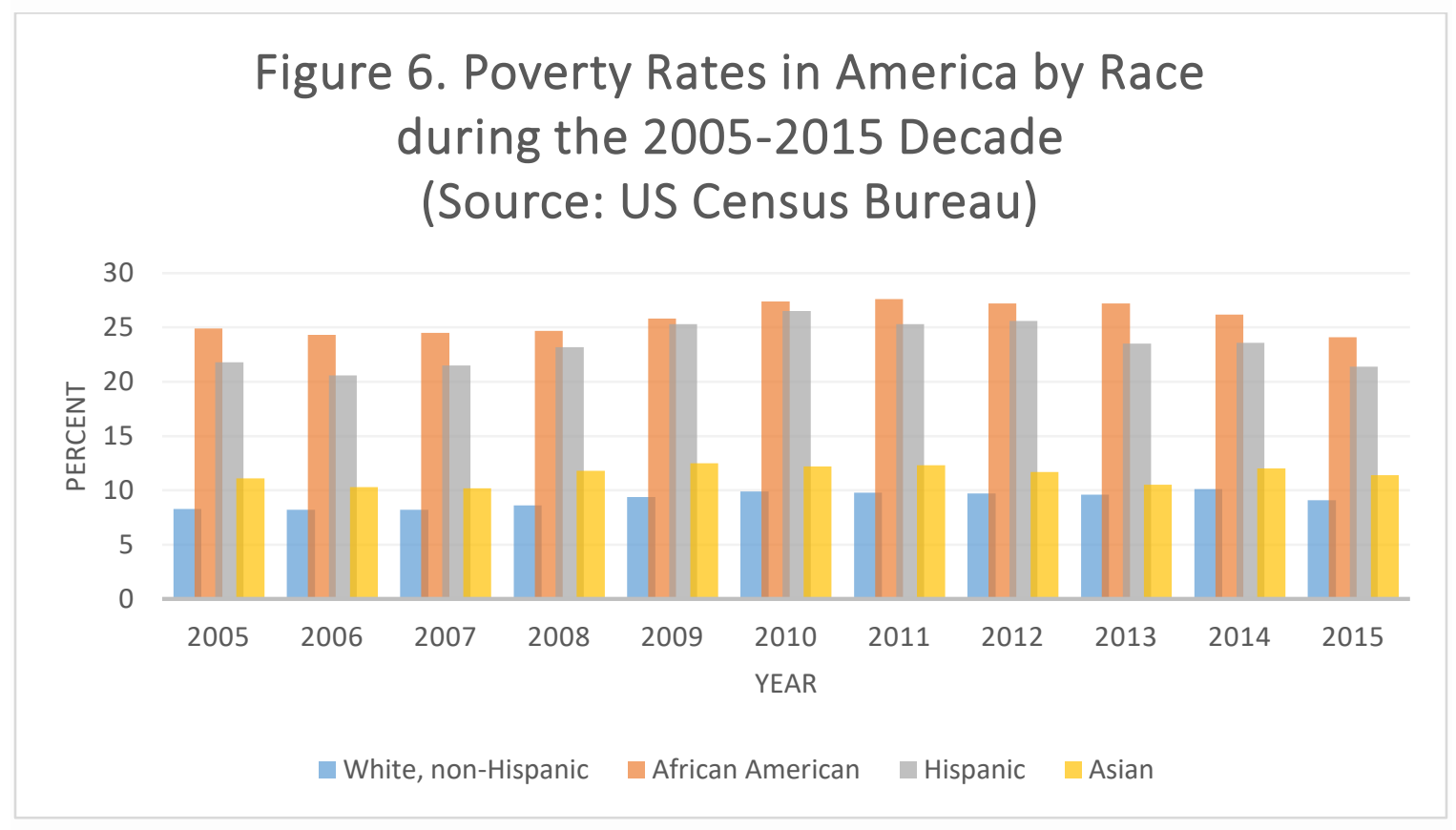




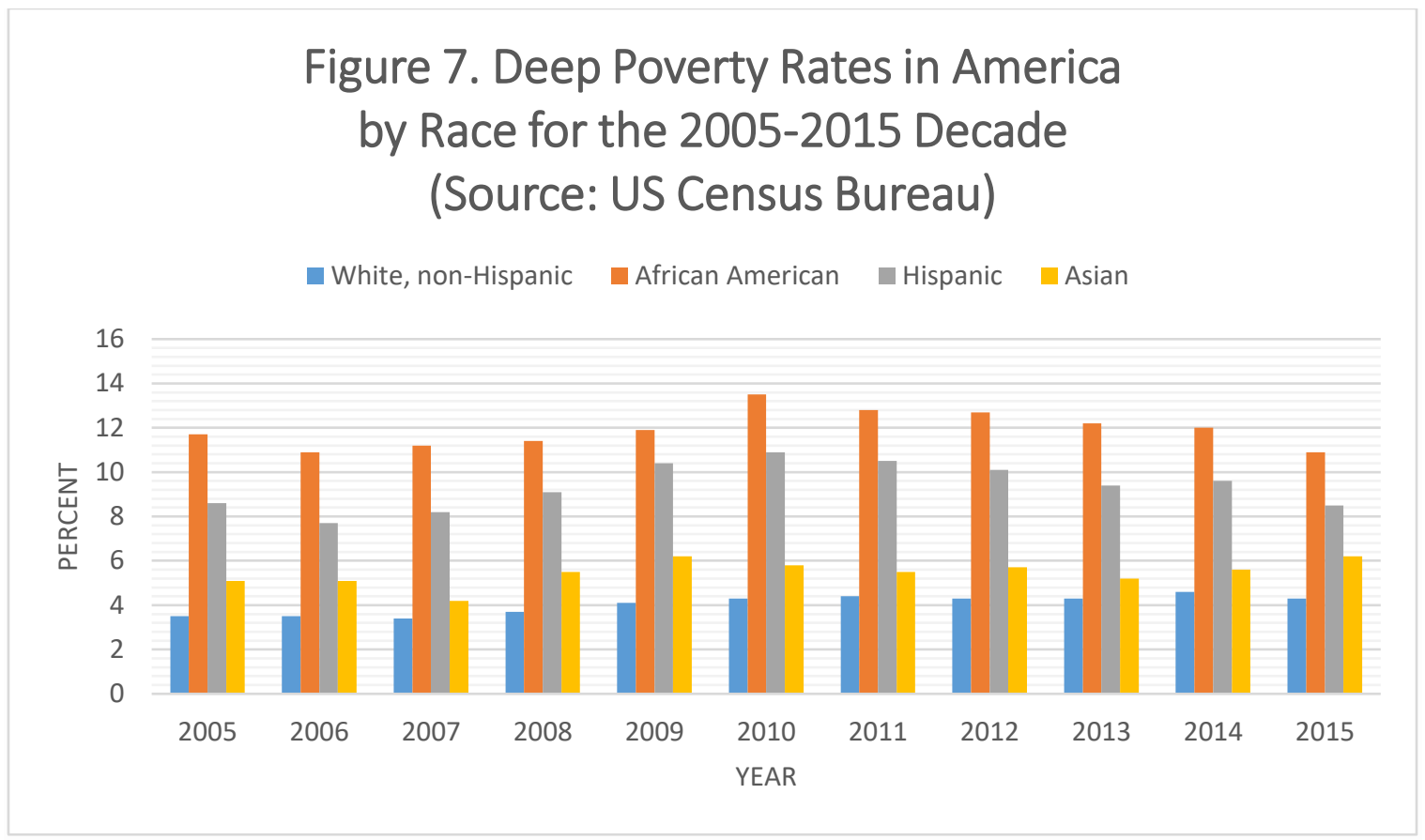

The persistence of poverty in America is perplexing because this country United States is one of the richest countries in the world. Some scholars use the term "paradox" to explain the presence of poverty in affluent countries (Davis, 1969; Peterson, 1991; Prasad, 2012; Weisbrod, 1966). Despite the nation's gradual economic recovery enhanced by the 2009 stimulus package which moved 6.9 million Americans away from poverty in 2010 (Center on Budget and Policy Priorities [CBPP], 2011), the statistics above depict a worrisome picture for American citizens. Having children's well-being at risk at the aforementioned high percentages should be a source of concern for household members, community leaders, researchers, politicians, advocates, religious organizations and-more important-lawmakers at local, state, and national levels. It is therefore understandable that child well-being has been identified as a context for great social work challenges not only for the American society but also the entire human race (Sherraden et al., 2014; United Nations, 2013). 


\section{Multifaceted Impact of Poverty on Children}

Although children are perceived to be a naturally a resilient population (Evans \& Fuller-Rowell, 2013), there is a strong body of evidence that shows that poverty has disastrous short-term, mid-term and long-term impacts on them. Using data collected between 2011 and 2012 by the National Survey of Children's Health (NSCH) through interviews with 95,677 families with dependent children, Sacks, Murphey \& Moore (2014) conducted a large-scale study on adverse childhood experiences (ACE) in the Unites States. Findings showed that poverty, also called economic hardship, is the most dominant form of ACE, ahead of divorce and/or separation, domestic violence, neighborhood violence, parental substance abuse, parental mental illness, death of a loved one, and parental involvement with the criminal justice system. More rigorous national and international studies on child development demonstrate the multifaceted effects of poverty on several aspects of children's lives, including health, education, behavior, family and social relationships, and subjective well-being. Some of these studies are reported below.

\section{Impact of Poverty on Child Health}

Researchers found associations between poverty and vulnerability to a broad range of healthcare issues, including mortality and morbidity, developmental delays and low birth weight (Aber, Bennett, Conley, \& Li, 1997; Bradshaw, 2002; Duncan \& Brooks-Gunn, 2000). Poor children are more likely to be exposed to hazardous living conditions, catch infectious diseases, and die by asphyxia than their non-poor counterparts. In addition, children who grow up in poor households are less likely to be taken to doctors' appointments and therefore end up having less access to complete, 
wraparound prenatal care as compared to their peers in self-sufficient homes (Bradley \& Corwyn, 2002).

Other research findings have examined health disparities and suggest a significant correlation between socioeconomic status and access to maternal care. Disadvantaged pregnant and breastfeeding women and their children were found to have less access to maternal care and mental health services than their counterparts with higher socioeconomic backgrounds (Bamfield, 2007; Huston, 1991). A lack of prenatal care can seriously jeopardize the health of children during successive stages of their development (Bamfield, 2007). Similarly, low birth rate can predispose them toward developing chronic health conditions such as heart problems and pulmonary diseases (Osmond, Barker, Winter, Fall, \& Simmonds, 1993; Wadsworth \& Kuh, 1997).

Another area of concern is obesity. In fact, studies on child development revealed that poverty-stricken children are more likely to develop obesity during later stages of development than are children not born and raised in poverty (Hernandez \& Pressler, 2014; Lee, Andrew, Gebremariam, Lumeng, \& Lee, 2014). One explanation for this finding is the fact that low income children, particularly those in developed countries, are mostly fed with innutritious foods. A lack of nutrients in the daily diet can result in obesity (Bradshaw, 2002). Meanwhile, Torres \& Wong (2013) found that children experiencing pre-teen poverty are at a greater risk of struggling with depression when they become adults as opposed to their counterparts who did not endure poverty before the age of 10 . 


\section{Impact of Poverty on Child Education}

Better-quality schools can influence the relationship between poverty and educational outcomes in a desirable way. In most countries, however, poor children usually attend underperforming schools (Prentice, 2007). Since parental backgrounds play a major role in determining academic performance for children (Ansalone, 2001; Buchmann \& DiPrete, 2006; Fuligni, 1997), parents who did not go far in school tend to undermine the importance of a good education. Therefore, under normal circumstances, children from underprivileged families are at greater risk of being absent from school. Accumulation of absences over a given school period results in less likelihood that impoverished students will achieve satisfactory educational outcomes (Attree, 2006, Horgan, 2007). Poor school achievement during early childhood could lead to future academic struggles and be an important factor for school dropout (Bynner, Elias, McNight, Pan, \& Pierre, 2002). Exposure to poverty also negatively affects the development of children's brains (Noble, Norman, \& Farah, 2005; Hanson et al., 2013) and, consequently, diminishes their intellectual ability and academic performance (Anderson, Leventhal \& Dupéré, 2014; Campbell et al., 2001). Chronic poverty is also found to be associated with early learning deficiencies, especially in the areas of mathematics, print concepts, reading, writing, vocabulary and oral fluency (Danziger \& Danziger, 1995).

\section{Impact of Poverty on Child Behavior}

Contemporary researchers have found associations between poverty and lack of cognitive control, resulting in internal and external maladjustment in behaviors (Flouri, Midouhas, \& Joshi, 2014; Henninger \& Luze, 2014; Lipina et al., 2013). Internal and 
external maladjusted behaviors can be exhibited at home, in school, and/or in other settings. Maladjusted behaviors tend to be found more in children from low socioeconomic backgrounds (Duncan and Brooks-Gunn, 2000). When exhibited on school grounds, these behaviors (especially external maladjusted behaviors) may result in school suspension or worse (Bradshaw, 2002).

\section{Impact of Poverty on Family Relationships}

Poverty contributes to family dysfunction either directly or by moderating or mediating the relationship with other variables (Banovcinova, Levicka, \& Veres, 2014; Russell, Harris, \& Gockel, 2008). Conger and associates (1994) proposed the Family Stress Model to explain the influence of economic hardship in creating emotional distress for parents, impeding their caregiving abilities in the process. The Family Stress Model was empirically tested within racially diverse populations, including African-Americans and European Americans. Results from a study that contained a sample size of 422 twoparent families corroborated the basic tenets of the model, as findings showed an association between poverty and inappropriate parenting strategies (Conger et al., 2002). A more recent study by Wadsworth et al. (2008) indicated that poverty triggers stressful conditions for family members thereby affecting the overall functioning of children, especially those with Hispanic and White non-Hispanic ethnic groups. These findings imply that African American children tend to be more resilient to adverse effects of poverty than are their Caucasian and Hispanic counterparts. One possible explanation for this ethnic difference was provided by Grant et al. (2000) whose research findings showed that African American boys tend to use avoidance as a coping mechanism for 
stressful situations. However, such findings should be interpreted with caution due to a lack of replicative studies in this particular area.

Meanwhile, economically deprived families are more likely to be involved with child protection services due to maltreatment. In other words, children from economically disadvantaged families are at a greater risk of home removal and foster care placement than are their peers from higher-income households (Barth, Wildfire, \& Green, 2006; Besharov \& Laumann, 1997; McGuinness \& Schneider, 2007; Moraes, Durrant, Brownridge, \& Reid, 2006). These findings do not imply that only poor people abuse and neglect their children. Rather, these studies suggest that low income families are more likely to be reported and investigated for child maltreatment, even though the whole process could involve biases against them.

\section{Impact of Poverty on Social Relationships}

Poverty can play a big role in impacting children's ability to make and keep friends from higher socioeconomic statuses. Poor children have a tendency to feel ashamed of bringing their friends home or having to deal with friends' requests to visit their homes (Horwath, 2007, p. 114). For this reason, low income children tend to associate themselves with peers from similar backgrounds. Meanwhile, poor children usually live in neighborhoods where resources are limited and thus are less likely to have access to recreational facilities than their wealthy peers (Wager et al., 2007). Due to budget constraints, low-income parents cannot afford to pay for their children to participate in social activities (Attree, 2006). In addition, living in disadvantaged neighborhoods exposes children to higher doses of crime and drug-related activities which, ultimately, may limit their scope of community involvement (Brooks-Gunn et al., 
1997). That is, some children may prefer not to socialize beyond the scope of the home environment. Children who do not socialize, especially those who are poor, may develop low self-esteem (Ansalone, 2001; Ermisch, Francesconi, \& Pevalin, 2001), suffer from social exclusion (Brooks-Gunn \&Duncan, 1997), and become targets for bullying attacks from peers.

This chapter depicted poverty as a serious issue in the United States. Statistics have shown that children are affected by poverty in larger numbers and found to be the most vulnerable individuals among the poor. Despite a slight decrease in the past two years, today's poverty rates are still higher than before the Great Recession. Deep poverty can no longer be perceived as a problem germane only to less-developed nations, as millions of American households have fallen below 50 percent of FPL over the past decade. The next chapter reviews efforts undertaken by the federal government to address poverty in America. 


\section{CHAPTER II. HISTORICAL DEVELOPMENT OF THE AMERICAN SOCIAL WELFARE STATE}

Before the Great Depression, the federal government had little involvement in providing welfare services. Authorities at state and local levels delegated power and resources to private, non-for-profit organizations for poverty-relief purposes. Even the Depression of 1873 which followed the US Civil War did not trigger federal responses. Instead states took the lead in addressing personal, family and community problems through voluntary agencies. One particular agency, the Charity Organization Societies (COS), was established in 1877 with the mission of coordinating relief efforts at micro, mezzo, and macro levels (Farley, Smith, \& Boyle, 2012). Expanded to most American cities by the 1890s, the COS attempted to organize the charities of the city, understand the phenomenon of poverty, and develop constructive anti-poverty measures. By the early $20^{\text {th }}$ century, a number of states established departments of public welfare, which managed state institutions and developed community-level relief programs, including Mothers' Pensions, the forerunner to "Aid to Dependent Children" (ADC).

The first major federal initiative arguably came with the establishment of the Children's Bureau by the Taft administration on April 9, 1912 (Public Law [P. L.], 62116; U.S. Children's Bureau, 2014). This law authorizes the said bureau to embrace a whole-child philosophy with an emphasis on research related to maternal and child health. In short, this law targets the well-being of all children, regardless of their socioeconomic status (U.S. Children's Bureau, 2014). The 1926 publication of the Public Aid to Mothers with Dependent Children by the Children's Bureau was to raise public awareness concerning benefits for female parents that assumed the role of primary 
caregivers of their children. This document was also a precursor for the "Aid to Dependent Children" component of the Social Security Act of 1935 (U.S. Children's Bureau, 2014). From the 1930s onward, however, the U.S. Congress has passed a panoply of anti-poverty and welfare-related measures, the most notable ones being the Social Security Act of the 1935, the Economic Opportunity Act of 1964, the Omnibus Budget Reconciliation Act [OBRA] of 1981, and the Personal Responsibility and Work Opportunity Reconciliation Act of 1996.

\section{The Social Security Act of 1935 and the New Deal}

The Great Depression, which struck in 1929 and persisted until 1941, took the U.S. economy by storm, shaking the banking system in which all faith to handle or reverse the situation was lost. Unemployment rates skyrocketed, as the workforce was crippled in every aspect. Famine hit people in urban as well as in rural areas throughout the country. Prisoners on parole opted against leaving the jail environment for fear of being deprived of basic resources. It looked as though this great nation was about to plunge into despair (The Roosevelt Institute, 2014). In the midst of such economic adversity, the newly elected president, Franklin D. Roosevelt, along with Congress, rose to the occasion with a cascade of legislative measures and presidential executive orders forming the "New Deal." The first of these was the Banking Act of 1933, which was intended to restore equilibrium in the banking system. This law made bank failure less likely by ensuring deposits.

Equally important was the Federal Emergency Relief Act (FERA), the first federal grant in aid program enacted by Congress in 1933. FERA provided states with funds for relief of the unemployed and the act encouraged states to set up work relief 
programs. In other words, under FERA, states were recipients of grants and loans for public assistance, anticipating the public assistance titles of the Social Security Act of 1935. Meanwhile, FERA regulations stipulated that grant in aid funds must be spent by public agencies. That is, these funds could not be used to contract with private agencies like the Red Cross or another charity organization. As a temporary relief policy, FERA was replaced by the Works Progress Administration (WPA) in 1935.

The flagship social policy in the New Deal was arguably the Social Security Act of 1935 which created the Social Security Board, which in turn was re-named the Social Security Administration (SSA) in 1946. The Social Security Act of 1935 established three key public assistance programs: Aid to Dependent Children (ADC), Old Age Assistance (OAA), and Aid to the Blind (AB). These were run by the states with federal financial participation. The law guaranteed pensions for older adults and unemployed workers who have been employed in covered employment. The 1935 Social Security Act also included the Old Age Insurance. This program, together with the OAA, shielded senior citizens against eventual negative life outcomes by providing them financial protection in case of loss of income (Murray \& Pancoast, 1945). Congress added Survivors Insurance (SI) to the Social Security Act in 1939. Aid to the Permanently and Totally Disabled (APTD) and Disability Insurance (DI) were later added in 1950 and 1956, respectively (P. L. 73-66; P. L. 74-271).

With respect to child poverty, ADC proved to be a significant legislation purported to safeguard the well-being of children whose fathers were dead, incapacitated or irresponsible. The program sought to prevent family economic dysfunction by providing monthly payments to mothers in order for them to remain in the home 
environment and care for their children. ADC had been in existence for nearly 30 years when Congress revised and upgraded the program with the establishment of the Aid to Families with Dependent Children (AFDC) program as part of the Public Welfare Amendments of 1962 (P. L. 87-543). This move by Congress was to circumvent claims that $\mathrm{ADC}$ was an incentive for out-of-marriage pregnancies and a disincentive for the formation of two-parent families. Hence, contrary to its predecessor which focused mostly on children, AFDC saw the family as a unit. One of the reforms brought by AFDC was to provide a stipend for the caretaker(s). AFDC also provided an option for the states to provide benefits to two parent families, though only about half of the states did so. The Public Welfare Amendments of 1962 allowed states to increase social services, provide job-related training programs to recipients, and professionalize the program.

Under AFDC, states were required to continue meeting federal requirements such as fair hearing, availability of the program across subdivisions, uniform standards, review of state plans (P. L. 87-543). In other words, all of these requirements were in the 1935 law. With AFDC states should also be in compliance with the civil service standards, which was administratively required by the Social Security Board. The estimated income need and the amount of the ADC or AFDC benefit was to be set by the states. Although the states differed widely in the amount of the benefit, in all states benefits were below the poverty line (after the FPL was established in the 1960s).

Other significant components of the New Deal that had a direct bearing on poverty include but are not limited to the Works Progress Administration (WPA), the Civilian Conservation Corps (CCC), the Federal Housing Administration (FHA), the Farm Security Administration, and the National Youth Administration (The 
Roosevelt Institute, 2014). It should be noted that FHA is not necessarily an antipoverty program. Its intent was to stabilize the housing market by providing federally insured mortgages and to stabilize the banking system. Congress did support public housing projects that provided rental housing for the poor during the 1930s, especially the Housing Act of 1937.

As with several other nationally funded programs, the New Deal was criticized by both sides of the political spectrum. Conservatives complained that the programs went too far (federal overreach). Radicals and liberals, on the contrary, argued that the programs were too short in length to generate satisfactory results. The WPA, the largest work relief program, continued into the 1940s. The Social Security Act and federal aid to public housing authorities continued well beyond World War II. Despite this, some critics contended that the New Deal programs did not go far enough for the nation to fully recover from the unprecedented economic crisis in the shape of the Great Depression (The Roosevelt Institute, 2014).

A growing number of authors, however, argued that the New Deal, as implemented under the Roosevelt administration, remains a national and international benchmark of accomplishment for today's social challenges (O'Brien, 2014; Rose, 2009). Moreover, Amenta (1998) argued that the work relief programs of the New Deal, such as the WPA, were much bolder than contemporary European responses to the Great Depression and gave the New Deal its particular character. Furthermore, Boushey (2014) noted that the family-centered policies in the New Deal package represent a significant part of the groundbreaking work for the country's strong economic platform that existed up to the 1970s. The social welfare measures of the New Deal, in particular the old age 
insurance program, together with increased regulation of banking and home lending constituted a huge contribution in preventing a return to depression conditions after the World War II. Therefore, the New Deal stimulus package has been a considerable watershed in American public welfare history.

\section{The Economic Opportunity Act of 1964 and the War on Poverty}

Three decades after the passage and successful implementation of the 1935 Social Security Act, Lyndon Baines Johnson wanted to create a "Great Society" and therefore declared a "War on Poverty" on behalf of the American people. Much of the planning for the War on Poverty had been undertaken during the Kennedy administration (1961-63). Walter Heller, Chair of the Council of Economic Advisors (1961-64), recommended a War on Poverty to Johnson the day after Kennedy was assassinated and Johnson enthusiastically endorsed the idea (Farmbry, 2014). In his January 8, 1964 State of the Union address, the $36^{\text {th }}$ United States President contended:

This administration today, here and now, declares unconditional war on poverty in America. I urge this Congress and all Americans to join with me in that effort.... Our aim is not only to relieve the symptoms of poverty, but to cure it and, above all, to prevent it. No single piece of legislation, however, is going to suffice. (Johnson, 1964, para 17, 25).

President Johnson and his staff, however, anticipated that the aforementioned war would be a long struggle. In fact, the president was quoted saying, "The war on poverty is not fought on any single, simple battlefield and it will not be won in a generation. There are too many enemies: lack of jobs, bad housing, poor schools, lack of skills, discrimination; each intensifies the other" (New York Times, 1989, para 3.). Being 
cognizant of the multifaceted nature of poverty as a social problem, the president urged Americans not to underestimate the economic war in which the nation was about to engage. Nonetheless, the Johnson administration was convinced that America could eventually win this war. Indeed, the military language (War on Poverty) used to describe the wraparound anti-poverty public policies undertaken under his administration is emblematic of the war-winning mentality that seems to be a mainstream American value (Johnson, 1964).

The Economic Opportunity Act (EOA) — signed into law on August 20, 1964was the centerpiece of the war on poverty. In fact, the EOA encompassed several key programs such as Head Start, Job Corps, Work Study, Neighborhood Youth Corps, VISTA, Community Action Program, and Legal Services Program, most of which were administered by the Office of Economic Opportunity (P. L. 88-452). The Social Security Amendments of 1965 expanded the original legislation by creating two fundamental health programs: Medicare, which provided health insurance to the elderly, and Medicaid, which provided health benefits to the poor (US Social Security Administration, n. d.). Two other Great Society laws that are worth mentioning are the Food Stamp Act of 1964 and the Older Americans Act of 1965.

Following the successful completion of pilot studies between 1961 and 1964 under the auspices of the Secretary of Agriculture, the original the Food Stamp Act was signed into law on August 31, 1964. This law promotes food security and improves the overall health of low income children and families through nutritious foods (P. L. 88-525; United States Department of Agriculture [USDA], 2014). In 2008, Congress changed the name of the program which now becomes the Supplemental Nutritional Assistance 
Program or SNAP (P. L. 110-246). Meanwhile, the Older Americans Act targets the wellbeing of individuals who are 60 and over, providing them with a broad range of homebased and community-based services such as meals, transportation, caregiver support, abuse prevention, job training and volunteer opportunities, and legal services (P. L. 8973). Originally enacted in 1965, the Older Americans Act has since been reauthorized by Congress on multiple occasions with the latest modifications being made on April 2016 (P. L. 114-144). During Johnson's presidency, Congress passed about two hundred bills in just two years (1965-1967), all of which were components of the "Great Society" project (The Washington Post, 2014).

The war on poverty was further extended in the early 1970s with the addition of several key programs such as (1) the Earned Income Tax Credit (EITC) which is designed to bolster the financial situation of working low-to-moderate income individuals and families; (2) the Housing Choice Voucher Program (HCV) which subsidizes quality, affordable housing for very low-income families; (3) the Special Supplemental Nutrition Program for Women, Infants and Children (popularly known as WIC) which improves the health of pregnant women, breastfeeding mothers, and young children through nutritious diets; (4) the Child Support Enforcement (CSE) program which collects financial child support on behalf of custodial parents; and (5) Supplemental Security Income (SSI) which provides economic assistance to old, blind and disabled people. SSI consolidated three public assistance programs - OAA, AB, and APTD - and placed the new program under federal administration. The Nixon administration has proposed a Family Assistance Program that would have federalized all four public assistance 
programs (including AFDC). Congress did not accept President Nixon's proposal, but did ultimately approve SSI.

Today, some fifty years after the declaration of war on poverty, some Americans might feel the same way as did former president Ronald Reagan who once said that America had lost the war against poverty (Reagan, 1986). However, statistics have shown that the poverty level decreased from 19 percent in 1964 to 11.2 percent ten years later (1974) and then increased to 14.5 percent in 2013 (DeNavas-Walt \& Proctor, 2014; Luhby, 2014; Washington Post, 2014). In other words, despite their effectiveness having been particularly hampered by the economic burden of the Vietnam War and the 1973 Oil Crisis, the war on poverty programs succeeded in almost halving the poverty rates in the first decade that followed their implementation (please see Figure 8 below). These data speak for themselves and prove that, despite all the criticism, the Johnson administration inflicted a major blow to poverty as a social problem (Ashmore, 2008; Bauman, 2008; Germany, 2007; Orleck, 2005; Washington Post, 2014). The graph below (Figure 8) depicts poverty rates in America from 1964 to 2012. 


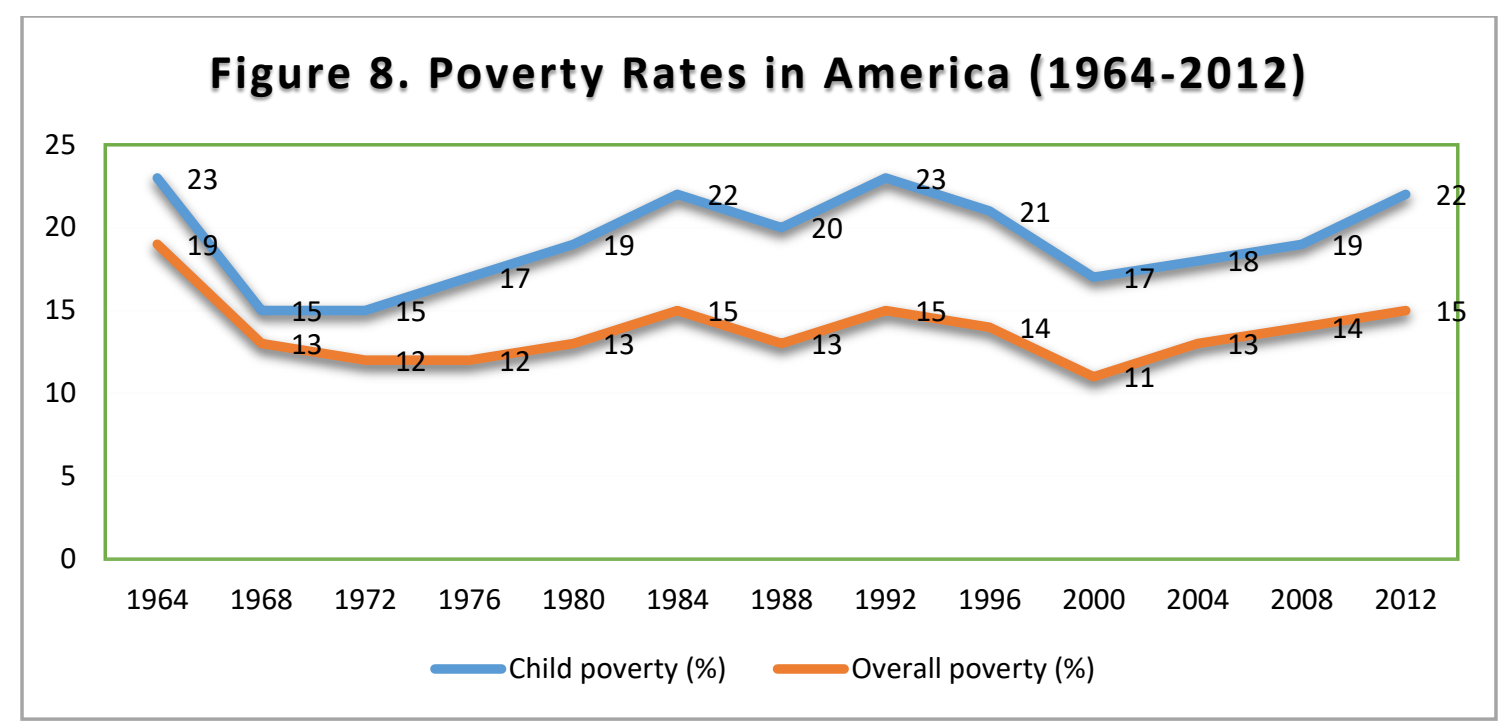

Figure 8. Child and overall poverty rates in America from 1962 to 2012. All rates are rounded to the nearest whole number. There was a significant drop in rates in 1974 following the implementation of the War on Poverty programs. Then there was a rise in rates between early 1980s and early 1990s due to austere welfare policies. In 2000, the national poverty rates dropped to 11 percent only to rise again in the following years, most notably during the Great Recession.

\section{The Omnibus Budget Reconciliation Act of 1981 and Neoliberalism, Austerity, and Devolution Revolution}

Ronald Reagan's ascendency to power in 1981 led to a paradigm shift in social welfare policies from liberal views to conservative approaches. This period was characterized by the rise or rebirth of neo-liberal policies which emphasize devolution. That is, the role of the federal government in providing social services was supplanted by the delegation of administrative power to states, local governments and the private sector (Hasenfeld \& Garrow, 2012; Kincaid, 1998; Morgan \& Campbell, 2011). In simple terms, the theory behind neoliberalism is that government spending for welfare services distorts the labor market by rewarding idleness. Therefore, it is in the best interests of the federal government to privatize social services because advocates of privatization would favor introducing free market ideas into the welfare system. Efficiency and cost savings are a secondary benefit, as the government would avoid 
having to rent, buy or build offices, recruit and train staff for service delivery, and settle lawsuits in or out courts. The privatized services will still need staff, but public bodies will not be burdened with paying for staff members' health insurance, retirement plans and other benefits. Expansion of public employment distorts markets in the neoliberal thinking, while privatization reduces the costs of government and increases economic opportunity for contracting enterprises.

The amendment of Title XX of the Social Security Act in 1981. Title XX of the Social Security Act became law in 1975 under the Social Services Amendments of 1975 (P. L. 93-647) and as a complement of the 1974 Community Development Block Grant Act (P. L. 93-383). The purpose of this law was to strengthen and stabilize states' budgets for social services. In effect, Title XX requires that federal money allotted to social services be given to states in the form of a block grant, hence the name Social Services Block Grant Program (SSBG). Block grants started in the Johnson Administration, but were pushed more vigorously by Presidents Nixon and Ford. Reagan, however, pushed block grants further than any of his predecessors. In retrospect, Title XX was a transitional measure, between the categorical grants that characterized the New Deal and the 1960s and the new block grants of the Reagan administration of the 1980s. Being the first program that capped federal social service funding, Title XX did shift considerable power to the states, but it also required state matching of federal dollars. The Omnibus Budget Reconciliation Act [OBRA] of 1981 expanded the program slightly, eliminated the state matching requirement, and cut federal appropriations for social services (P. L. 97-35). The amendment of Title XX of the Social Security Act by the 1981 OBRA demonstrated the Reagan administration's brand of federalism, which involved an 
expanded role for the states. The strategy included an emphasis on austerity because of the administration's commitment on lowering taxes and its goal of reducing the federal deficit. This, of course, resulted in tremendous cuts to social welfare programs.

Ironically, the administration ended up increasing the deficit due to huge tax cuts and increases in defense spending.

Although in existence since 1966, block grants in social welfare became a more acute policy prescription with the Reagan administration which, as early as 1981, already sought to merge as many as 85 existing programs into just seven block grants. The OBRA of 1981 combined 77 small federal programs into nine block grants which accounted for 17 percent of the federal aid pie (Finegold, Wherry, \& Schardin, 2004). This was the beginning of the devolution revolution that has characterized social welfare policies in America since. The total amount of these block grants was significantly (25 percent) less than what the monetary value of these programs would have generated if added separately (Conlan, 1998). This was a sharp departure from Nixon who actually allocated more money to states through block grants (Finegold, Wherry, \& Schardin, 2004).

\section{The Personal Responsibility and Work Opportunity Reconciliation Act of 1996 and Welfare Reform}

Public assistance to economically disadvantaged families in the United States underwent its biggest paradigm shift yet when Congress created the Temporary Assistance to Needy Families (TANF) program as part of the Personal Responsibility and Work Opportunity Reconciliation Act [PRWORA] in 1996 (P. L. 104-193). The introduction of TANF to the federal safety net system has dramatically changed the social 
welfare landscape that the country adopted during the Great Depression and modified in the 1960s. The enactment of the PRWORA fulfilled a presidential campaign promise made by Bill Clinton to end welfare "as we know it" and return power to the states. In his first State of the Union address on January 25, 1994, the president reiterated his willingness to replace welfare with work (Clinton, 1994, 2006). Two earlier versions of PRWORA were vetoed by the president; however, the third and final bill that reached his desk was deemed veto-proof because Clinton was facing a tough re-election race in November 1996 and republicans hoped to use a veto against him as a campaign issue. PRWORA was, in fact, a section of the "Contract with America," a campaign document drafted and used by the Republicans in the 1994 elections (West's Encyclopedia of American Law, 2005). The central measure of PRWORA—also called the welfare reform act—was the creation of the TANF program as a block grant to states. The decision to sign this so-called "bipartisan bill" into law on August 22, 1996 by President Clinton stirred controversy among some members of his staff and precipitated the departure of Wendell E. Primus, David Ellwood, Peter Edelman and Mary Jo Bane from the Department of Health and Human Services. These four high-ranking welfare advisors resigned in protest to the president's decision to "end welfare as we know it" (Vobejda \& Havemann, 1996).

Movement toward TANF. The movement toward TANF in the 1990s corresponded to the problem of caseload growth in the American social welfare system. TANF replaced Aid to Families with Dependent Children (AFDC) which, as mentioned above, was an upgraded version of the ADC. One could raise the question: what was wrong with the AFDC program? Some believed that the program was more a part of the 
problem it sought to address than of the solution. Moffitt (1987) argued that AFDC had created dependence on federal benefits and potentially led to counterproductive outcomes by fostering generational poverty. The 1950 decade saw only a 17 percent increase in the AFDC rolls. However, with the Johnson administration launching a War on Poverty in the middle of the 1960s, AFDC participation rate grew exponentially over the next ten years or so. In fact, the number of families on public assistance exceeded 3.35 million in 1975, a significant rise from the 745,300 family recipients in 1960 (Administration for Children \& Families, 2014).

The take-up rate is a measure of the percentage of eligible persons who take advantage of a particular social welfare program. Boland (1973) found that an estimated $84 \%$ of eligible families and $91 \%$ of eligible single mothers received AFDC benefits in 1970. Much of the increase in AFDC caseloads between 1967 and 1970 resulted from increased likelihood that eligible persons would apply and be approved for benefits. Such intensification of the AFDC aggregate take-up rates was consistent with the spirit of the War on Poverty. Community Action Programs and other organizations provided more and better publicity about AFDC eligibility to poor families. In addition, the Office of Economic Opportunity’s Legal Services Programs supported the appeals of applicants who had been rejected for assistance, resulting in changes in eligibility procedure which resulted in more favorable decisions on applications for assistance (Bamberger, 1965).

Such substantial growth in public assistance was a mismatch between reality and America's welfare philosophy. In fact, the country has long adopted a residual view of poverty and social welfare which tends to blame those who live on public assistance. Diffused via the mainstream media, this view traces the root of poverty to the person's 
own failure to thrive in society and questions welfare recipients' attitude toward hard work as a core American value (U. S. House Budget Committee Majority Staff, 2014). The residual view also claims that extending public assistance to able-bodied individuals will more than likely lead to dependency on the federal government. For this reason, proponents of this approach recommend a strong labor market as the main poverty reduction policy (Moffitt, 1987). Policymakers, however, had struggled to reshape the program over the years. Not until 1996 was the U. S. Congress able to make major changes to the then 34-year-old program with the enactment of the PRWORA. Indeed, although the explosion of welfare was somewhat halted with the rise of neoliberalism under the Reagan administration, AFDC continued to register high participation rates in the 1980s. In 1995, as many as 84.3 percent of eligible individuals and families claimed their cash benefits (US Department of Health and Human Services [USDHHS], 2014a). Hence, the steady expansion of AFDC caseloads between 1965 and 1995 was the main, if not the only, event that paved the way for the welfare reform act of 1996.

Although heralded as the most significant piece of welfare legislation since the Social Security Act (SSA) of 1935, TANF has constantly been the subject of vehement controversies among researchers as studies of its effectiveness have yielded mixed results. Despite early success claims (Bitler, Hoynes \& Kuka, 2014), there has been a growing concern in the literature about the effectiveness of the program in helping lowincome families reach self-sufficiency (Aratani \& Aber, 2014; Ozawa \& Yoon, 2005; Sheely, 2012). 


\section{The Stimulus Package}

In response to the Great Recession that hit America between December 2007 and June 2009, Congress passed the American Recovery and Reinvestment Act [ARRA] (P. L. 111-5). Popularly known as the Stimulus Package, the ARRA was a $\$ 789$ billion bill which was signed into law by President Obama on February 17, 2009. Like the New Deal in the 1930s and the EOA in the 1960s, the ARRA was considered a Keynesian-type of macro intervention intended to address a crisis of national proportion. The main purpose was to curb unemployment, jumpstart the economy, and keep American families afloat throughout the recession (Carter \& Tippins, 2012; Karger, 2014). Although not a social welfare policy per se, the Stimulus Package did in fact extend most of the public assistance programs.

The recovery of the economy under the stimulus package was, at best, slow. In fact, during the enactment of the ARRA in 2009, the national unemployment rate reached 8.3 percent. Three years later, in February 2012, the nation still faced the same rate of unemployment (Bureau of Labor Statistics [BSL], 2014), prompting talks of a jobless recovery (Carter \& Tippins, 2012). Although recent economic data indicate that the labor market has consistently shown improvement over the last couple of years, a large number of Americans are still unemployed or underemployed. However, compared to Europe, the American recovery from the recession is far ahead.

Indeed, UNICEF's researchers Bitler et al. (2014) found that the 2009 stimulus package did mitigate to some extent the effects of the recession on child poverty in America. Karger (2014) argued that the interminable crippling state in which some European countries find themselves nowadays is due to their own failure to embrace 
Keynesianism following the Great Recession. Keynesianism is the economic principle developed during the Great Depression that posits that deficit spending can lead to recovery by stimulating demand and creating jobs (Keynes, 1936). In sharp contrast is the economic austerity or discipline which asserts that a country should not spend beyond its financial realm, the same way a household's expenses should not exceed its income. In fact, European countries impose discipline through cuts on government services and through increased taxes, abiding by the economic orthodoxy principle. According to Karger (2014), some European countries deliberately ignore that cuts on spending will lead to unemployment. By preferring or being forced to adopt Austerity over Keynesianism, countries like Greece and Portugal are sinking into poverty.

\section{Today's Safety Net Programs}

Today's federal safety net consists of a vast array of programs that appear under various forms: Earned Income Tax Credit (EITC), Child Tax Credit (CTC), Head Start and Early Head Start, Temporary Assistance to Needy Families (TANF), School Meals Programs, Supplemental Security Income (SSI), Unemployment Insurance (UI), Supplemental Nutritional Assistance Program (SNAP), Housing Choice Voucher (HCV), Women, Infants, and Children (WIC), Child Care Assistance and Low-Income Home Energy Assistance Program (LIHEAP). Although not traditionally classified under the rubric of welfare, entitlement programs such as Medicare, Medicaid, Social Security, GI Bill, Job Corps and Pell Grant are all considered part of the federal safety net.

Taken as a whole, the aforementioned programs constitute the backbone of today's social safety net and can be classified — for simplicity purposes - into the 
following five categories: cash assistance programs (EITC, UI, cash portion of TANF, Social Security, SSI), food assistance programs (SNAP, WIC, School Meals), education assistance programs (Head Start and Early Head Start, GI Bill, Job Corps, Pell Grant), medical assistance programs (Medicaid, Medicare, Affordable Care Act) and housing assistance programs (HCH, LIHEAP). The aforementioned safety net programs can also be classified into two broad categories: means-tested and non means-tested. Means-tested benefits are available only to households that fall within a certain bracket in terms of income and wealth. Examples of means-tested programs include TANF, SNAP, Head Start, SSI, HCV, WIC, Medicaid, Pell Grant and the refundable portion of EITC. Non means-tested programs, in contrast, are not based upon household earnings or assets and may include UI, Social Security and Medicare, although there are retrospective work requirements for participation in these programs. Yet, some lists of safety net programs exclude the social insurance programs, though they clearly have had a major role in limiting poverty for certain groups (e.g., the elderly). In other words, narrowly captured, the social safety net refers primarily to the means-tested benefits which aim at helping the nation's families with dependent children cope with economic difficulties.

Furthermore, the American welfare state is bifurcated into a two-tiered system: an upper-tier and a lower-tier (Howard, 1999; Sherraden, 1991, p. 53). Upper-tier programs include Social Security (OASI), Medicare, Disability Insurance, Workers' Compensation, and Unemployment Benefits. These programs are universal and offer substantial benefits. Stigma are generally not associated with receiving these benefits. Lower-tier programs, in contrast, include SNAP, School Meals, Medicaid, SSI, TANF, WIC, and Housing Choice Voucher. These programs are residual and target people who are at the bottom of society. 
Recipients of these benefits are often stigmatized in the eyes of the public (Howard, 1999; Sherraden, 1991, p. 53)

This chapter pinpointed the most significant antipoverty policy prescriptions designed and implemented under the auspices of the federal government. The federal government was slow to react vis-à-vis poverty until the Great Depression. Between 1930s and early 1970s, the federal government adopted Keynesian-inspired policies to alleviate and prevent poverty at the same time. The Social SSA and the EOA are two examples of broad-based policies intended to address poverty in America. Beginning 1980s, however, the pendulum of social welfare has swung toward neoliberalism, austerity, and devolution, culminating in the welfare reform of 1996. Coping with poverty seems to become the focus of the central government since then. The next chapter meticulously explores the literature on concurrent program participation and selfsufficiency. 


\section{CHAPTER III. LITERATURE REVIEW}

Research on poverty and safety net programs has mushroomed over the past twenty years, following the 1996 welfare reform and the latest recession. In America, there are currently seven research-based poverty centers that generate cutting-edge findings on the federal safety net. Three of these centers-University of California-Davis Center for Poverty Research, University of Michigan National Poverty Center, and University of Wisconsin-Madison Institute for Research on Poverty—are sponsored by the United States Department of Health and Human Services. The other four-Center for the Study of Poverty and Inequality, National Center for Children in Poverty, West Coast Poverty Center, and Center for Poverty Research — are housed at Stanford University, Columbia University, the University of Washington, and the University of Kentucky, respectively. Additionally, scholars from across the globe have shown interests in studying the American way of addressing poverty. Therefore, the literature on poverty policies and interventions is richly populated with local, national and international studies.

\section{Toward Concurrent Program Participation}

Most studies related to the federal safety-net target the effectiveness of single

programs. For example, extensive research has been conducted on the effectiveness of the Earned Income Tax Credit (Dahl \& Lochner, 2012; Eissa \& Hoynes, 2006; Evans \& Garthwaite, 2014; Hoynes, Miller, \& Simon, 2015; Meyer, 2008; Simpson, Tiefenthaler, \& Hyde, 2010). The Supplemental Nutrition Assistance Program (SNAP) has equally received considerable attention from researchers in a predominantly quantitative manner (Almond, Hoynes, \& Schanzenbach, 2011; Gregory \& Deb, 2015; Mykerezi \& Mills, 
2010; Nord, 2012; Ratcliffe, McKernan, \& Zhang, 2011; Shaefer \& Gutierrez, 2013; Tiehen, Jolliffe, \& Gunderson, 2012). So has the Temporary Assistance to Needy Families program [TANF] program (Aratani et al., 2014; Banerjee \& Damman, 2013; Bitler et al., 2014; Bloom, Loprest, \& Zedlewski, 2011; Rodgers \& Tedin, 2006; Sheely, 2012; Siegel, Green, Abbott, Mogul, \& Patacsil, 2004). A similar trend is followed with studies related to the Supplemental Nutrition Program for Women, Infants, and Children - popularly known as WIC (Bitler \& Currie, 2005; Figlio, Hamersma, \& Roth, 2009; Hoynes, Page, \& Stevens, 2011; Joyce, Racine, \& Yunzal-Butler, 2008; Lee \& Mackey-Bilaver, 2007; Ludwig \& Miller, 2005), and those that pertain to the Children's Health Insurance Program [CHIP] (Baicker \& Finkelstein, 2011; Howell \& Kenney, 2012; Joyce \& Racine, 2005; Levine \& Schanzenbach, 2009; Lindrooth \& McCullough, 2007; Yang \& Gaydos, 2010).

Some scholars have called for more research on concurrent enrollment in social welfare programs. In reviewing three recent books on poverty in the United States, Meyers (2014) concluded that the persistence of poverty in American may be connected to social researchers' failure to ask the right questions on the subject. Her review points to the fact that the poverty literature is too narrow in scope as research is often limited to descriptive studies of the incidence and prevalence rates of poverty. As a result, more important areas that need to be investigated are overlooked. Meyers' (2014) recommendations for future research include asking investigative questions about the relationships between social welfare policies and their impacts on participants. Similarly, after reviewing several safety net programs, Gassman-Pines and Hill (2013) urged future researchers to turn their attention toward investigating how children and families are 
affected by the relative impact of their participation in multiple safety net programs. Furthermore, while examining changes in nine safety net programs in the wake of the 1996 welfare reform legislation, Aratani and associates (2014) noted gaps in the body of research on welfare policies. Looking forward to closing such gaps in the literature, Aratani and associates (2014) recommended that future research be guided toward answering questions that deal with participation in multiple safety-net programs. Nevertheless, despite these suggestions, there are as yet a relatively small number of researchers who have investigated the simultaneous participation of low-income people in multiple safety net programs.

Aratani and associates (2014) examined whether the implementation of the 1996 welfare reform has resulted in the expansion or the shrinkage of the other safety net programs at the national level. State-level data collected on nine programs between 1994 and 2002 revealed that the constriction of benefits under TANF has led to a reduction in enrollment in other federally-funded welfare programs. Aratani and associates (2014) study proposed one of the following two explanations for the decrease: (1) states decrease funding and limit access to social programs or (2) poor people have become selfsufficient or have not applied for programs. However, there could be a combination of both sets of explanations. In addition, some public welfare programs (before TANF) provided access to other safety net benefits. Applicants for AFDC might be informed about their eligibility for Medicaid and Food Stamps. In some states, this was automatic. Public assistance caseworkers (at least before the separation of payments and services) were expected to inform AFDC and other public assistance clients of benefits available to them. With falling TANF enrollment, otherwise eligible Medicaid and Food Stamp 
beneficiaries might not be informed of their eligibility for these programs. Meanwhile, the 1994-2002 time-period analyzed in this study may not be reflective of what the current situation really is today for two reasons. First, TANF was still considered a success during that timeframe. Therefore, there was no perceived need for states to increase funding in other programs. Second, this 1994-2002 time-period preceded the Great Recession during which there was somewhat of an expansion of services as promoted by the American Recovery and Reinvestment Act (ARRA). Hence, the findings from the study by Aratani and associates need to be replicated.

Gilbert, Nanda and Paige (2014) used administrative data from the State of Maryland to investigate concurrent participation in other public assistance programs among WIC recipients. Since participation in WIC automatically meets the eligibility requirements for TANF, SNAP and Medicaid (USDA, 2015), Gilbert and associates (2014) measured the enrollment of WIC beneficiaries in these programs. Results demonstrated a minuscule percentage of cross-program participation between fall 2009 and fall 2010, as only $8 \%$ of WIC recipients were enrolled in all three of the other programs (SNAP, TANF and Medicaid). In addition, 28 percent of WIC beneficiaries were found to have no enrollment whatsoever in any of these programs.

The importance of these findings can be understood in light of the growing concerns associated with low participation in welfare programs, even in times of recession. Arguably, one of the goals of these programs is to support low-income families who endure economic hardship. So when benefits are not claimed by eligible people, there is reason for program stakeholders to worry. However, Gilbert and associates' (2014) study of concurrent enrollment in multiple safety net programs has a few 
shortcomings. First and foremost, the study did not account for cross-participation among recipients of TANF, SNAP, and Medicaid only. In fact, the study was focused on the trajectory of WIC clients alone in the federal welfare system as opposed to a thorough analysis of all four programs under consideration. Second, the sample only included participants whose household income was at or below the FPL.

It is true that such an income criterion could ensure cross-program uniformity, but this could also affect the overall validity of the study due to disparities in eligibility requirements across programs. For example, there are more restrictions associated with participating in TANF than there are for WIC, SNAP, and Medicaid. As Gilbert and associates (2014) noted, the 5-year TANF time limit may have precluded WIC recipients from being eligible for enrollment in both programs. Therefore, this low-participation finding should be interpreted with caution. Finally, despite claims of statistically significant differences in mean family income among enrollees in multiple programs as opposed to WIC-only recipients, no effect sizes were reported. Instead, the significance of such findings were reported in terms of $p$-values. This was a questionable decision by Gilbert and associates (2014), considering the absence of randomization in the original sample.

Shaefer and Edin (2013) studied the combined role played by means-tested income transfer programs in mitigating extreme poverty among American households. Extreme poverty is defined as the condition in which households with children live on income less than or equal to $\$ 2$ per day, per person (Shaefer \& Edin, 2013). Using the Survey of Income and Program Participation (SIPP), Shaefer and Edin (2013) found that, in 2011, safety net benefits reduce extreme poverty almost by half for 3.55 million 
children in 1.65 million families. These are interesting findings because extreme poverty has long been considered a developing-country issue and not a concern for the American people. To generate such striking results about the living conditions of citizens in one of the richest countries in the world, Shaefer and Edin's (2013) research has significant implications for the social welfare arena. Indeed, in 2013 the number of children who lived in households with an annual income below 50 percent of the poverty threshold is estimated at 6.5 million -8.8 percent of the child population and 32.6 percent of all people in deep poverty (DeNavas-Walt et al, 2008).

Shaefer and Edin (2013), however, did not include in their study all the non-cash benefits that low-income American families actually receive. With SNAP, TANF, SSI, SSDI, UI and simulated refundable credits as independent variables in the study, other fundamental programs such school meals, WIC, and Head Start were not incorporated in the research. The inclusion of such vital programs would have decreased the country's rate of extreme poverty to a greater extent than what the findings from Shaefer and Edin's (2013) study actually revealed. Therefore, with respect to extreme poverty, America's social safety net could be stronger than first appeared.

Under a cross-sectional design, Slack, Kim, Yang, and Berger (2014) conducted a quantitative study on the various sources of income for low-income families in the United States. A nationally representative sample of 3000 primary caregivers were selected, using the longitudinal Fragile Families and Child Well-Being dataset. After eliminating some participants due to missing data, the final sample of 2,864 was classified into four clusters, based on the participants' income sources. Participants in cluster $1(n=948)$ rely heavily on both work wages and welfare benefits such as food assistance and healthcare 
assistance. Individuals in the cluster 2 group $(n=261)$ do not work and maintain survival only through government aid. In cluster 3 , participants $(n=795)$ have little connection with the labor force and/or government aid (except for Medicaid). Finally, the cluster 4 group $(n=860)$ rely strongly on earnings but not much on welfare. Ten different sources of income were identified through this study-SSI, TANF, SNAP, Medicaid, HCV, childcare subsidies, child support, EITC, UI, and earnings. The results, therefore, demonstrated the fundamental role of the safety net programs in helping both employed and unemployed families meet their economic needs.

Based on this study's findings, however, some questions can be raised about whether or not the safety-net program could lead families to self-sufficiency. In fact, combining cluster 1 and cluster 4 signifies that 63 percent of the participants $(n=1808)$ have a strong connection with the workforce and, yet, still receive or qualify for federal benefits. This could mean that people in these clusters only secure temporary or lowpaying jobs. While Slack et al.'s (2014) study is strong in terms of the inclusion of a broad range of programs, one shortcoming is its failure to account for informal sources of economic support such as under-the-table employment or aid received from family members and friends.

Cancian, Han, and Noyes (2014) investigated the economic situation of lowincome families who have been disconnected from employment as well as from multiple welfare programs. Using administrative data made available by the Department of Health and Human Services of Wisconsin, Cancian et al. (2014) analyzed large-scale, longitudinal samples of TANF and SNAP recipients collected in 2001, 2007 and 2010. The dataset also includes information related to other federal welfare programs such as 
healthcare assistance, UI, SSDI, SSI, and earnings. The longitudinal nature of this dataset allows cross-program and cross-cohort comparisons. A family disconnection measure separated former welfare beneficiaries into four groups: (1) those with no income whatsoever, (2) those without earnings, TANF, and SNAP, (3) those without earnings, TANF, SNAP, and healthcare assistance, and (4) those without earnings, TANF, SNAP, healthcare assistance, and child support. From this study, Cancian et al. (2014) found that, when compared to SNAP beneficiaries, TANF recipients participated in more other federal programs, but were less disconnected after leaving the welfare rolls. This is not surprising, as TANF, at least in some states, may have a linking function that connects recipients to other sources of assistance.

These findings can be understood within the context of TANF and SNAP eligibility requirements. While participation in SNAP usually requires an income at or below $130 \%$ of the FPL, eligibility for TANF is determined at the discretion of states. Maximum benefits vary by state, but earnings of $50 \%$ or more of the FPL disqualify households from receiving TANF in half the states. That is, with the beneficiaries of TANF further below the FPL, that fact alone would make them eligible for more federal benefits than their SNAP counterparts. Meanwhile, despite having originated from a relatively strong source, the results of Cancian et al.'s (2014) research do not reflect the reality at the national level for several reasons. First, based on the study demographics, the participants with Hispanic ethnicity varied between 7.8 and 13.5 percent across programs and cohorts. These numbers neither reflect the proportions of Hispanics in the population of Wisconsin nor in the national population. In fact, according to the US Census Bureau (2015b), Hispanics accounted for 17 percent of the US population in 
2014. Meanwhile, Wisconsin's Hispanics constituted 6.6 percent of its population in 2015 (US Census Bureau, 2015c). Second, the take-up rate for TANF and SNAP in Wisconsin is exceptionally low (Cancian et al., 2014). Third and finally, the study did not take into consideration unofficial sources of income the study participants may have relied upon instead of participating in government benefits. Therefore, these research results should be interpreted with caution (Cancian et al., 2014).

\section{Toward Self-Sufficiency}

As a concept, self-sufficiency has taken the literature by storm. A general search for the concept on two different electronic databases, Google Scholar and ProQuest, generated 200,000 and 184,131 results, respectively. Even when narrowed down, using the Self-Sufficiency Research Clearinghouse, the search still yielded 1907 hits. Clearly, contemporary welfare states embrace the concept of self-sufficiency as a viable option toward social citizenship (Betzelt, Bothfeld, \& Béraud, 2011; Fleckenstein, 2012; Kildal \& Nilssen, 2011). For all the talk about self-sufficiency, however, this term is not explicitly defined either by the government or by scholars. That is, there is no precise definition for this concept which, therefore, remains relatively vague across the literature (Hawkins, 2005; Hetling, Hoge, \& Postmus, 2016; Perry-Burney \& Jennings, 2003; Sandfort \& Hill, 1996). Yet, the term self-sufficiency has been mostly associated with antipoverty policies and, more specifically, welfare-for-work programs (Bowen, Desimone \& McKay, 1995; Cancian \& Meyer, 2004; Caputo, 1997; Gowdy \& Pearlmutter, 1993; Johnson \& Corcoran, 2003; Parker, 1994).

Although the notion of self-sufficiency has been around since the days of Aristotle (Wheeler, 1955), its adoption by American policymakers dates to the 1960s. 
President John Fitzgerald Kennedy called for self-sufficiency in his 1962 Message to Congress on Public Welfare, which led to the Public Welfare Amendments of 1962 (Gilbert, 1966; Kennedy, 1962). Five years later, Congress created the Work Incentive (WIN) program through the enactment of the 1967 Social Security Amendments (P. L. 90-248). WIN promoted self-sufficiency among welfare recipients through the establishment of employment and training programs (Ballou, 2014; Gowdy \& Pearlmutter 1993). Since then, this notion has taken center stage in the poverty-reduction discourse (Hawkins, 2005; Hong, Sheriff, \& Naeger, 2009) and become, arguably, the ultimate goal of the antipoverty welfare programs in America (Hawkins, 2005). The term self-sufficiency echoes the values and principles fostered in American society which emphasize economic independence as a means of achieving and living what is known as the American Dream (Cochran, 1985; Shain, 1994). As understood under TANF, selfsufficiency is the state of having enough income that would make an individual or household ineligible for cash assistance (Gowdy \& Pearlmutter, 1993; P. L. 104-193). Critics argued that the way in which self-sufficiency is perceived and measured within the welfare system is obscure and thus should not be relied upon for program evaluation purposes (Daugherty \& Barber, 2001; Gowdy \& Pearlmutter, 1993). In 1996, following Gowdy and Pearlmutter's (1993) criticism of the dualistic nature of the current way of measuring self-sufficiency (self-sufficient vs. non self-sufficient), the SelfSufficiency Matrix (SSM) was developed during a 2004 taskforce organized by Snohomish County, Washington. The SSM is a multidimensional scale which calculates self-sufficiency based on the following 25 different outcomes: access to service, career resiliency, childcare, clothing, education, employment stability, English language skills, 
food, daily function ability, housing, self-sufficiency standard income, area median income, federal poverty income, legal aid services, household management skills, human relations, goal setting and utilization of resources, mental health, parenting, physical health, safety, substance abuse and support system. Each of these outcomes is then measured along a five-stage continuum: In-crisis, Vulnerable, Stable, Safe and Thriving (Snohomish County Self-Sufficiency Taskforce, 2004). Although a more robust and holistic scale than the Federal Poverty Threshold which measures income money only, the SSM is not consistent with the letter or the spirit of current social welfare policies. Therefore, the SSM is not applicable to the context of this research.

The attainment of economic self-sufficiency among welfare beneficiaries has been studied by many researchers. Hall, Graefe, and De Jong (2010) used the 1996 and 2001 panels of the SIPP longitudinal dataset to analyze the attainment and maintenance of economic self-sufficiency among female immigrants who exit the welfare rolls. Their performance in the labor market in terms of their ability to find and maintain employment and earn better wages was compared to that of their counterparts in two control groups: (a) those who were eligible but chose not to participate in TANF (eligible group) and (b) the newcomers who were ineligible due to not meeting the state residency requirements (ineligible group). Results indicate that, compared with the control groups, immigrant women who leave TANF have the greatest likelihood becoming economically selfsufficient. In fact, TANF leavers were as likely to find employment as the eligible group, but significantly more likely (36 percent) than the ineligible group. Compared to the other two groups, TANF leavers also earned higher wages. In other words, TANF leavers earned \$2.22 more than the eligible immigrant women and \$3.00 more than the ineligible 
immigrant women. However, participants in the treatment group (TANF leavers) were less likely to secure stable employment than their counterparts in both groups (Hall et al., 2010).

Despite its relatively strong methodology, Hall et al.'s (2010) study is limited to female immigrants on welfare and therefore does not reflect the workforce trajectories for all former TANF beneficiaries, especially women who were born in the United States. In the same vein, both U.S.-born and immigrant males were excluded in Hall et al.'s (2010) research. Hence, Hall et al.'s (2010) findings alone—although a significant contribution the social welfare literature—-should not be used to interpret economic self-sufficiency among recipients of public assistance. More demographically diverse studies need to be conducted before any unbiased conclusion can be made on the relative success of TANF. In the meantime, Hall et al.'s (2010) work serves a reference point for future research.

Using the National Longitudinal Survey of Youth (NLSY), Loeb and Corcoran (2001) studied economic self-sufficiency among AFDC recipients. The ultimate purpose of the study was to examine the impact of work experience on living wages among two comparable groups of low-income women: those who received AFDC and those who did not. Results yielded similar living wages for participants from both groups who had more or less the same level of experience.

Some considerations should be taken into account in interpreting the results of Loeb and Corcoran's (2001) inquiry. First and foremost, the study used data collected between 1978 and 1992, a timeframe that does not encompass the1996 welfare reform years. In addition, the sample consisted of women aged between 27 and 34 who were adolescents at baseline. Considering that most people in the United States work until the 
age of 65, there is a strong age limitation in Loeb and Corcoran's (2001) findings. Finally, what was considered work experience between 1970s and 1990s may not be the case in today's context, as many experienced workers have been negatively impacted by the Great Recession. Hence, the conclusions drawn from Loeb and Corcoran's work may not be applicable to TANF beneficiaries in the post-Great Recession era.

Johnson \& Corcoran (2003) expanded the scope of self-sufficiency by investigating employment stability and mobility among former welfare recipients in the state of Michigan. Analyzing data from the Women's Employment Survey (WES) collected between 1997 and 2002, Johnson \& Corcoran (2003) found that the vast majority of participants have difficulties maintaining their current employment and, consequently, fail to move through the employment pipeline. One possible explanation for the findings of Johnson \& Corcoran's (2003) study can be traced back to the sample. Despite being randomly selected for the study, the participants were included based on their low status in the labor market. Indeed, only low-skilled workers in entry-level positions made up the sample. With no post-secondary degrees, it is understandable that these participants faced tough barriers related to job stability and mobility. Moreover, these findings reflect the conditions of ex-TANF recipients in the State of Michigan only and thus may or may not be generalized to other areas of the country.

Another study conducted by Holzer, Stoll, and Wissoker (2004) in four different states generated results fairly similar to Johnson and Corcoran's (2003). Relatively large numbers of job sites in Chicago, Cleveland, Milwaukee and Los Angeles were selected via stratified methods. Telephone interviews were conducted with 750 hiring managers for entry-level positions in each of the aforementioned cities with the objective of 
investigating employees' performance and persistence in the labor market. Findings suggested that workers with TANF backgrounds struggled to maintain employment due to frequent job absences. Among other personal issues, lack of transportation prevented them from being consistently on the worksites. Consequently, these workers failed to garner the experience necessary for upward mobility (Holzer et al., 2004). As with most of the studies described above, one limitation in Holzer et al.'s (2004) research is the fact that the data used for analysis was collected in the late 1990s. Hence, its conclusions may have had more implications for the pre-Great Recession decade than now. Nonetheless, Holzer et al.'s (2004) findings serve as grounds for future research.

Combining longitudinal data collected from surveys between 1999 and 2003 with administrative data from the New Jersey Division of Family Development, Wood, Moore, and Rangarajan (2008) explored the economic trajectory of welfare recipients over a five-year spell. Consistent with previous studies, results demonstrated that more than half of the participants were not able to remain employed on a consistent basis. While 88 percent of the participants found employment during their enrollment in the program, many of them actually worked intermittently during the 60 month period. Whether these findings are applicable in today's economic conditions remains to be seen, as the current economy is very different from the one that the country experienced during the 1999-2003 quinquennium. Pending more recent research, Wood et al.'s (2008) work reinforces the idea that most TANF recipients do not reach self-sufficiency over time.

\section{Limitations of Previous Research and Rationale for the Current Study}

As mentioned previously, the current scholarship on concurrent enrollment in multiple antipoverty welfare programs is limited. In addition, the small pool of studies in 
this area falls under the rubric of one the following four trends: (1) availability of and accessibility to multiple programs; (2) barriers associated with simultaneous participation in multiple services; (3) income packaging; and (4) impact of multiple programs on wellbeing. Therefore, the existing literature fails to adequately account for the impact of these programs on attainment and maintenance of economic self-sufficiency among participants. Hence, studies examining participation in multiple programs have not investigated in-depth a major purpose of the social safety net in the United States: the attainment and maintenance of economic self-sufficiency.

Meanwhile, most of the studies reviewed in this proposal used data collected between the 1970s and 1990s. Considering the impact of PRWORA in reshaping the public assistance landscape in America, it can be argued that data collected before the 1996 welfare legislation may not be useful for the evaluation of federal programs in the post-Great Recession era (Slack et al., 2014). This study uses the most current dataset available to assess the merits and shortcomings of federal policies. The 2008 SIPP Panel captures the severe socio-economic conditions faced by low-income households not only as a result of the implementation of the welfare reform but also following the 2008 Great Recession. Furthermore, the literature has given considerable attention to female-headed households with children that receive TANF. This research focuses on female householders, male householders, as well as married couples.

\section{Significance of Current Study}

This research will hold macro-implications for poverty and social welfare stakeholders at local, state, and national levels, including policy designers, social researchers, social advocates, service providers and end-users of programs. This research 
will be of paramount importance for stakeholders at local, state, and federal levels of governance. The findings of this study will allow policymakers to reassess poverty and social welfare interventions from a proximal-distal perspective, i.e., the relatively longterm impact of policy. In fact, most of the current welfare policies are povertyremediation measures. The federal government has spent billions of dollars toward addressing poverty instead of preventing the issue itself. Thus, it would be important to determine the long-term impact of poverty-prevention interventions.

Drawing on findings from the literature, Holzer, Schanzenbach, Duncan, \& Ludwig (2008) estimated the economic costs of child poverty on the American economy to average $\$ 500$ billion per year, or 3.8 percent of the country's gross domestic product (GDP). Holzer et al.'s (2008) methodology was related to the economic efforts made by the federal government to address healthcare, criminal justice, and workforce unproductivity costs. According to Holzer et al.'s (2008), childhood poverty is linked to poor health conditions during adulthood, a higher level of street crimes, and lack of opportunities in the labor market. In other words, had child poverty not existed, the United States would have saved on an annual basis 3.8 percent its gross domestic product (GDP) on healthcare, criminal justice and "foregone earnings and productivity" expenditures (p. 13). Holzer et al.'s (2008) estimates on federal poverty-triggered expenses can be open to debate due to three reasons. First, street crimes are not necessarily a function of poverty, even if most of these crimes tend to be committed by the poor. Indeed, drug- and alcohol-related motives are also strong predictors of such crimes. Second, several federal anti-poverty areas such as education, housing, food, and cash assistance were omitted in Holzer et al.'s (2008) study. Finally, his work was 
conducted before the Great Recession and the subsequent implementation of the American Recovery and Reinvestment Act (ARRA). Therefore, these estimates on the annual poverty-related expenses in the country are far from accurate.

Taking a slightly different yet more tangible method, the Center on Budget and Policy Priorities [CBPP] (2015) also attempted to measure the economic costs associated with poverty. In fact, using data from the Office of Management and Budget, the CBPP (2015) estimated the federal expenditures on public assistance programs at $\$ 370$ billion in 2014. It should be noted, however, that this estimate covered only the following safety net programs: EITC, CTC, SSI, UI, SNAP, HCV, Home Energy Assistance, School Meals Program, Childcare Assistance, and Child Welfare Assistance. One fundamental problem associated with this report can be related to the fact that not all of the programs listed above target poor families. For instance, households with a yearly joint income of up to $\$ 149,000$ are still eligible for the child tax credit (CTC). Similarly, unemployment insurance (UI) is not limited to the poor but to unemployed individuals with a proven work history. Furthermore, the Supplemental Security Income (SSI) is not necessarily available to everyone who lives in poverty. There is a means test of assets and income which determines eligibility for SSI. The program primarily targets three groups of people: elderly, blind and disabled who lack economic support. Assistance is provided to these individuals because of age or because their physical conditions may preclude them from being economically self-sufficient. Another major flaw associated with the CBPP report is the exclusion of the federal expenses on educational programs such as Head Start, Pell Grant and Job Corps. These are three key federal means-tested programs aimed at improving the economic conditions of low-income families through education and job 
training. By omitting these fundamental benefits in its calculation, the CBPP's (2015) report cannot be considered accurate.

A more accurate estimation is provided by the US House Budget Committee Majority Staff (2014) which extends the federal expenses on social safety net programs to nearly $\$ 800$ billion for the 2012 fiscal year. This estimate encompassed 92 federally-sponsored programs which can be clustered into the following categories: education and job training programs, health programs, food programs, cash programs, housing programs, energy programs, veterans programs, and social services programs. The table below (Table 1) explains in a detailed manner the type, number, example and costs of federally-funded welfare programs as well as the agencies that ensure the supervision of these programs at the federal level.

\begin{tabular}{|l|c|l|c|l|}
\hline \multicolumn{5}{|c|}{ Table 1. Federal Expenditures on Safety Net Programs } \\
for the Fiscal Year 2012 \\
\hline \multicolumn{1}{|c|}{ Programs } & N* $^{*}$ & \multicolumn{1}{|c|}{ Examples } & $\begin{array}{l}\text { Costs in } \\
\text { \$billion }\end{array}$ & Federal Agency Involved \\
\hline $\begin{array}{l}\text { Education } \\
\text { and Job } \\
\text { Training } \\
\text { Programs }\end{array}$ & 28 & $\begin{array}{l}\text { Childcare services; Pell } \\
\text { Grant; Workforce } \\
\text { Investment Act; Head } \\
\text { Start; Job Corp; Title I } \\
\text { of the Elementary and } \\
\text { Secondary Education } \\
\text { Act; American } \\
\text { Opportunity Tax Credit }\end{array}$ & 94.4 & $\begin{array}{l}\text { Department of Education } \\
\text { DHHS*; CNCS* } \\
\text { Department of labor } \\
\text { Department of the Interior } \\
\text { Department of the Treasury } \\
\text { Environment Protection } \\
\text { Agency }\end{array}$ \\
\hline $\begin{array}{l}\text { Health } \\
\text { Programs }\end{array}$ & 8 & $\begin{array}{l}\text { Medicaid; CHIP*; IHS*; } \\
\text { Federal Health Centers; } \\
\text { Medicare Part D; } \\
\text { MCHSBG* }\end{array}$ & 291.3 & $\begin{array}{l}\text { Department of Health and } \\
\text { Human Services (DHHS) }\end{array}$ \\
\hline $\begin{array}{l}\text { Food } \\
\text { Programs }\end{array}$ & 17 & $\begin{array}{l}\text { SNAP*; NSLP*; SBP*; } \\
\text { WIC*; CACFP* }\end{array}$ & 105.0 & $\begin{array}{l}\text { Department of Agriculture } \\
\text { DHHS; Homeland Security }\end{array}$ \\
\hline
\end{tabular}




\begin{tabular}{|c|c|c|c|c|}
\hline $\begin{array}{l}\text { Cash } \\
\text { Programs }\end{array}$ & 5 & $\begin{array}{l}\text { SSI*; TANF*; EITC*; } \\
\text { CTC*; Title IV-E (Foster } \\
\text { Care Adoption) }\end{array}$ & 220.0 & $\begin{array}{l}\text { SSA* } \\
\text { DHHS*; The Treasury }\end{array}$ \\
\hline $\begin{array}{l}\text { Housing } \\
\text { Programs }\end{array}$ & 22 & $\begin{array}{l}\text { Tenant-based Rental } \\
\text { Assistance; Project-based } \\
\text { Rental Assistance; Public } \\
\text { Housing; Low-income } \\
\text { Housing Tax Credit; } \\
\text { Home Investment } \\
\text { Partnership Program; } \\
\text { Homeless Assistance } \\
\text { Grants }\end{array}$ & 49.6 & $\begin{array}{l}\text { Department of Housing and } \\
\text { Urban Development (HUD) } \\
\text { Department of Agriculture } \\
\text { Department of the Treasury }\end{array}$ \\
\hline $\begin{array}{l}\text { Energy } \\
\text { Programs }\end{array}$ & 2 & $\begin{array}{l}\text { Weatherization } \\
\text { Assistance Program; } \\
\text { LIHEAP* }\end{array}$ & 3.9 & $\begin{array}{l}\text { Department of Energy } \\
\text { DHHS* }\end{array}$ \\
\hline $\begin{array}{l}\text { Veterans } \\
\text { Affairs }\end{array}$ & 2 & $\begin{array}{l}\text { Disability Pension; VA } \\
\text { Health }\end{array}$ & 21.0 & $\begin{array}{l}\text { Department of Veterans } \\
\text { Affairs }\end{array}$ \\
\hline $\begin{array}{l}\text { Social } \\
\text { Services } \\
\text { Programs }\end{array}$ & 8 & $\begin{array}{l}\text { Community Development } \\
\text { Block Grant; Economic } \\
\text { Development Assistance } \\
\text { Program; Defender } \\
\text { Services and the Public } \\
\text { Defender of the District } \\
\text { of Columbia; Schools } \\
\text { and Libraries Support }\end{array}$ & 13.0 & $\begin{array}{l}\text { ARC*; CSOSADC*; HUD } \\
\text { Department of Commerce } \\
\text { Department of } \\
\text { Transportation } \\
\text { The Judiciary; FCC* } \\
\text { Legal Services Corporation }\end{array}$ \\
\hline Total & 92 & & 798.2 & 20 \\
\hline \multicolumn{5}{|c|}{$\begin{array}{l}\text { * N = Number; CHIP = Children's Health Insurance Program; IHS = Indian Health Service; } \\
\text { MCHSBG= Maternal and Child Health Services Block Grants; SNAP= Supplemental Nutritional } \\
\text { Assistance Program; NSLP= National School Lunch Program; SBP= School Breakfast Program; } \\
\text { WIC= Women, Infants, and Children; CACFP= Child and Adult Care Food Program; SSI= } \\
\text { Supplemental Security Income; SSA = Social Security Administration; TANF= Temporary } \\
\text { Assistance to Needy Families; EITC= Earned Income Tax Credit; CTC= Child Tax Credit; } \\
\text { LIHEAP= Low-income Home Energy Assistance Program; DHHS= Department of Health and } \\
\text { Human Services; CNCS= Corporation for National and Community Service; ARC= Appalachian } \\
\text { Regional Commission; CSOSADC= Court Services and Offender Supervision Agency for the } \\
\text { District of Columbia; FCC= Federal Communications Commission }\end{array}$} \\
\hline Sour & & nittee Majority Sta & & \\
\hline
\end{tabular}


As seen in the table above, the federal government involvement in combatting poverty is quite extensive. Twenty different agencies administer 92 programs aimed at remediating the devastating effects of poverty on children and adults. However, some programs such as the Workforce Investment Act, the American Opportunity Tax Credit, the Child Tax Credit and the Veterans Affairs (VA) do not necessarily belong in this list based on their target population (although the poor may benefit from these programs). For example, the American Opportunity Tax Credit can be claimed by a family whose joint annual income is up to $\$ 180,000$. Similarly, middle-class families with joint income of up to $\$ 149,000$ can claim the Child Tax Credit. Moreover, the Workforce Investment Act serves the unemployed (not necessarily the poor), while the VA provides services only to people with military backgrounds, not necessarily the poor. Hence, the nearly $\$ 800$ billion estimate of federal expenditures on safety net programs for the fiscal year 2012 was slightly over calculated. All adjustments considered, the economic costs of the federal antipoverty programs could be between 700 and 750 billion dollars in 2012. Yet, these numbers do not reflect today's reality in terms of poverty relief efforts in America for two reasons. First and foremost, relief efforts at state and local levels are excluded and, second, the costs associated with the implementation of the Affordable Care Act (ACA) — which does not benefit only the poor — were not available in 2012. Therefore, it can be concluded that poverty remediation costs weigh heavily on the shoulders of the nation.

This chapter provided an in-depth exploration of the body of scholarship on multiple program enrollment and economic self-sufficiency. The vast majority of researchers have demonstrated preference for single programs. TANF, SNAP, EITC, and 
Medicaid are by far the most widely researched single programs of the social safety net. Researchers who studied multiple program participation used non-experimental designs and utilized data collected years before the Great Recession. Considering the large number of low-income families in America, the literature on economic self-sufficiency is arguably all but limited. Even the Great Recession failed to trigger a proportional investigative response from poverty and social welfare researchers. The federal government continues to spend decent amounts of money on a broad range of social programs on an annual basis. The gaps in the literature coupled with welfare expenditures constitute the rationale for the current investigation. A critical examination of the most common theories, theses, models, and perspectives about poverty and social welfare are presented in the next chapter. 


\section{CHAPTER IV. PERSPECTIVES, THESES, THEORIES, AND MODELS ABOUT POVERTY AND SOCIAL WELFARE IN AMERICA}

Poverty and social welfare have long been considered cross-disciplinary topics. Therefore, their depth and breadth are being studied and reviewed in several fields, including social work, sociology, economics, law, philosophy, and political science. By the same token, theories associated with poverty and/or social welfare emanate from diverse disciplines. Discussed in this chapter are some of the most widely-disseminated perspectives, theses, theories and models that have attempted to explain aspects of poverty and social welfare.

\section{Theoretical Perspectives on the Etiology of Poverty}

The etiology of poverty is a matter that has puzzled social researchers for centuries. Even today theorists struggle to reach an agreement on what should constitute the causal agent of poverty. The literature has witnessed the emergence of a plethora of theories stemming from constant efforts by social scientists to explain poverty and its causes. The individualistic theory, the cultural theory and the structural theory are the three main theoretical perspectives on poverty found across the literature. These theories will be critically analyzed in the paragraphs below.

Individualistic theory of poverty. The individualistic theory posits that poverty results from individual deficiencies, such as lack of skills, laziness, or poor choices. Proponents of this perspective trace the root of poverty no further than the poor's own failure to thrive in society (Huber \& Form, 1973; Huber, 1974; Gans, 1995; Kluegel \& Smith, 1986; Rainwater, 1970). The basic tenets of this theory are grounded in the capitalist ideas of wealth promoted during the Protestant Reformation in which the poor 
were labeled as cursed by God (Weber, 1930, 2001). The individualistic theory of poverty rests on the premises that (1) America is a land of opportunities; (2) every citizen can live the American Dream through hard work and discipline in the labor market; and (3) the government should not interfere with the flow of the labor market by providing welfare assistance to the poor, except in case of force majeure (Rank, 2004; Stone, 2002). This is therefore a conservative perspective that promotes the work ethic and a limited welfare state, although historically liberals as well have promoted work. The difference lays in the means used, with liberals favoring soft services like counseling and job training and conservatives favoring mandated services such as time limits and work participation rates.

Estimates conducted under the auspices of American Enterprise Institute and Los Angeles Times in 1985 revealed that roughly two-thirds of Americans believed that individuals are responsible for their own economic hardships (Lewis \& Schneider, 1985). The replication of the study in 2016 demonstrated that Americans' attitudes about the cause of poverty have not changed in the past 30 years, as 66 percent of the participants held the poor accountable for their own fate (Doar, Bowman, \& O'Neil, 2016). The individualistic theory of poverty does not take into consideration the fact that people who are born with major genetic, cognitive, or physical deficiencies should not be blamed for these problems. Ryan (1976) coined the term "blaming the victim" to describe the limits and shortcomings of the individualistic theory. Ryan (1976) pointed out the erroneous tendency in America to assign "exceptionalistic explanations to universalistic problems" (p. 19). Another problem with the individualistic theory is the exclusion of environmental factors in impacting people's economic conditions. For example, natural 
disasters, recession, unemployment and underemployment, and low-paying jobs are some of these factors not necessarily inherent to individuals. Social welfare policies such as EITC and TANF are founded upon the individualistic theory (Campbell \& Wright, 2005; Hasenfeld, 2009; Levitan, Mangum, Mangum, \& Sum, 2003; Maskovsky, 2001; O’Connor, 2001).

Cultural theory of poverty. Oscar Lewis is credited for his work in developing the cultural theory of poverty which posits that poverty results from (1) self-segregation of the poor and (2) the transmission of a culture of poverty from parents to children (Lewis, 1966). According to Lewis (1966), the poor isolate themselves from society based on their infrequent utilization of social and community resources such as banks, parks, libraries, hospitals, museums and art galleries. The utilization of these resources would provide the poor with information and social capital necessary to escape poverty. Conversely, self-isolation from the mainstream society leads to the perpetuation of an unfit set of values and norms regarding poverty. Hence, by not taking advantage of the opportunities available to them in the community, the poor fabricate a culture of poverty which has been transferred from one generation into another (Lewis, 1966). Children who are born and raised in impoverished environments tend to assimilate this culture of poverty even before reaching 8 years old. These children become psychologically unprepared to exploit the social opportunities presented in their community and thus seem to be trapped in a cycle of poverty which their parents and grandparents could not escape.

Murray (1990) extended Lewis's (1966) work by contending that the culture of poverty is characterized by criminal activities, illicit drugs, and family disintegration. 
Describing the British underclass, Murray (1990) argued that members of this class choose to remain poor because of the culture of poverty encouraged by the distribution of welfare. Hence, cultural theorists tend to blame those who live on public assistance, questioning their attitude toward hard work as a core American value. These theorists basically blame public assistance programs themselves for providing perverse incentives to the poor. Their conclusion implies that welfare programs lead to generational poverty by discouraging work among able-bodied individuals through unreasonable incentives (Murray, 1984, 1990).

The cultural theory of poverty has drawn a wave of criticism mainly from social exclusion theorists who argue that the poor do not have the means to exploit the opportunities in their communities because of their exclusion from the mainstream society. Contrary to Lewis who contended that the poor exclude themselves from society, social exclusion theorists argue that the society excludes the poor from the opportunities and privileges that the non-poor have access to. Silver (1994) explained:

....people may be excluded from: a livelihood; secure, permanent employment; earnings; property, credit or land; housing; the minimal or prevailing consumption level; education, skills and cultural capital; the benefits provided by the welfare state; citizenship and equality before the law; participation in the democratic process; public goods; the nation or the dominant race; the family and sociability; humane treatment, respect, personal fulfilment, understanding. (p. 541)

Social exclusion constitutes a barrier preventing the poor from exiting poverty. In other words, the poor share similar values as the rest of society, but face more barriers than other members of the society. Removing these barriers is therefore necessary for 
escaping poverty. Social exclusion rejects the notion of culture of poverty, as povertyborn children manage to exit the cycle of poverty to lead a successful life. This process may or may not necessitate adaptation to the mainstream culture.

The structural theory of poverty. In stark contrast to the individualistic theory, the structural theory of poverty posits that poverty is the result of a systemic failure. Adherents of this perspective argue that the government should constantly take reasonable steps to reduce inequality by ensuring economic opportunities for its citizens through creation of jobs, regulation of the minimum wage, and expansion of social safety net programs (Blank, 1997; Jencks, 1996; Tobin, 1994). Structural theories are consistent with the work of Emile Durkheim, the French sociologist and philosopher who argued that social influences exist even in circumstances where individuals resort to taking their own lives (Durkheim, 1897; 1951).

\section{Theses of Welfare Expansion}

Social researchers provide multiple explanations for the exponential growth in welfare caseloads, particularly from the middle of the 1960s and the middle of the 1970s. Beardwood (1968) attributed this welfare explosion to the mass exodus of the southern rural poor African-Americans to the North in a quest for better living conditions between 1945 and 1965. Moynihan (1965a) stressed that the disintegration of the family unit within the black community led to the formation of single-parent families, mostly headed by females. So the migration from the south to the north combined with the rise in female-headed households accounted for the huge increase in welfare rolls in the 1960s. While Rodgers (1982) underlined the gap between demand (number of people in need) and supply (lack of jobs) that characterized the 1960s, Patterson (1981) emphasized the 
positive effects of the Civil Rights Movement and the War on Poverty in reducing stigmas associated with welfare participation. Patterson (1981) also emphasized the mobilization of legal and political power that resulted in changes in the administration of public assistance eligibility determination. Still, McCarty and Zald (1973) and Moynihan (1965b) pointed to welfare officials as the driving force behind the late 1960s and early 1970s rise in the welfare take-up rate. The continued exploration of the welfare explosion topic by public policy experts gave birth to competing theories. The first one is the thesis of "Social Control" proposed by American sociologists and political activists Richard Cloward and Frances Fox Piven in 1971, while the second one - the thesis of "Mass Society"-was developed by Danish-born sociologist Kirsten Anderson Grønbjerg in 1977. In the following paragraphs, a close look is attributed to each of these two theses.

Social control thesis. According to Piven and Cloward's $(1971,1993)$ thesis, in western capitalist societies, welfare serves as a thermostat to regulate the political climate, or a switch to manipulate the behavior of the poor. This theory is thus based on two fundamental assumptions about welfare: (1) a moderating role characterized by increases in welfare programs during times of social rebellion; and (2) the promotion of low-wage work among the poor through decreases in welfare expenditures during periods of political calm. That is, with a climate of political stability, governmental leaders are more likely to adopt austerity tactics by cutting spending on welfare programs. By contrast, during times of political instability, pro-welfare policies are likely to be implemented in order to restore equilibrium.

Piven and Cloward $(1971,1993)$ associated the expansion of the federal welfare programs in the United States between the 1960s and the 1970s with the urban riots that 
ravaged American cities in the 1960s and the Democratic Party's increasing dependence on the urban Northern African-American vote in order to win elections. In only three years (between 1965 and 1968), 160 major American cities were affected by the riots perpetrated mostly by African-Americans (Feagin \& Hahn, 1973). In their book entitled "Regulating the Poor," Piven and Cloward $(1971,1993)$ contended that some of the "Great Society" programs under the Johnson administration were a direct result of such political turmoil. In other words, the explosion of welfare during the early stages of the "War on Poverty" was a political strategy to appease the African-American community and halt the progression of the 1960s urban riots.

Piven and Cloward $(1971,1993)$ also asserted that the welfare provision under the "New Deal" package in the 1930s was implemented not as a result of the "Great Depression" per se, but because the government felt threatened by growing protests and incidents of sabotage in the labor market. The socio-political and economic chaos that surrounded the Great Depression climate prompted the passage and implementation of antipoverty policies in the 1930s. The distribution of welfare was then shrunk over the next two decades due to a lack of social and political revolts during the 1940s and the 1950s.

The welfare state literature contains empirical evidence that supports Piven and Cloward's $(1971,1993)$ thesis by demonstrating associations between civil disobedience and increases in social welfare policies in the latter half of the 1960 decade (Betz, 1974; Chamlin, 1992; Hicks \& Swank, 1983; Isaac \& Kelly, 1981; Jennings, 1979; Schram \& Turbett, 1983a). Other researchers, however, inflicted a major blow to Piven and Cloward's (1971) Social Control Thesis upon finding no relationships between political 
unrest and growth in welfare expenditures in the late 1960s (Albritton, 1979; Durman, 1973). One explanation to these contradictory findings from Albritton (1979) and Durman (1973) was provided by Schram and Turbett (1983b):

We hypothesize that the welfare explosion in the late 1960s was in part the result of a two-step process in which civil disorder impelled the national government to enact liberalizations of welfare policy which in turn were most actively implemented by those states most wracked by rioting. (408)

To test their hypothesis, Schram and Turbett (1983b) handcrafted a "Standardized Riot Severity Score" to measure the rigor, frequency and magnitude of the urban riots across states during the 1960s and the 1970s (p. 410). Schram and Turbett (1983b) found relationships between riots and increases in welfare at the state level, not necessarily at the city level. In fact, responding to civil disorder of great magnitude is more a function of states rather than cities. Similarly, in the U.S. public assistance system, states and the federal government control welfare spending more than cities do, both before and after 1996. That is, the urban riots triggered the passage of liberal welfare policies (first-step process) which, in turn, are enforced primarily in states most severely damaged by social disturbances. These findings, therefore, not only support the aforementioned hypothesis but also represent a viable source of empirical evidence for the Piven and Cloward's (1971) Thesis of Social Control (Schram \& Turbett, 1983b).

One recent study conducted by Chamlin, Burek, \& Cochran (2007) tested the Piven and Cloward (1971) thesis using data from the Wisconsin experiment of the impact of TANF program participation on workforce participation and welfare exit. Chamlin et al. (2007) tested the following two hypotheses: (1) "the implementation of TANF 
legislation should lead to an increase in the size of the labor force above and beyond that which could be accounted for by ongoing social processes" and (2) "the implementation of TANF legislation should lead to a decline in the size of the welfare population above and beyond that which could be accounted for by ongoing social processes" (p. 136-137). These hypotheses are related to the other side of Piven and Cloward's (1971) thesis of social control which suggests that welfare is restricted during periods of political stability in order to regulate the poor's attitudes and behaviors toward the workforce. The Wisconsin experiment accumulates workforce data as well as time-limit data on TANF recipients from 1985 to 2004 and 1991 to 2004, respectively. A sample size of 240 for workforce participation and 168 for time-limit was collected for analysis (Chamlin et al., 2007). Results did not corroborate the hypotheses and, ultimately, provided little support for one side of the Piven and Cloward's (1971) thesis of social control (Chamlin et al., 2007).

One way to interpret Chamlin et al.'s (2007) findings can be related to the fact the integration of TANF recipients into the labor market is contingent upon the strength of the economy as was the case in the early years that followed the implementation of the program at the national level (Murray \& Primus, 2005; Sheely, 2012). Chamlin et al.'s (2007) findings can also be interpreted in light of potential barriers to employment faced by TANF recipients. These include disabilities, low education, age, physical and mental illness, lack of transportation, lack of affordable childcare (Banerjee \& Damman, 2013; Bloom et al., 2011; Danziger \& Seefeldt, 2003; Dworsky \& Courtney, 2007; Pavetti, 2002; Sandstrom, Seefeldt, Huerta, \& Loprest, 2014; Siegel et al., 2004). Finally, the small sample involved in the Wisconsin experiment does not allow generalization of 
findings to the entire U.S. population. Therefore, the results of this test are not enough to refute Piven and Cloward's (1971) thesis of social control (Chamlin et al., 2007).

Mass society thesis. Grønbjerg’s (1977) Mass Society Thesis is a diametrically opposing schema to that of Piven and Cloward (1971, 1993). According to Grønbjerg's (1977) thesis, citizens who cannot support themselves economically are entitled to receive public assistance as a natural right. Therefore, the expansion of welfare in the 1960s and 1970s was a signal that the United States was edging toward a "mass society" defined as a rapid shift in the allocation of welfare assistance by the government to hitherto excluded individuals and groups (Aigner, 1982).

By evoking the notion of entitlement, Grønbjerg's (1977) thesis is somewhat an extension of the liberal view of social welfare which links social assistance to humanitarian actions from the government to remediate social problems (Wilensky, 1975). By the same token, Grønbjerg's (1977) thesis draws a similar connotation with Marshall's concept of "social citizenship" which emphasizes social rights. These comprise a vast array of prerogatives ranging from "the right to a modicum of economic welfare and security to the right to share to the full in the social heritage and to live the life of a civilized being according to the standards prevailing in the society" (Marshall, $1992,8)$. So the explosion of welfare facilitated the gradual merger of the "periphery" with the "center." That is to say, welfare recipients (periphery) become integral members of the conventionally accepted society (center) through the expansion of government assistance (Grønbjerg, 1977).

To test her thesis, Grønbjerg (1977) regressed the outcome (welfare explosion) on multiple predictors such as voter participation, median education, professional workforce, 
urbanization, industrialization, and state per capita revenue. These predictor variables where hypothesized to be factors associated with a rapid change toward "mass society." Grønbjerg (1977) also included in her analysis some factors of need such as family dysfunction, migration, and unemployment. Results demonstrated that (1) the need factors were better predictors of welfare expansion in the 1960s than were the "mass society" factors; (2) both the need factors and the "mass society" factors were key predictors of the large rise in AFDC caseloads in 1970s; and (3) the "mass society" factors were highly associated with interstate differences in AFDC caseloads between the 1960s and 1970s. Based on these findings, Grønbjerg (1977) rejected in its entirety Piven and Cloward's (1971) social control thesis in favor of her mass society hypothesis.

In a comparative analysis of the "Mass Society," thesis, Schram and Turbett (1983a) pointed out the fact that Grønbjerg (1977) failed to account for the social control thesis in the multivariate analysis of the variables. By omitting rioting activities as a predictor of welfare growth, Grønbjerg (1977) actually introduced her work to the scientific community in a biased way. Schram and Turbett (1983a) continued their criticism of Grønbjerg's (1977) work by contending that the mass society thesis leaves doors open for "speculation” (p. 619).

Using multiple regression, Schram and Turbett (1983a) tested the mass society model while controlling for the social control thesis. To do so, Schram and Turbett (1983a) identified a list of possible welfare growth predictors that include (1) the mass society indicators (voter participation, median education, professional workforce, urbanization, industrialization, state per capita revenue) which were actually used in Grønbjerg's (1977) analysis; (2) the need indicators (family dysfunction, migration, 
unemployment) which were also included in Grønbjerg's (1977) work; (3) the social control indicators (severity of state-level riots). They also included "state median income" and "average community action expenditures per poor person" (p. 621). As per the results, median income and riots were the two most statistically significant predictors of the welfare explosion between the 1960 and 1970 decade while controlling for all the other variables. Hence, these findings attribute little credence to Grønbjerg's (1977) Mass Society Thesis, while providing more empirical support to the social control model (Schram \& Turbett, 1983a).

\section{Theories of Devolution and Racial Disparities in Social Welfare}

Perhaps the two most prominent empirically-proven theories about the devolution of welfare policies and racial disparities in public assistance are (1) Schneider and Ingram's Theory of Policy Design and Social Construction and (2) Soss' Racial Classification Model. The latter is often seen as an extension of the former. This proposed research relies on the premises of these two fundamental theoretical frameworks toward explaining relevant issues in the current welfare state in America. Through the lenses of these theories, the proposed research will particularly look at how federal welfare policies affect low-income recipients on their way toward economic selfsufficiency. A critical analysis of these theories is provided below.

Theory of policy design and social construction. Articulated in the 1990s by Anne Schneider and Helen Ingram, the Theory of Social Construction and Policy Design is an empirically tested framework that explains the political drives behind the formation of policy designs (Schneider \& Ingram, 1997). This theoretical framework, therefore, sets the stage for assessing the merits and shortcomings of social policies in addressing social 
problems. The Theory of Social Construction and Policy Design rests on two fundamental propositions: the "target population proposition" and the "feed-forward proposition" (Ingram, Schneider, \& deLeon, 2007, pp. 98, 101).

Target population proposition. The "Target Population Proposition" posits that public policies are designed in accordance with the way their end-users (target population) are politically and socially perceived. That is, a target population constructed as deserving and powerful will have a greater share of the economic resources, and is likely to be subjected to supportive policies. On the other hand, a group of people identified by the government and members of the society as undeserving and powerless will have access to less economic opportunities but deal with tougher policy guidelines (Ingram et al., 2007; Schneider \& Ingram, 1997). Hence, the unequal treatment associated with policy designs further extends the economic disparities among social groups.

Feed-forward proposition. The "Feed-Forward Proposition" implies that policy designs produce long-lasting impacts on the end-users, affecting their behaviors and perceptions of themselves in the process. In doing so, policy designs set the stage for shaping future policies that can generate desirable outcomes. This "feed-forward" process ensures the continuity of the social construction patterns assigned to social groups, thereby maintaining or even exacerbating the socio-political-economic differences that exist between these groups (Ingram et al., 2007; Schneider \& Sidney, 2009).

Schneider and Ingram's Theory of Social Construction and Policy Design has grown in popularity and emerged as one of the most widely used theoretical frameworks for assessing social policies. Indeed, over just a 20 year span (from its inception in 1993 
to 2013), this theory was used in 111 empirical studies. Social researchers from various backgrounds have used this model to guide their inquiries on the effects of public policies on the intended target populations. The most popular fields of study where this theory was applied in the last two decades include social welfare, immigration, criminal justice, health, education, environment and urban affairs (Pierce et al., 2014).

Relevance to social welfare and current study. As a result of the biased approach adopted by the government in the design of social policies, the federal safety net is composed of two preponderant classes of programs: one that is designed for deserving individuals and another one for undeserving ones. The double standard in public policy approaches to target populations lead to what social scientists have labeled a "two-tier" welfare system where the privileged population receive the top-tier benefits and the underprivileged groups are recipients of the bottom-tier benefits (Fraser \& Gordon, 1994; Lieberman, 1998; Orloff, 1996). The top-tier welfare programs provide benefits to recipients with proven work history and may include but are not limited to the Unemployment Insurance program, the Old Age, Survivors and Disability Insurance program, and the Medicare program. The bottom-tier welfare programs, in contrast, are designed for needy individuals and families who cannot provide for themselves and therefore rely on the government for economic survival. Since this class of people is constructed as undeserving, there are relatively stronger requirements for receiving benefits (Chang, 2015). The welfare programs that are considered bottom-tier are the means-tested benefits such as the Temporary Assistance to Needy Families program (TANF), the Supplemental Nutritional Assistance Program (SNAP), or the Housing Choice Voucher program (HCV). 
The difference in treatment between the advantaged and the disadvantaged groups on the part of the government also widens the gaps of inequality among them. Therefore, Schneider and Ingram's Theory of Social Construction and Policy Design increases awareness about social and economic disparities in the design and implementation of governmental efforts toward alleviating social problems at local, state and federal levels. By promoting democratic practices and social justice in the creation of public policies, this framework holds a substantial implication for the social work profession. With respect to the proposed study, the Theory of Social Construction and Policy Design will serve as a framework for the analysis of the effects of the federal safety net programs on recipients' empowerment toward self-sufficiency. Particular attention will be paid to the bottom-tier programs due to the fact that these programs target the disadvantaged populations.

Racial classification model (RCM). Developed and tested in 2008 by Joe Soss, Richard C. Fording, and Sanford F. Schram, the Racial Classification Model (RCM) extends Schneider and Ingram's groundbreaking work on social construction and policy design by identifying race as a key element in the choice, transfer and implementation of welfare policies. The RCM is based on three fundamental propositions.

Proposition 1. The first proposition suggests that welfare policies aim to answer preconceived questions related to the sociopolitical conditions of "specific target populations" (Schneider \& Ingram, 1997) and are implemented based on the "salient social classifications and reputations" of these targeted populations. This means, policies designed to address social problems would become irrelevant in the absence of a target 
group perceived through social classification lenses (Soss, Fording, \& Schram, 2008, p. 539).

Proposition 2. The second proposition posits that racial prevalence in a given welfare program serves as a basis for policymakers to anticipate success or failure associated with its implementation. That is, the prevalence of African-Americans on program caseloads may force legislators to adopt policies that emphasize strong workforce participation. Furthermore, the reputation of these African-Americans in regard to the labor market may influence the decision of a welfare official in enforcing more stringent regulations against them as opposed to their White or Hispanic counterparts (Soss et al., 2008).

Proposition 3. The third proposition asserts that differences must exist among racial groups in order for them to be tractable by those charged with choosing, implementing and enforcing welfare policies. When "racial contrasts" form and become significant, policies are tailored and applied based on the reputations of racial groups in the mainstream culture. Such contrasts grow even bolder when welfare officials observe behaviors that are consistent with the way individuals and racial groups are depicted within the broader social context (Soss et al., 2008).

From the three propositions specified above derive four sets of hypotheses related to "race/ethnicity," "social control," "ideology and innovative problem solving," and “task environment" which, in turn, produce multiple distinct hypotheses (Soss et al., 2008). The latter are related to what Soss et al. (2008) referred to as "second-order devolution," the legal authority granted by states to lower levels of governance concerning the administration of the TANF program (p. 543). According to Soss et al. 
(2008), the transfer of administrative power from states to local governments (secondorder devolution) is expected to be higher in: (1) states that contain a large number of African-Americans and Hispanics; (2) states that have a weak labor force but a strong welfare take-up rate; (3) states that show class bias in voter turnout (4) states that invest heavily in the erection of incarceration facilities; (5) states that embrace a "conservative" approach to fiscal policy and where citizens' political viewpoints are highly divergent; and (6) states with a lower level of population density.

These hypotheses, among others, were tested for the 48 contiguous states (excluding Nebraska due to its nonpartisan legislature) by means of the Binary Logit Model. This statistical procedure allows the identification of state-level predictors of devolution. The overall results strongly support the hypotheses and therefore provide empirical grounds for the RCM. One possible limitation of the RCM is the fact that the model only accounts for TANF devolution and, thus, does not provide for the devolutionary process as pertains to other social welfare programs. Florida and other states have proposed imposing or strengthening work requirements in a number of second tier welfare programs, such as Unemployment Insurance, SNAP, and Medicaid, but were restrained by the Obama administration. If Republicans have their way, there may be a TANF-like emphasis on work requirements in other programs in the near future.

In fact, TANF's strong emphasis on work requirements and penalties or a lack thereof constitutes a perfect match for testing the RCM assumptions. Therefore, the empirical findings upon which the RCM is built might not necessarily be applicable to second-order devolution in other programs like the social services block grants (SSBGs). However, this model, combined with the theory of policy design and social construction, 
constitutes the theoretical foundations for the hypotheses that will be developed in this dissertation.

\section{Theories of Savings and Economic Self-Sufficiency}

Self-sufficiency has always been a desired outcome for policymakers in the United States as evidenced by the body of legislation that has shaped social welfare in this country since the 1950s (Bowen et al., 1995; Cancian \& Meyer, 2004; Caputo, 1997; Gowdy \& Pearlmutter, 1993; Hawkins, 2005; Hong et al., 2009; Johnson \& Corcoran, 2004; Parker, 1994). One purpose of the 1996 law — the latest major social welfare reform - is to empower poor families with children toward economic independence (Gowdy \& Pearlmutter, 1993; P. L. 104-193). A few emerging theories related to savings and economic self-sufficiency are discussed below.

Financial capability framework. The financial capability theory is one of the most recently developed approaches in social work and welfare economics that attempt to explain the mechanisms of economic self-sufficiency among the poor. This theory contends that both the acquisition of financial knowledge and the accessibility to financial transactions are necessary for individuals to reach desired self-sufficiency outcomes (Johnson \& Sherraden, 2007). Both conditions are expected to be met in order for people, especially low-income families, to reach their economic goals and objectives. That is, the combination of financial education/literacy and institutional opportunities are fundamental conditions for disadvantaged populations to become economically autonomous (Johnson \& Sherraden, 2007). Nussbaum (2000) and Robeyns (2005) had similar views on the financial approach by emphasizing the combined effect of individual characteristics and environmental factors in determining someone's financial capabilities. 
The roots of this perspective can be traced back to the seminal work on capabilities developed in 1987 by Indian economist Amartya Sen and which garnered him the 1988 Nobel Prize in Economics. Sen (1987) described capabilities in terms of personal abilities and structural opportunities for individuals to take reasonable steps toward the fulfillment of their goals. This implies a sense of freedom in making decisions on their own behalf and accessing the opportunities available in their immediate environment (Sen, 1993). Sen's capability theory was bolstered by American philosopher Martha Craven Nussbaum who argued that internal characteristics are not enough for the attainment of well-being; the environment should be structured in such a way that individuals can perform to the fullest extent of their capabilities (Nussbaum, 2000). As an approach, financial capability is being adopted in social work through the work of the Elizabeth Johnson and Margaret S. Sherraden who proposed financial education and savings as concrete means toward economic independence among low-income families (Johnson \& Sherraden, 2007).

Behavioral economic theory. Developed in the late 1980s by Canadian behavioral finance scientist Herst M. Shefrin and American economist Richard H. Thaler, the behavioral economic theory is a well-developed framework for understanding savings and accumulation of assets among families (Okech, 2011). This theory stipulates that people, including the poor, can save and accumulate possessions through the process of mental discipline. That is, by setting goals and objectives, individuals may choose to limit their daily expenses in order to save money for a mid-term or a long-term project such as buying a home or sending children to college. Under this framework, self-discipline is an essential factor for saving (Shefrin \& Thaler, 1988; Thaler, 1994). 
The behavioral economic theory is built on Adam Smith's (1759) Theory of Moral Sentiments which explains human behaviors through a psychological lens (Ashraf, Camerer \& Loewenstein, 2005). Smith $(1759,1976)$ evoked sympathy as a natural drive that guides human beings' feelings toward others (p. 9). The desire to see other people happy implies working for the greater good of society. Since Smith $(1759,1976)$ elaborated on the happiness of others, many scholars consider Adam Smith a protoutilitarian (Campbell, 1971; Campbell \& Ross, 1981; Otteson, 2002; Smith, 1759, 1976; Valcarce, 2010; Witztum \& Young, 2013). About two centuries later, progressive social campaigner Irvin Fisher contributed to the development of Utility Theory, which accounts for people's choices of goods and services (Fisher, 1930; Stigler, 1950). Utility Theory for decision making has been antagonized by and perhaps supplanted by Prospect Theory introduced by Kahneman and Tversky in 1979. This theory explains the behavior of people during financially risky situations (Kahneman \& Tversky, 1979).

Behavioral perspective. More recently, there has been a shift from the Behavioral Economic Theory toward the adoption of the Behavioral Perspective which accounts for the financial comportment of the poor (Duflo, 2006; Hall, 2008; Mullainathan \& Shafir, 2009). The Behavioral Perspective - proposed by Harvard University economist Sendhil Mullainathan and Princeton University behavioral scientist Eldar Shafir- posits that the poor share similar natural financial impulses with the wealthy, but have less room to maneuver than do their wealthy counterparts (Mullainathan \& Shafir, 2009). That is, subjected to the same financial opportunities such as automatic enrollment in savings plans, the poor would be able to save at a similar rate as the non-poor. The reality is that the poor do not usually hold jobs that offer automatic 
enrollment in 401(k) plans as do the wealthy. Therefore, the poor earn cash money which is more volatile and likely to be spent than money directly deposited into a bank account (Mullainathan \& Shafir, 2009). Being marginalized in the banking world and/or the retirement savings system, the likelihood for them to save is significantly less compared to the non-poor who participate in savings by institutional default (Mullainathan \& Shafir, 2009). In addition, the poor are more likely to miss on monthly payments of bills and incur late payment charges than are the non-poor who can set automatic payments of bills through their bank accounts. Based on their propensity for incurring late payment fees, the poor have a narrower margin of error than do the non-poor. According to Mullainathan and Shafir (2009), the government can facilitate the integration of the poor into the banking system by setting automatic deposits of income-based benefits through financial institutions.

Institutional theory of savings. Popularly known as Assets Theory, the Institutional Theory of Savings was developed in the 1990s by Michael Sherraden, a social work researcher at Washington University in St. Louis. In his book Assets and the Poor: A New American Welfare Policy, Sherraden (1991) argued that the current incomebased welfare system in the United States is unfair because the middle and upper classes depend on assets, which the poor do not have access to in order to progress economically. Sherraden's (1991) argument is grounded in the fact that the rich often receive tax credits for homeownership and business while the poor are generally provided with means-tested assistance. Means-tested welfare benefits were found to be negatively associated with savings among the poor. Such relationship between welfare receipt and savings can be explained by the fact that beneficiaries tend to spend the income received from the 
government in order to remain eligible for assistance. In other words, since asset limits are an eligibility requirement for public assistance, low-income participants cannot save because saving would disqualify them for benefits (Campbell, 2014; Hurst \& Ziliak, 2001; Ziliak, 2003). Without savings the poor are unable to accumulate assets and become economically self-sufficient.

Sherraden (1991) hypothesized that the poor can save if provided with opportunities to do so and that the government can play a significant role in helping lowincome families save and accumulate assets through matching funds. Sherraden (1991) proposed an asset-building strategy known as Individual Development Accounts (IDA) as a plausible way to test his hypothesis. The IDA program is a preventive measure against intergenerational poverty which targets low-income individuals and families. Program participants usually completed 12 hours of financial education and asset-specific training before starting to save. The amount of money saved is matched by the government up to a certain point as defined by the program. The IDA program pursues the following goals and objectives: financial literacy, taste for saving, old debts clearing, credit building, low income homeownership, entrepreneurship, small business development, and asset accumulation (Sherraden, 1991). Since early 2000s, there have been demonstration projects on IDAs across the country with the strongest site in Tulsa, Oklahoma. Randomized clinical trials with large sample sizes indicated that IDA is a promising asset-building strategy among low-income families (Grinstein-Weiss et al. 2008, 2013; Han, Grinstein-Weiss, \& Sherraden, 2009). By helping poor families accumulate assets, IDA is paving the way for a better future for children. In this sense, this program is a viable option against intergenerational poverty in America. 
The US Congress already proved some proclivity toward IDA by passing the Assets for Independence Act as Title IV of the Community Opportunities, Accountability, and Training and Educational Services Human Services Reauthorization Act of 1998 (P. L. 105-285). For the 2015 fiscal year, this law appropriates $\$ 18.95$ million to the Department of Health and Human Services for the demonstration and support of assets-based projects targeting the economic self-sufficiency of low-income households (USDHHS, 2014b). The expansion of this program is desirable so that more low income Americans can be empowered toward the attainment and maintenance of financial self-sufficiency.

\section{Limitations of Theories}

However appealing the individualistic, cultural, and structural hypotheses on poverty might be, none of them provides a thorough explanation or captures the breadth of the problem in sight. In fact, all three approaches have limitations as individuals should not be blamed for a systemic failure (Ryan, 1976) nor should the government bear full responsibility for those who deliberately refuse to live as productive citizens. Similarly, being born and raised in poverty does not always perpetuate poverty, nor does receiving welfare benefits always lead to generational poverty. Other limitations are related to the fact that none of the theories actually captures factors such as religious and spiritual beliefs, cultural values and meanings of goods, as well as the costs of maintaining a job in terms of transportation, clothing, fatigue, and childcare arrangements (Butterfield, Rocha, \& Butterfield, 2010; Edin \& Lein, 1997). Furthermore, these three approaches have not been empirically tested and therefore should be considered as views or perspectives instead of theories. 
Meanwhile, the social control thesis provides no explanations for the "semiwelfare state" that occurred in the aftermath of Hurricane Katrina where the U. S. Congress authorized $\$ 62.3$ billion to respond to the 2005 disaster (Katz, 2008). By the same token, this model falls short in explaining the $\$ 789$ billion economic stimulus package approved by Congress in 2009 to reverse the Great Recession. In either instance, no street protests or rioting activities were involved. Instead, both were residual procedures taken toward reshaping and bolstering the economy after tough times.

Elsewhere, notwithstanding its popularity among scholars, Schneider and Ingram's theory of social construction and policy design neither fully accounts for the rampant inequality and racial disparities in the social welfare system nor explains the devolutionary process of welfare policies from states to lower levels of administration. Concerning the transfer of power from states to local government, Lowi (1998) argued that behaviors can best be shaped at local levels of governance. Policy researchers have found associations between enforcement of welfare sanctions at state and/or local levels and racial makeup of welfare rolls (Fellowes \& Rowe, 2004; Fording, 2003; Soss, Schram, Vartanian, \& O’Brien, 2001). Other studies have shown that the devolution of welfare policies from state to local authorities created racial differences by exposing minority enrollees to unfair treatments (Grubb, 1984; Lieberman, 1998). All of these aforementioned findings, however, proved sporadic in terms of developing a new theoretical framework that encapsulates the devolution of welfare provisions from states to counties. Therefore, not until the emergence and embodiment of Soss' (2008) Racial Classification Model was the scholarship on social welfare fully equipped with a 
theoretical model that goes beyond the scope of Schneider and Ingram's theory of social construction and policy design.

As seen in this chapter, one single theoretical framework would not suffice in explaining the dynamics of the phenomena of poverty and welfare. Scholars and theorists across the social science spectrum have been a fundamental role in expanding the theoretical dialogue about poverty and public assistance. Their work helped the public understanding the cause of poverty, the rationale for the expansion of public welfare programs in the 1960s and the 1970s, the devolution revolution, and the accumulation of assets. Major theoretical views on poverty and welfare were presented mostly in a competing fashion: individualistic theory versus culture of poverty theory; social control thesis versus mass society thesis; and institutional theory of savings versus behavioral economic theory. With the exception of Soss et al.'s (2008) RCM, most theoretical perspectives have been around for many decades. Yet, there is a lack of empirical evidence to support or reject the claims of many of these theories discussed above. The next chapter formulates the study hypotheses and links them to relevant theoretical frameworks. 


\section{CHAPTER V. STUDY HYPOTHESES}

Given the scarcity of research on economic self-sufficiency as a function of receiving benefits from multiple government programs (Slack et al., 2014), it remains largely unknown which direction the results of this investigation may go. Nonetheless, based on the premises of (a) Ingram and Schneider's theory of policy design and social construction, (b) Lewis's culture of poverty theory, (c) Soss et al.' racial classification model (RCM), and (d) Piven and Cloward's social control thesis, it can be anticipated that the lower-tier means tested benefits do not empower the poor toward economic selfsufficiency. Therefore, the following two hypotheses are posited: (1) Low-income household members who receive one or more federal means-tested benefits will be less likely to attain and maintain economic self-sufficiency than their counterparts who do not participate in federal welfare programs; and (2) Low-income households that enrolled in more programs will have worse self-sufficiency outcomes than their counterparts that participate in fewer programs. Figure 2 below presents a graphical representation of the theoretical framework upon which the study hypotheses are founded. 


\section{Figure 9. THEORETICAL FRAMEWORK}

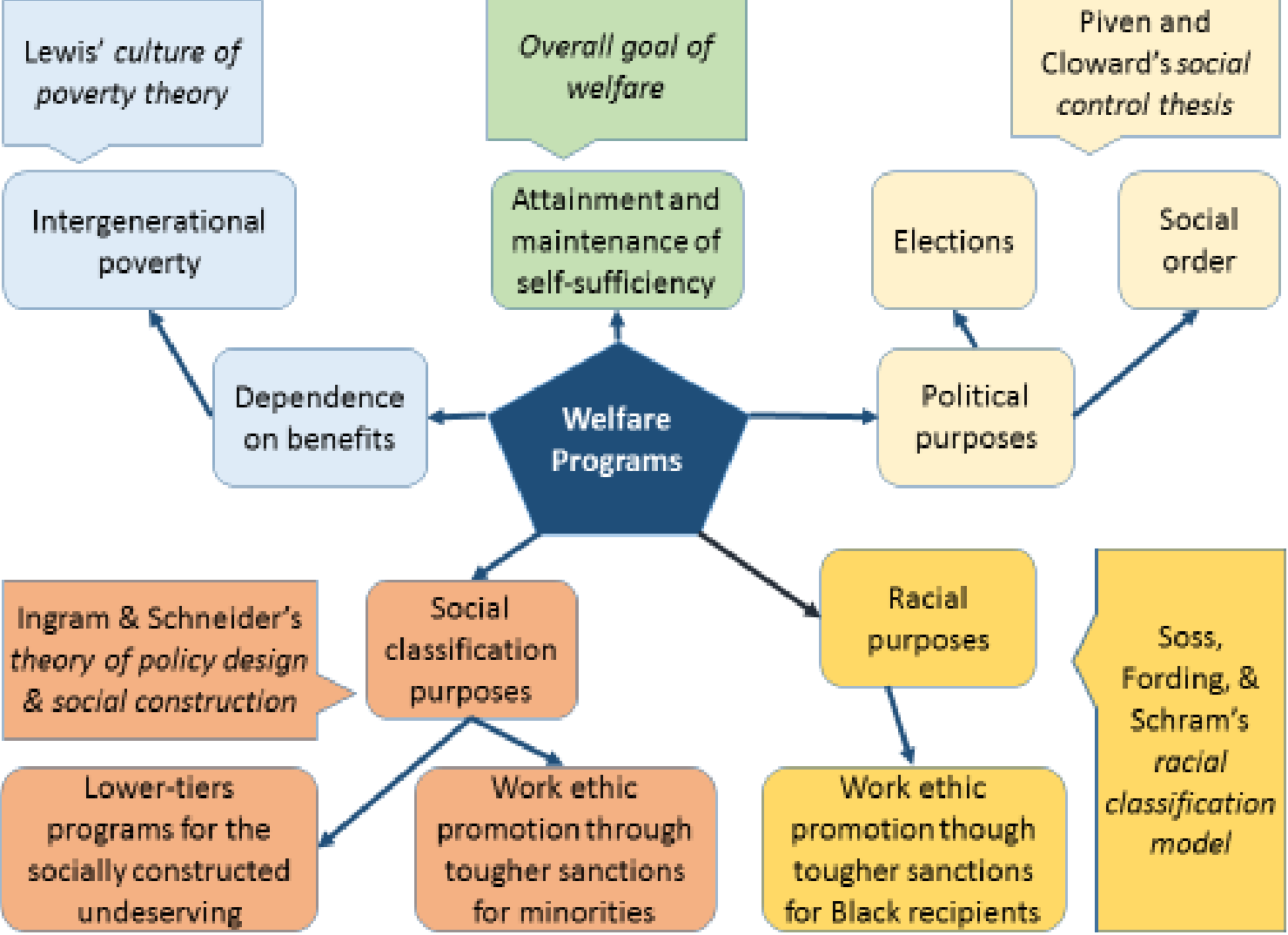

\section{Linking Study Hypotheses with the Theory of Policy Design and Social Construction}

Ingram and Schneider's theory of policy design and social construction lays down motives related to the conceptualization, development, and implications of antipoverty policies in America. In framing social welfare interventions, policymakers perceive the ultimate users of these interventions in a dichotomous fashion: the deserving and the undeserving. This double standard in public policy approaches toward target populations lead to what social scientists labeled a "two tier" welfare system where the privileged population receives the top-tier benefits and the underprivileged groups are recipients of the bottom-tier benefits (Fraser \& Gordon, 1994; Lieberman, 1998; Orloff, 1996). The top-tier welfare programs provide benefits to recipients with proven work history and 
may include but are not limited to the Unemployment Insurance program, the Old Age, Survivors and Disability Insurance program, and the Medicare program. The bottom-tier welfare programs, in contrast, are designed for needy individuals and families who cannot provide for themselves and therefore rely on the government for economic survival. The welfare programs that are considered bottom-tier include those providing means-tested benefits such as the Temporary Assistance to Needy Families program (TANF), the Supplemental Nutritional Assistance Program (SNAP), and the Housing Choice Voucher program (HCV).

Because low-income individuals and families who receive these programs are socially constructed as undeserving and powerless, there are relatively stronger requirements for receiving benefits (Chang, 2015). This class of people is also subjected to more stringent regulations rather than being regarded as having an entitlement to a fair share of the economic resources (Ingram et al., 2007; Schneider \& Ingram, 1997). In this case, the devolution revolution in the welfare state is interpreted as a political maneuver intended to mold the behavior of the poor toward the labor market. This behaviormolding process involves sanctions for noncompliance, especially among minority groups who have been socially labeled as having a certain proclivity for escaping the labor force. Hence, since socio-political and economic biases among social groups occupy center stage in the design and implementation of antipoverty policies, the purpose of welfare is not economic self-sufficiency, but the promotion of work ethic.

Schneider and Ingram's Theory of Social Construction and Policy Design, hence, increases awareness about social and economic disparities in the design and implementation of governmental efforts toward alleviating social problems at local, state 
and federal levels. By promoting democratic practices and social justice in the creation of public policies, this framework holds a substantial implication for the social work profession. With respect to this research project, this theory serves as the main framework to test the hypotheses, all of which have to do with low-income populations.

\section{Linking Study Hypotheses with the Culture of Poverty Theory}

The rise of neoliberalism in the early 1980s resurrected one tenet of the culture of poverty theory: welfare receipt is associated with a lack of work ethic which is transmissible from parents to children (Murray, 1990). The argument here is that welfare erodes recipients' desire to join the workforce - the primary pathway toward economic self-sufficiency. By systematically receiving benefits from the government, recipients can afford to cover some expenses without going through the hassles of the work shift, transportation, clothing, etc. In addition, securing a job may jeopardize some welfare benefits if recipients earn a few dollars above the income requirements for eligibility. This is known as the benefits cliff, an income cutoff above which low-income households become ineligible for certain welfare programs (Indiana Institute for Working Families, 2012). Considering the propensity for low-paying jobs among welfare recipients (Bloom et al., 2011; Dworsky \& Courtney, 2007; Pavetti, 2002), it would not make too much sense to work full time and earn just a little more than what the government actually provides in the form of public assistance.

However, by becoming somehow economically rational, the poor's behavior is

deemed irrational by members who are external to their culture. Lewis (1966) argued that the culture of poverty resulted in people doing things that seemed irrational to nonmembers of the culture. So under the cultural theory of poverty, it is believed that 
welfare, in its current state, produces counterproductive outcomes and thus becomes more a part of the problem than of the solution (Reagan, 1988). So all things considered, welfare does not promote economic self-sufficiency but keeps recipients in poverty from one generation to the next (Lewis, 1966). This is not its purpose in the sense that policymakers planned to make people dependent on the assistance programs. Perhaps, there are unintended consequences in policy design.

\section{Linking Study Hypotheses with the Racial Classification Model}

The proclaimed goal of economic self-sufficiency is not achievable because it is being supplanted by racially motivated social-control priorities for TANF as a whole. TANF is designed to help poor families with children, lead needy parents to economic self-sufficiency, decrease out of wedlock pregnancies, and promote two-parent families (P. L. 104-193). However, those are not racially neutral objectives. According to Soss et al. (2008), states have been given latitude by the central government on how to operate welfare. Soss et al. (2008) concluded that U.S. states with a higher percentage of blacks receiving TANF reveal more restrictive and punitive policies for implementing TANF (regarding work requirements, the lifetime limit, being cut off for not showing up for appointments, etc.). That is, the implementation of TANF has to do with negative imagery of the black population. People form negative attitudes about welfare. These attitudes, in turn, influence the policies intended to help recipients move out of welfare. Therefore, the racially motivated implementation of welfare policies contradicts the selfproclaimed goal of welfare which is to lead people toward economic self-sufficiency. This goal has been supplanted by social racial biases. Soss et al.'s (2008) argument dovetails nicely with Ingram and Schneider's theory of policy design and social construction. 


\section{Linking Study Hypotheses with the Social Control Thesis}

Piven and Cloward's social control thesis can be combined with the racial differentials argued in Soss et al.'s (2008) work. The motivation to regulate welfare is infused with the notion to control the black population. According to Piven and Cloward's social control thesis, welfare has served as a means to regulate the political atmosphere in America. The dependence of the Democratic Party on the black voters is one reason why a Democrat-controlled government tends to expand welfare benefits. Welfare recipients, in turn, are expected to show up to the polls and cast their ballots in favor of Democratic politicians. Since 1980, in contrast, Republican-led governments at the federal level have shrunk the welfare state for political purposes. Allocating too many benefits to the poor may be upsetting to the white voting bloc. So controlling the distribution of these benefits is essential to keep white voters happy. Welfare also serves as a way to restore political equilibrium. As mentioned above, Piven and Cloward (1971) linked the expansion of welfare to the chaotic political scenes orchestrated by the black community during the urban riots of the 1960s. Welfare, in this case, is used as a political strategy to control mayhem. Furthermore, public assistance benefits serve to discipline the workforce, assuring a supply of low wage labor (Piven \& Cloward, 1971). In short, the goal of the welfare state here is to control the political climate and regulate the workforce rather than help the poor reach the level of economic self-sufficiency advocated in the War on Poverty discourse.

This chapter-one of the shortest in this investigation—generated two hypotheses based on the underlying principles of the theory of policy design and social construction, the culture of poverty theory, the RCM and the social control thesis. The most direct 
route to self-sufficiency is welfare through decent work. This is one of the stated goals of the welfare reform of 1996. However, the aforementioned theories argued otherwise. Welfare is served for different purposes, including creating dependence, further dividing ethnic groups, shaping the behavior of recipients, and maintaining social order. If this line of argument is true, then welfare will not lead low-income households to economic selfsufficiency. Such argument is in stark contrast with the self-proclaimed goal of welfare described above. Hence, this chapter highlighted two opposing positions pertaining to economic independence among welfare recipients. The next chapter focuses on the methodology under which this investigation is conducted. 


\section{CHAPTER VI. METHODOLOGY}

\section{Research Design}

In this study, participants were categorized into two groups of low-income households: those that received lower-tier federal means-tested benefits (intervention group) and those that did not receive these benefits, but were likely eligible for them (comparison group). This research falls under the rubric of quasi-experimental designs with repeated measures. That is, the study variables were measured for each wave of a longitudinal dataset (please see Figure 10 below).

\section{Figure 10. STUDY DESIGN}

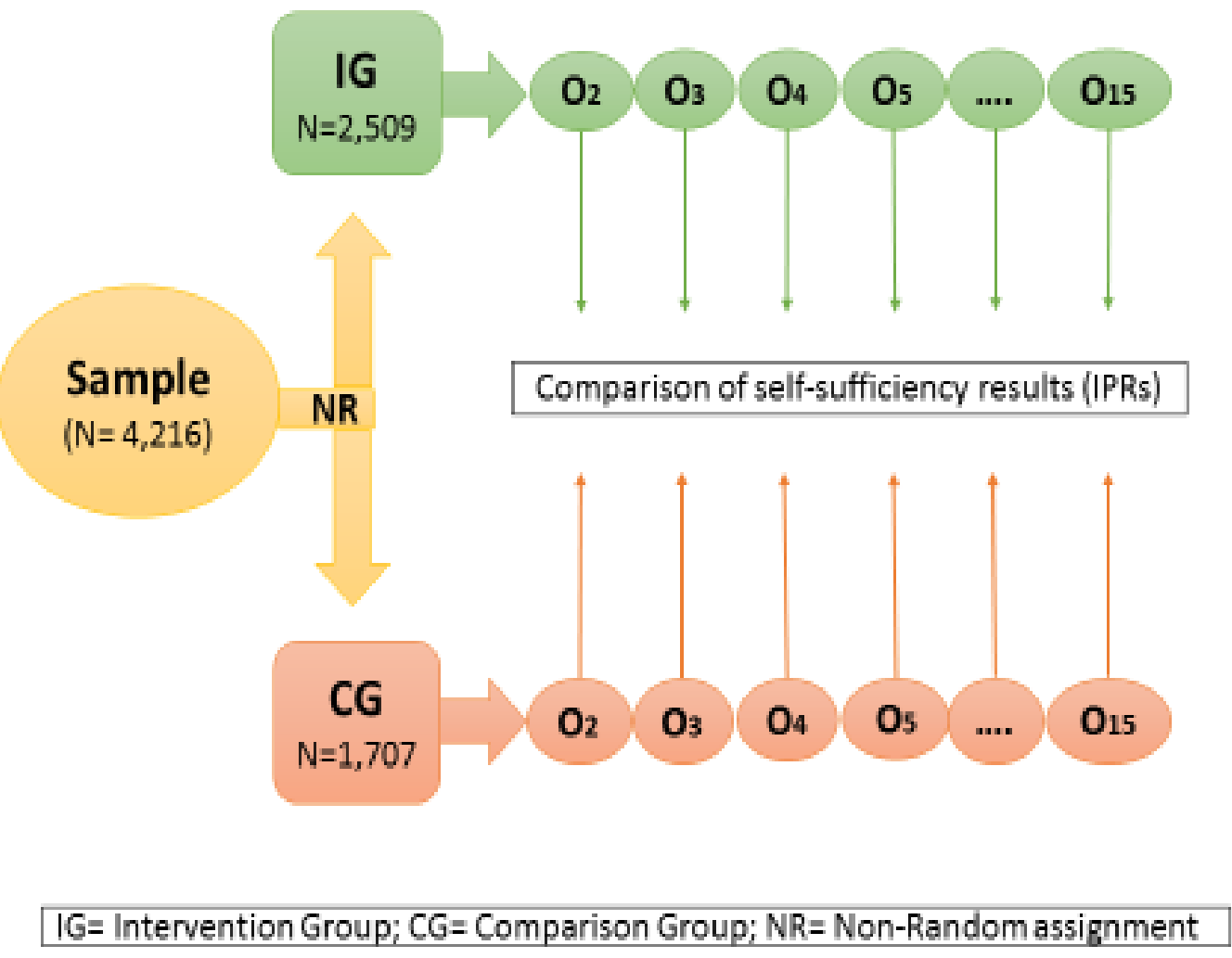


This research attempted to ensure that the intervention group and the comparison group were comparable by running propensity score matching (PSM) at baseline. PSM has been heralded as a bias reduction approach in nonexperimental studies that involve comparison of groups (Dehejia, \& Wahba, 2002). Participants in the intervention group were matched against those in the comparison group based on observed covariates (Apel \& Sweeten, 2010; Rosenbaum \& Rubin, 1983). Over the past decade, PSM has received considerable attention among social researchers across the world and is one of the most commonly used strategies to decrease preexisting differences among participants in observational studies. That is, PSM is a mechanism by which a researcher can evaluate the impact of an intervention in a nonexperimental environment (Apel \& Sweeten, 2010). Although a less rigorous method when compared to experimental designs (Peikes, Moreno, \& Orzol, 2012), PSM was found to be empirically superior to logistic regression in terms of bias reduction in nonexperimental quantitative research (Cepeda, Boston, Farrar, \& Strom, 2003).

Yet, after using the optimal matching model—a type of PSM reputed for producing the closest matches possible between the intervention group and the comparison group - (Gu \& Rosenbaum, 1993), the original sample of 12,119 participants $(\mathrm{n}=12,119)$ was reduced almost by half. Such a huge sample loss was a risk too big to take, especially when there are other statistical approaches that allow researchers to control for pre-existing differences between non-randomized groups (see the Data Analysis section). Sociologists used matching extensively in the 1930s only to find that the amount of data that was discarded (because no match was identified) was enormous (Chapin, 1947). Harvard University researcher Gary King and Massachusetts Institute of 
Technology professor Richard Nielsen coined the term "PSM paradox" to caution against the risk of data quality degradation due to excessive trimming during the matching process (King \& Nielsen, 2016, p. 1). Hence, PSM was avoided in this research investigation.

\section{Data}

This quantitative study used a secondary analysis of a longitudinal dataset to examine the relationship between participation in multiple public assistance programs and economic self-sufficiency among beneficiaries. Secondary data analysis has grown exponentially across social science and public health disciplines (Cheng \& Phillips, 2014; Hofferth, 2005). In 1983, 31 percent of published studies on family research employed secondary data sources. This number rose to 51 percent and 75 percent in 1993 and 2003, respectively (Hofferth, 2005). Public and private organizations alike have funded projects that develop secondary data resources. Some advantages of existing data can be related to their large sample size, availability and accessibility, relevance, and representation of a given population (Hofferth, 2005).

All data used in this study were from the Survey of Income and Program Participation (SIPP). Established in 1983, the SIPP is a US Census Bureau initiative that provides up-to-date information about participation in government programs. A nationally representative dataset, SIPP stands out as a vital source to gauge how American households fare with respect to income, assets, employment, education, social program participation, and so forth. Longitudinal in nature, SIPP has undergone progressive expansion to contain 14 different panels and 124 waves. Each panel is made 
of a certain number of waves. SIPP has also undergone massive improvement over time in terms of design rigor.

This study specifically analyzed data from the 2008 Panel— the most current publicly available panel. This panel consists of 16 waves of data collected between September 2008 and December 2013. Using stratified and systematic sampling methods, the 2008 SIPP Panel targeted approximately 65,500 households across the United States, most of which were low-income. About 13,500 eligible households were unreachable due to environmental constraints. Another 10,000 household members could not complete the first interview (Wave 1) because the targeted occupants either declined to participate in the survey or were not available for the interview. About 105,000 individuals in 42,000 households - roughly 81 percent of the targeted sample - participated in the survey at baseline (first wave of data collection). All household members aged 15 or older were deemed eligible for the interview process which was conducted in their homes on a fourmonth periodic basis. The panel waves consist of ensuing interviews conducted only with individuals who participated in prior interviews.

The 2008 SIPP longitudinal public files contain core data and topical modules data. Each wave of core data provides basic information about a broad range of areas, including job, business, income, labor force, assets, education, health insurance, welfare receipt, family, household, and sociodemographic characteristics. The topical modules explore some topics with more depth and serve as addenda to some core topics. Wave 1 collects information on recipiency history, employment history and tax rebates. Work disability history, education and training history, marital history, migration history, fertility history, household relationships, and tax rebates are covered in wave 2 . Waves 3 
and 11 deal with participation in TANF and retirement and pension plan coverage, whereas assets and liabilities, medical expenses, dependent care, child well-being, and poverty-related issues are captured in waves 4,7 and 10 . While waves 5 and 8 cover annual income and retirement accounts, taxes, child care and work schedule, wave 6 collects information for adult well-being, child support, child and adult disabilities, and employer-provided health benefits. Wave 9 covers informal care-giving and adult wellbeing, whereas wave 13 provides information about professional certifications and educational certificates. Topic modules are not available for waves 12 and 14 through 16 . The current investigation uses the core data due to the cross-wave uniformity of the information on program participation. Indeed, the core data survey asked the very same questions in each wave of data collection. As seen above, this cross-wave uniformity does not exist in the topical modules.

Strengths of SIPP. SIPP has been touted as the most comprehensive large-scale survey of estimates on income, financial hardship, and participation in government programs (Bauman, 1999a,b; Beverly, 2001; Czajka \& Denmead, 2008; Heflin, Sandberg, \& Rafail, 2009; Meyer, Mok, \& Sullivan, 2009; Shaefer \& Gutierrez, 2013; Wu \& Eamon, 2010). In other words, SIPP is the flagship income-related dataset in the United States, ahead of the Current Population Survey, the American Community Survey, the Medical Expenditure Panel Survey, the National Health Interview Survey, the Panel Study of Income Dynamics, the Health and Retirement Study, and the Medicare Current Beneficiary Survey (Czajka \& Denmead, 2008). Not only SIPP's strong emphasis on lowincome households but its very large sample size and longitudinal features allow the evaluation of the effectiveness of programs, whether at local, state, or federal levels. In 
addition, it is worth mentioning that the collection of data for the 2008 SIPP Panel coincided with both the unfolding and the aftermath of the Great Recession. Since participation in public assistance programs during economic hardship tends to be higher than in normal times (TANF excepted), the 2008 SIPP Panel allows assessment of how low-income households responded to welfare programs. This panel also reflects the implementation of the 2009 stimulus package which reinforced most of the safety net programs. Its relatively recent period of time of data collection (September 2008 to December 2013) makes the 2008 SIPP Panel an invaluable resource to address the methodological gaps that exist in the current social welfare literature.

\section{Missing Data Management}

As with most longitudinal endeavors, this investigation was not exempt from missing data. 17.6 percent of all cases included in this research had missing values. Table 2 provides a complete description of the percentages of missing data across waves. As seen in table 4, at the Year 1 follow-up 6.4 percent of cases had missing values. The percentage of missing data increased gradually thereafter to reach the level of 6.6 percent at the Year 2 follow-up, 7.7 percent at the Year 3 follow-up, 12 percent at the Year 4 follow-up, and 17.6 at the 56 month follow-up.

\begin{tabular}{|l|c|c|}
\hline \multicolumn{3}{|c|}{ Table 2. Cross-Wave Missing Data Patterns } \\
\hline \multicolumn{1}{|c|}{ Waves } & $\mathrm{n}=4,216$ & Percent \\
\hline Wave 1 (Baseline) & N/A & N/A \\
\hline Wave 2 (4 month follow-up) & 173 & 4.1 \\
\hline Wave 3 (8 month follow-up) & 201 & 4.8 \\
\hline Wave 4 (12 month follow-up) & 270 & 6.4 \\
\hline
\end{tabular}




\begin{tabular}{|l|c|c|}
\hline & & \\
\hline Wave 5 (16 month follow-up) & 244 & 5.8 \\
\hline Wave 6 (20 month follow-up) & 260 & 6.2 \\
\hline Wave 7 (24 month follow-up) & 277 & 6.6 \\
\hline Wave 8 (28 month follow-up) & 235 & 5.6 \\
\hline Wave 9 (32 month follow-up) & 249 & 5.9 \\
\hline Wave 10 (36 month follow-up) & 323 & 7.7 \\
\hline Wave 11 (40 month follow-up) & 354 & 8.4 \\
\hline Wave 12 (44 month follow-up) & 458 & 10.9 \\
\hline Wave 13 (48 month follow-up) & 520 & 12.3 \\
\hline Wave 14 (52 month follow-up) & 594 & 14.1 \\
\hline Wave 15 (56 month follow-up) & 740 & 17.6 \\
\hline
\end{tabular}

Missing data were also evident in the full panel. From baseline to wave 15 participants gradually abandoned the study. Table 3 provides a side-by-side comparison between the full SIPP panel and the study sample where there was a gradual loss of participants across the waves. As displayed in Table 3 below, a total cross-wave attrition rate of 31.3 percent was registered for participants in the full panel. This attrition rate is almost the double of that recorded for participants in the study sample (17.6 percent). 


\begin{tabular}{|c|c|c|c|c|}
\hline \multicolumn{5}{|c|}{$\begin{array}{l}\text { Table 3. Attrition Rates Comparison for Full 2008 SIPP Panel } \\
\text { and Study Sample } \\
\text { (please see Sample section for details about } \\
\text { selection of study participants) }\end{array}$} \\
\hline \multirow{2}{*}{$\begin{array}{l}\text { Waves of } \\
\text { Data }\end{array}$} & \multicolumn{2}{|c|}{$\begin{array}{l}\text { Original } 2008 \text { SIPP Panel } \\
(\mathrm{n}=105,477)\end{array}$} & \multicolumn{2}{|c|}{$\begin{array}{l}\text { Study Sample } \\
(\mathrm{n}=4,216)\end{array}$} \\
\hline & $\begin{array}{l}\text { Number of } \\
\text { Participants }\end{array}$ & $\begin{array}{l}\text { Attrition } \\
\text { rate }(\%)\end{array}$ & $\begin{array}{l}\text { Number of } \\
\text { households }\end{array}$ & $\begin{array}{l}\text { Attrition } \\
\text { rate (\%) }\end{array}$ \\
\hline Wave 1 & 105,477 & 0.0 & 4,216 & 0.0 \\
\hline Wave 2 & 98,175 & 7.0 & 4,035 & 4.1 \\
\hline Wave 3 & 95,050 & 9.9 & 4,015 & 4.8 \\
\hline Wave 4 & 91,071 & 13.7 & 3,946 & 6.4 \\
\hline Wave 5 & 90,389 & 14.3 & 3,972 & 5.8 \\
\hline Wave 6 & 88,117 & 16.5 & 3,956 & 6.2 \\
\hline Wave 7 & 85,392 & 19.1 & 3,939 & 6.6 \\
\hline Wave 8 & 84,441 & 20.0 & 3,981 & 5.6 \\
\hline Wave 9 & 82,281 & 22.0 & 3,967 & 5.9 \\
\hline Wave 10 & 79,377 & 24.8 & 3,893 & 7.7 \\
\hline Wave 11 & 78,151 & 26.0 & 3,862 & 8.4 \\
\hline Wave 12 & 77,354 & 26.7 & 3,758 & 10.9 \\
\hline Wave 13 & 76,048 & 28.0 & 3,696 & 12.3 \\
\hline Wave 14 & 75,016 & 28.9 & 3,622 & 14.1 \\
\hline Wave 15 & 72,566 & 31.3 & 3,476 & 17.6 \\
\hline
\end{tabular}


An analysis of the randomness of missing data was conducted. Researchers have stressed the importance of determining the mechanisms and patterns of missing data in order to identify the right course of action to be implemented when handling the issue (Bennett, 2001; Dong \& Peng, 2013; Tabachnick \& Fidell, 2012). Rubin (1976) identified three separate mechanisms in missing data: missing completely at random (MCAR), missing at random (MAR), and missing not at random (MNAR). In MCAR data, the mechanism of missingness is unsystematic or unrelated to the observed data. Under MCAR, missing data are considered a random version or a subset of the overall sample (Dong \& Peng, 2013). Under the MAR assumption, the mechanism of missingness is systematic or depends on the observed data, but not the missing/unobserved values. When the missingness is related to or depends on the unobserved/missing values, data is said to be missing not at random (Little \& Rubin, 2002; Rubin, 1976).

Little's (1988) missing completely at random test, also known as MCAR test, allows researchers to discover whether data are MCAR or not. Under Little's (1988) MCAR test, the null hypothesis is that data are MCAR at the 95 percent confidence level. That is, any result greater than or equal to 0.05 is not significant and thus researchers should fail to reject the null hypothesis. If, by contrast, a result is less than 0.05 , researchers should reject the null hypothesis because the data are not MCAR. The missing data portion in this proposed research is not completely at random. When data are not MCAR, methodologists recommend that researchers run further analysis of the missing data to know whether the values are missing at random (MAR) or missing not at random (MNAR). However, there are currently no available tests to assess missing at 
random (MAR) data (Baraldi \& Enders, 2010; Bhaskaran \& Smeeth, 2014; Horton \& Kleinman, 2007; White et al., 2011).

Some missing data experts contend that the missing at random (MAR) conditions may be satisfied when attrition is caused by the mobility of participants (Enders, Dietz, Montague, \& Dixon, 2006; Graham, Hofer, Donaldson, MacKinnon, \& Schafer, 1997). Bhaskaran and Smeeth (2014) argued that the determination of missing at random (MAR) can be assumed based on prior knowledge and advice from experts, while other scholars recommend a comparison in mean differences between the missing portion and the nonmissing portion of the sample (Diggle, Liang, \& Zeger, S. L., 1995; Schafer \& Graham, 2002; Tabachnick \& Fidell, 2012). In the current study the plausibility of missing at random (MAR) was assessed through the comparison of the means and standard deviations between participants with missing data and those with no missing data (see Table 4). As evidenced in Table 4, there are similarities on the key variables between cases with missing values and those with no missing values. Therefore, it can be assumed that the missing portion of data selected for this research was missing at random (MAR).

\begin{tabular}{|l|c|c|c|c|}
\hline \multicolumn{5}{|c|}{ Table 4. Diagnosis of Missing Data Randomness } \\
\hline \multirow{2}{*}{ Variables } & \multicolumn{2}{|c|}{$\begin{array}{c}\text { Cases with } \\
\text { missing values } \\
(\mathrm{n}=1,941)\end{array}$} & $\begin{array}{c}\text { Cases with no } \\
\text { missing values } \\
(\mathrm{n}=2,275)\end{array}$ \\
\cline { 2 - 6 } & Mean & SD* & Mean & SD* \\
\hline Interest earning checking account owned & 1.84 & .362 & 1.81 & .395 \\
\hline Savings account owned & 1.71 & .452 & 1.70 & .459 \\
\hline Respondent was born in the United States & 1.23 & .421 & 1.22 & .414 \\
\hline US Citizenship Status of Respondent & 1.14 & .347 & 1.14 & .345 \\
\hline
\end{tabular}




\begin{tabular}{|l|c|c|c|c|}
\hline & & & & \\
\hline Highest Degree received & 2.75 & 1.335 & 2.73 & 1.392 \\
\hline Hispanic ethnicity & 1.79 & .405 & 1.78 & .414 \\
\hline Worked less than 35 hours some weeks & .69 & 1.232 & .59 & 1.262 \\
\hline Race of the respondent & 1.34 & .577 & 1.27 & .515 \\
\hline Gender & 1.62 & .485 & 1.63 & .482 \\
\hline Ownership status of living quarters & 1.58 & .493 & 1.48 & .500 \\
\hline Household type & 2.03 & .908 & 1.97 & .909 \\
\hline Respondent's age range & 2.23 & .747 & 2.40 & .696 \\
\hline Metro status & 1.18 & .388 & 1.22 & .415 \\
\hline State poverty rate average & 2.74 & .922 & 2.65 & .897 \\
\hline Means-tested cash or noncash receipt & .59 & .493 & .57 & .495 \\
\hline$*$ Standard deviation & & & & \\
\hline
\end{tabular}

Methodologists often recommend multiple imputation as one of the most effective methods of missing data management (Baraldi \& Enders, 2010; Kang, 2013; Little \& Rubin, 2002; Pigott, 2001; Young \& Johnson, 2015). The application of multiple imputation necessitates a survey nonresponse mechanism deemed ignorable (Pigott, 2001). When survey nonresponse is ignorable, researchers can generate unbiased estimates by using imputation techniques or discarding missing values (Bollinger \& Hirsch, 2013). Under the Bayesian framework, in which the probability of an event can be estimated, the notion of ignorability applies to both MCAR and MAR data (Ibrahim \& Molenberghs, 2009). That is, the reason why the missingness occurred can be ignored, as 
the analysis of data can be informed based upon the observed values (Ibrahim \& Molenberghs, 2009; Pigott, 2001). In this investigation, multiple imputation (MI) was used to replace the missing cases across the waves. Values were imputed for respondents who participated in the study for at least three years (36 months). In other words, survey respondents who missed more than five interviews were excluded at baseline. This approach is consistent with the MAR assumption where the missing values depend on the observed data. In a long form of data arrangement, the observed values would serve as benchmarks to estimate the missing values during the imputation process (Young \& Johnson, 2015).

\section{Sample}

This study sample was restricted to (1) respondents aged between 18 and 65 at baseline, (2) individuals with no physical or mental disabilities, and (3) respondents in households that were at or below 150 percent of the federal poverty level (FPL). Moreover, a few unusual cases where negative integers were registered for household total income were removed from the sample. 12,119 respondents met these initial criteria for sample inclusion. However, in cases where more than one individual per household met the inclusion criteria, one individual from the household was selected at random. This was a way to meet the assumption of independence of observations for regression analysis purposes. After randomly selecting one respondent per household, the sample size was reduced to 7,153 . Furthermore, households that dropped out of the study before reaching wave 10 were excluded. In other words, participating households with missing information for more than 5 full waves over the study timeframe were not included in the final sample. A total of 4,216 low-income households constituted the study sample at 
baseline which was divided into an intervention group $(\mathrm{n}=2,436)$ and a comparison group $(n=1,780)$. A complete display of the frequency distributions of each variable in the final sample is provided in the results section.

Table 5 below provides a case inclusion /exclusion comparative analysis for 7,153 households in the initial sample. Based on the means and standard deviations of the variables in display, it can be argued that the excluded cases were more or less a random sample of the overall sample. In other words, there were no significant differences in means and standard deviations between the included cases and the excluded cases, making the latter category, in and of itself, a sub-sample.

\begin{tabular}{|l|c|c|c|c|}
\hline \multicolumn{5}{|c|}{ Table 5. Case Inclusion / Exclusion Comparison in Initial Sample } \\
$(\mathbf{n}=7,153)$ & $\begin{array}{c}\text { Included Cases } \\
(n=4,216)\end{array}$ & $\begin{array}{c}\text { Excluded Cases } \\
(\mathrm{n}=2,937)\end{array}$ \\
\hline \multicolumn{1}{|c|}{ Variables } & Mean & SD* & Mean & SD* \\
\hline Interest earning checking account owned & 1.82 & .380 & 1.84 & .364 \\
\hline Savings account owned & 1.71 & .456 & 1.72 & .449 \\
\hline Immigration status of respondent & 1.22 & .417 & 1.22 & .415 \\
\hline US Citizenship Status of Respondent & 1.14 & .346 & 1.15 & .360 \\
\hline Highest Degree received & .48 & .500 & .50 & .500 \\
\hline Hispanic ethnicity & 1.79 & .410 & 1.81 & .393 \\
\hline Worked less than 35 hours some weeks & .64 & 1.249 & .63 & 1.248 \\
\hline Race of the respondent & 1.30 & .546 & 1.64 & 1.001 \\
\hline Gender & 1.63 & .483 & 1.60 & .491 \\
\hline
\end{tabular}




\begin{tabular}{|l|c|c|c|c|}
\hline Ownership status of living quarters & 1.58 & .559 & 1.69 & .529 \\
\hline Household type & 2.50 & 1.461 & 2.74 & 1.472 \\
\hline Respondent's age & .55 & .498 & .65 & .478 \\
\hline Metro status & 1.26 & .501 & 1.27 & .541 \\
\hline Means-tested cash or noncash receipt & .58 & .494 & .54 & .498 \\
\hline School breakfast & .23 & 1.279 & .15 & 1.295 \\
\hline Medicaid & 1.80 & .401 & 1.78 & .415 \\
\hline Number of children in the household & 1.25 & 1.433 & 1.13 & 1.372 \\
\hline Region & 3.02 & 1.472 & 3.10 & 1.547 \\
\hline Food stamps receipt & 1.78 & .429 & 1.77 & .433 \\
\hline WIC coverage & 1.97 & 1.64 & 1.97 & .170 \\
\hline Residence in public housing project & .55 & 1.449 & .88 & 1.395 \\
\hline Change in family composition & 1.99 & .078 & 2.00 & .000 \\
\hline Household non-cash benefits & .58 & .494 & .54 & .498 \\
\hline Household cash benefits & .11 & .317 & .11 & .311 \\
\hline$*$ Standard deviation & & & & \\
\hline
\end{tabular}

\section{Study Variables}

Independent variables. Two independent variables (IV) were employed in this investigation, both of which measured a different aspect of program participation. In this case, both IVs were closely related to-yet different—from each other. Each IV was developed to test a specific hypothesis in this study. The independent variable for Hypothesis 1 was participation in one or more lower-tier federal means tested programs. 
In the 2008 SIPP Panel, the variable RHMTRF accounted for household means-tested cash or noncash receipt. The question is formulated as follows: Did someone in this household receive means-tested cash or noncash benefits? The variable RHMTRF captured the full range of means-tested welfare benefits, including cash and non-cash assistance. The cash-portion was essentially made up of TANF and SSI benefits. This predictor variable was not intended to measure other forms of cash benefits such as EITC, UI, and Social Security. SSI is not available to all of those who live in poverty. The program primarily targets three groups of people: elderly, blind and disabled who lack economic support. Poor people under age 65 who do not have disabilities are not eligible for SSI benefits (P. L. 92-603). Consistent with the purpose of this research, respondents who reported physical and/or mental disabilities at baseline are eliminated from the sample. Indeed, work-limiting health issues were found to be negatively associated with attainment and maintenance of economic self-sufficiency (GarcíaGómez, Jones, \& Rice, 2010; Pelkowski \& Berger, 2004; Wood et al., 2008). The noncash portion gathers information about foods stamps/SNAP, WIC, Medicaid, free or reduced-price lunches, free or reduced-price breakfasts, government energy assistance, and government subsidized rent. Respondents who received one or more of these aforementioned cash/non-cash benefits are coded as 1 for "Yes." In contrast, those who did not receive any of these benefits are coded as 0 for "No."

For Hypothesis 2, the independent variable was the sum of all means-tested benefits that a household received. In the original 2008 SIPP dataset, these programs included food assistance (RCUTYP27), health assistance (RCUTYP57), free-or reduced school meals (EHOTLUNC and EBRKFST), housing assistance (EGVTRNT and 
EPUBHSE), energy assistance (EEGYAST), and cash assistance (RHCBRF). All of these variables were coded as 1 for "Yes" and 2 for "No." The sum of RCUTYP27, RCUTYP57, EHOTLUNC, EBRKFST, EGVTRNT, EPUBHSE, EEGYAST, and RHCBRF created the variable BENEFITS which takes the following four values: $1=$ one benefits, $2=$ two benefits, $3=$ three benefits, and $4=$ four benefits. No households received more than four benefits. Given the nature of Hypothesis 2 (total number of benefits per household), the analysis was run only for the intervention group.

Outcome variable. As the dependent variable, economic self-sufficiency is measured through cross-wave differences in a household's income-to-poverty ratios (IPR). A household's total income divided by its poverty threshold is referred to as IPR. If its income is equal to or exceeds its poverty threshold, a household is deemed "not in poverty" because its IPR is equal to or greater than 1.0. Conversely, a household is "in poverty" when its IPR is less than 1.0 (US Census Bureau, 2016). In this research, participants in both intervention and comparison groups were selected if their total monthly household income at baseline was at or below $150 \%$ of the FPL. This threshold would correspond to an IPR of 1.5 or less, whereby all participants (poor and near-poor) are not considered economically self-sufficient.

Researchers have used different poverty cutoff points in studying low-income populations. In their assessment of economic safety programs among families with children, Slack et al. (2014) drew a sample of recipients who were at or below 200 percent (2.0 IPR) of the FPL. Cancian et al. (2014) used the same income range as Slack et al. (2014) in their study on disconnected householders who formerly received TANF and SNAP. Other researchers opted for more stringent income limits by examining 
individuals whose household income did not exceed 100 percent (1.0 IPR) of the FPL (Gilbert et al., 2000), or 130 percent (1.3 IPR) of the FPL (Irving, 2013). It becomes difficult to have one cutoff point across the board because (a) states are granted more power to determine the eligibility requirements for TANF and (b) SNAP, HCV, WIC, and Medicaid have different minimum income requirements on the federal poverty guidelines.

The federal poverty guidelines is another poverty measurement tool which should not be confused with the federal poverty level. Although closely related, the two measures are issued by different federal agencies and used for different purposes. The federal poverty line has been developed by the Census Bureau and used mostly for research purposes. The poverty guidelines, on the contrary, have been developed by the US Department of Health and Human Services and are used for program eligibility determination (Fisher, 1992). In most states, however, households with incomes higher than 150 percent of the FPL are not eligible for most welfare programs, including Medicaid, SNAP, TANF, WIC, and housing assistance. The $150 \%$ poverty threshold adopted in this study is consistent with previous research on poverty and social welfare (Hall et al., 2010).

A dummy variable was created to compartmentalize the outcome variable. Irving (2013) used similar procedures to measure income among welfare beneficiaries. In the dataset used for this study, household income is measured by the variable THTOTINC which was recoded into two categories. The first category contains households with IPRs less than or equal to 1.5, while the second category is formed of households with IPRs above 1.5 (self-sufficiency). In this study IPR was calculated by dividing THTOTINC 
(household income) by RHPOV (household poverty level). In such instances, selfsufficiency is operationally defined as the state of being off most welfare programs and out of poverty. In particular, means-tested benefits such as TANF, SNAP, HCV, and energy assistance are not designed to continue to provide benefits after the threshold of $150 \%$ of the FPL has been reached. The attainment and maintenance of economic selfsufficiency was measured on a quarterly basis (every four months) after baseline. Participants who reached an income level greater than 150 percent of FPL (IPR >1.5) at any wave of the survey and maintained their status of self-sufficiency during all subsequent waves were coded "yes" and "no" if both conditions were not met. The 44 month follow-up (one year before the last wave) was the "cutting off" point for the attainment of self-sufficiency. Participants who attained self-sufficiency at the 44 month follow-up were followed through the last wave to see whether self-sufficiency is maintained or not. By contrast, those who become self-sufficient before the 44 month follow-up were followed throughout the subsequent waves in order to monitor their maintenance of self-sufficiency. A quarterly measurement instead of an annual observation allowed to better control for households who cycled in and out of poverty over a short period of time.

IPR results from wave 1 through wave 15 were combined into one particular variable: CUMULIPR. This variable was the final indicator used to measure the attainment and maintenance of economic self-sufficiency among the participating households. For CUMULIPR, households that did not attain and maintain their state of self-sufficiency received a code of 0 . On the contrary, those that attained self-sufficiency 
on or before wave 12 (44 month follow-up) and maintained such level for the reminder of the study (wave 15) received a code of 1.

Control variables. In the literature certain variables have been consistently found to be correlated with poverty and welfare receipt. This study controlled for all available covariates in order to reduce effects that confound the relationship between the predictor variable and the outcome variable. Since this research involved panel data, two broad categories of covariates were identified: time-varying variables and time-invariant variables. Both of them are described below.

Time-varying variables. Time-varying variables are those that are not constant across longitudinal studies. Therefore, responses collected for such variables may change from one wave to another. In this research, family structure, education level, employment status, metro status, financial behavior, ownership status, and geographical location were all considered time-varying covariates. However, because the aim of this study was to predict outcome from baseline conditions (i.e., the time participants were identified as belonging to the intervention or comparison group), the covariates were captured at baseline only.

Family structure. Family structure represents a household's living arrangements. Family structure plays a role in the household well-being, as female-headed householders tend to experience more economic hardship than married couples or cohabiting partners (Buvinic \& Gupta, 1997; Raymo \& Zhou, 2012; Snyder, McLaughlin, \& Findeis, 2006). In this research, family structure means the situation in which a household is headed by an unmarried male individual, an unmarried female individual, or a married couple. In the 2008 SIPP dataset, family structure was represented by the variable RHTYPE which 
had six original categories. These were simplified as follows: $1=$ married couples and 2 $=$ single. Cohabiting households were classified in the single category.

Two other variables also contributed to the assessment of family structure. These are HNUMP and RFNKIDS which determined the total number of persons in a household and its number of children under 18, respectively. Both of these variables are dichotomous. HNUMP was coded as $1=$ Less than three and $2=$ Three or more, while CUMKIDS received the values of $1=$ Yes and $2=$ No.

Education level. Education is a strong predictor of economic self-sufficiency (Bilenkisi, Gungor, \& Tapsin, 2015; De Silva \& Sumarto, 2015; Janjua \& Kamal, 2011; Rolleston, 2011). In this study, education constitutes the level of schooling received by study participants. The variable EDUCATE measures the highest degree received or grade completed. This variable was originally coded in the 2008 SIPP Panel with 17 values, ranging from first grade to doctoral education. During the recoding process, new values were assigned to EDUCATE. Respondents with no post-secondary education were coded as 1 , while those with tertiary level of schooling received a value of 2 . The latter category encompasses participants who received any form of post-secondary education in a vocational, college, or university setting.

Employment status. Employment status is measured based on whether study participants work less than 35 hours per week or not. Work experience is associated with higher likelihood of finding employment and becoming self-sufficient (Wood et al., 2008). In this research, the variable EPTWRK denoted employment status among respondents. This variable has three categories: not working, part-time employment, and full-time employment. In order to obtain meaningful results in regression analyses, this 
variable was dummy coded as follows: part-time (coded 1, 0 otherwise) and full-time (coded 1, 0 otherwise) with unemployed as the reference category.

A series of other employment-related variables were created to assess the labor market, using data from the United States Bureau of Labor Statistics (BLS). The variables SUNEMPL and SWAGE were formed to measure the average state unemployment rate and the average state minimum wage, respectively.

Both variables were calculated through a multifold process. First, the original variable TFIPSST in the 2008 SIPP file was used to identify the states where respondents lived over the course of this study. Next, the researcher traced back unemployment rates and minimum wage rates for each state from 2008 to 2012, using BLS data. Then, fiveyear averages of state unemployment rates and minimum wage rates for the 2008-2012 period were calculated to form SUNEMPL and SWAGE. For SUNEMPL the value of 1 indicated an average unemployment rate of 6 percent or more, whereas 2 represented a rate less than 6 percent. Similarly, under SWAGE states with an average minimum wage rates of $\$ 7$ per hour or more were coded as 1 , while those with an average hourly rates of less than $\$ 7$ received a value of 2 .

Metro status. Metro status indicates whether study participants lived in metropolitan areas or not. Numerous studies have demonstrated that living in metropolitan areas is associated with better economic outcomes (Clampet-Lundquist \& Massey, 2008; Dohmen, 2005; Galster, 2002; Kling, Liebman, \& Katz, 2007; Kling, Liebman, Katz, \& Sanbonmatsu, 2004; Ludwig et al., 2012; Newman \& Harkness, 2002). The original variable TMETRO which had three categories (metro, not metro, and 
unidentified) was recoded to form a dichotomous variable identified as METRO where 1 means participants lived in metro areas, and 2 otherwise.

Geographical location. Closely related to metro status is geographical location. Two particular groups of variables determined the impact, if any, of geography on the outcome variable. In the first group, the variable SPORA was created by (a) averaging the poverty level for each state for the five-year period during which the survey was conducted, (b) dividing the 50 states of America and the District of Columbia into quintiles, (c) assigning each state a value of 1 to 5 for highest to lowest poverty level, and (d) assigning each study participant the value of their state. SPORA was coded as follows: (1) states with very high poverty rates, (2) states with high poverty rates, (3) states with moderate poverty rates, (4) states with low poverty rates, and (5) states with very low poverty rates. Another variable SPORA1 was added to appraise the average state poverty level in a binary way: $1=$ States with high to very high poverty rates, and 2 $=$ States with very low to moderate poverty rates.

The second group of variables started with TFIPSST, which recorded entries for all the 50 states and the District of Columbia in which respondents resided between 2008 and 2012. TFIPSST was then simplified into REGION, a variable which divided the states into the official four regions: Northeast, South, West, and Midwest (US Census Bureau, 2015a). For these four regions, three dummy variables were created: Northeast coded 1 and 0 for otherwise; South coded as 1 and 0 for otherwise; West coded as 1 and 0 for otherwise. The Midwest represents the omitted reference category.

Financial behavior. Many researchers have documented the challenges faced by low-income populations as pertains to savings (Bertrand, Mullainathan, \& Shafir, 2004; 
Mullainathan \& Shafir, 2009; Sherraden, 1991). Means-tested income support and other policies often play a negative role in savings due to asset limits as requirements for benefits. Such policies discourage savings among recipients (Ziliak, 2003; Hurst \& Ziliak, 2001). This research gauged self-beneficial financial decisions among participants via their involvement in the banking system and their ownership status. Two variables, EAST2A and EAST2B, determined whether the participants had interest-earning accounts and savings accounts, respectively. Participants with bank accounts (checking or savings) were originally coded in the 2008 SIPP file as 1 , and 2 otherwise.

Another variable closely related to financial behavior is ETENURE which identified homeownership status in the original survey. Respondents who owned their own living quarters were coded as 1 , while those who were renters received a code of 2 . The combination of EAST2A, EAST2B, and ETENURE generated FINANBHV, the variable controlling for financial capability among participating households. Households with bank accounts and homeownership status were coded as 1 for high financial capability. In contrast, those with no homeownership status and/or no involvement in the banking system were coded as 0 for low financial capability.

Time-invariant variables. Contrary to time-varying variables, time-invariant variables are not subject to change over time. These variables produce the same results across waves in panel studies. Time-invariant covariates are particularly important in dealing with missing data, a common problem in longitudinal research. Indeed, baseline entries collected for these variables can be rolled over and used to replace missing values in subsequent waves (Young \& Johnson, 2015). Immigration status, race/ethnicity, gender and age were identified as time-invariant covariates in this research. 
Immigration status. As compared with their US-born counterparts, low-income immigrant householders are less likely to be employed and less likely to become financially stable (Kaida, 2015; Waters \& Eschbach, 1995). In this research, immigration status captures whether study participants were foreign-born or US-born. . Immigration status was also controlled through non-U. S. citizenship versus U. S. citizenship. In the 2008 SIPP Panel, EBORNUS and ECITIZEN provided for the country of origin and citizenship status, respectively. Both variables were dichotomously coded as 1 for Yes and 0 for No. It would be beneficial to note that ECITIZEN could have also been taken as a time-varying covariate because noncitizen respondents at baseline could have acquired US citizenship status within the five-year study span. A meticulous look at the data, however, indicated that the citizenship status of the respondents remained unchanged across the waves. It is therefore appropriate to assign this variable under the timeinvariant section.

Racelethnicity. Race and ethnicity are found to be determinants of "economic factors" in capitalist societies (Huffman \& Cohen, 2004; Leicht, 2008; Light, Roscigno, \& Kalev, 2011; Roscigno, Garcia, \& Bobbitt-Zeher, 2007). In this research, the study participants were distinguished by race and ethnicity. In the SIPP data, the variable EORIGIN determined whether a participant is Hispanic (coded as 1) or not (coded as 0$)$, while ERACE identified participants who are White, African-American, Asian and Residual (other races). Due to small sample size, participants whose race is reported as "Residual" were removed from the sample. This approach is consistent with previous research on low-income families (Irving, 2013). Another variable was created by 
recoding ERACE into a dichotomous variable called "RACECODE" which controlled for White (coded as 1) versus non-White participants (coded as 2).

Gender. In the American society, the labor market is generally perceived as discriminatory against women based on the fact that researchers have continuously demonstrated that males are more likely to secure employment and earn more for the same work than their female counterparts. Hence, there have been associations between gender and economic opportunities (Bielby \& Baron, 1986; Correll \& Benard, 2007; McDonald, Lin, \& Ao, 2009; Wilkie, 1991). In this research, the variable ESEX determined whether study participants identify themselves as male or female. Male participants are coded as 1 and female as 2 . This variable was dichotomized to preserve the categorical nature of the whole dataset. 40 was chosen as the cutoff point by virtue of the effect being the greatest after having tested other cutoffs.

Age. Age is another factor associated with economic outcomes (Bjelland et al., 2010; Lippmann, 2008; Roscigno, Mong, Byron, \& Tester, 2007). In the original dataset, the variable YEAR registered the year in which the respondents were born. The year of birth allowed the computation of age of the study participants. The variable AGERANGE was created with a value of 1 for participants who were 40 years old and over and 2 for those who were less than 40 years old. 


\section{CHAPTER VII: DATA ANALYSIS}

\section{Multicollinearity Tests}

First and foremost, the researcher performed the multicollinearity test by running the collinearity diagnostics in multiple regression. The purpose of this procedure is to check the extent to which two or more predictors are interdependent with respect to an outcome variable. The "existence" of collinearity among explanatory variables is almost inevitable, but its "severity" is a red flag in regression analyses (Farrar \& Glauber, 1967, p. 106; Haitovsky, 1969). A variance inflation score (VIF) of 10 and above is an indicator of multicollinearity among the variables (Belsley, Kuh, \& Welsch, 1980; Myers, 1990). Multicollinearity can also be detected through tolerance measures. According to Menard (1995), a tolerance of 0.2 of less is a problematic score (Menard, 1995, pp. 71-72). The

presence of collinearity beyond these thresholds can disturb the predictive capability of the model by inflating the variance of the explanatory variables. Hence, highly correlated predictors in a model should be a cause of concern for researchers (Belsley et al., 1980). As evidenced in the multicollinearity diagnostics table below (Table 6), there were no predictors with a variance inflation factor (VIF) above 9 and a tolerance score inferior or equal to 0.2 . Under the VIF column, the highest score was 3.053 for the variable BENEFITS, while the lowest score was 1.041 for EPTWRK. In the same way, the highest score in the tolerance section was .960 for EPTWRK, whereas the lowest score was .328 for BENEFITS. Clearly, VIF and tolerance are the object mirror of each other. 


\section{Table 6. Multicollinearity Diagnostics}

\begin{tabular}{|c|c|c|c|}
\hline Variable & Description & Tolerance & $V I F^{\wedge}$ \\
\hline AGERANGE* & Respondent's age range & .862 & 1.160 \\
\hline ESEX* $^{*}$ & Sex of this person & .907 & 1.103 \\
\hline EBORNUS* & Immigration status & .395 & 2.534 \\
\hline ECITIZEN* & $\begin{array}{l}\text { US citizenship status of respondent at } \\
\text { baseline }\end{array}$ & .416 & 2.404 \\
\hline EORIGIN* & Hispanic or Latino ethnicity & .612 & 1.634 \\
\hline RACECODE* & Race of the respondent & .801 & 1.249 \\
\hline EDUCATE* & Education attainment at baseline & .850 & 1.177 \\
\hline METRO* & Metro status at baseline & .883 & 1.133 \\
\hline REGION* & $\begin{array}{l}\text { Region of the United States where } \\
\text { respondent lived at baseline }\end{array}$ & .695 & 1.439 \\
\hline SUNEMPL* & $\begin{array}{l}\text { Average state unemployment rates at } \\
\text { baseline }\end{array}$ & .715 & 1.398 \\
\hline SWAGE* & $\begin{array}{l}\text { Average state minimum wage rates at } \\
\text { baseline }\end{array}$ & .576 & 1.735 \\
\hline SPORA* & Average state poverty rates & .479 & 2.088 \\
\hline RHTYPE* & $\begin{array}{l}\text { Household type or living arrangement at } \\
\text { baseline }\end{array}$ & .741 & 1.349 \\
\hline RFNKIDS* & $\begin{array}{l}\text { Presence of children under } 18 \text { in the } \\
\text { household at baseline }\end{array}$ & .364 & 2.746 \\
\hline HNUMP* & $\begin{array}{l}\text { Cumulative number of people in } \\
\text { household at baseline }\end{array}$ & .397 & 2.522 \\
\hline FINANBHV* & $\begin{array}{l}\text { Financial capability with respect to bank } \\
\text { accounts and homeownership at baseline }\end{array}$ & .845 & 1.184 \\
\hline EPTWRK* & Work or employment status at baseline & .960 & 1.041 \\
\hline
\end{tabular}




\begin{tabular}{|c|l|c|c|}
\hline RHMTRF** & $\begin{array}{l}\text { Participation in welfare benefits at } \\
\text { baseline }\end{array}$ & .342 & 2.922 \\
\hline BENEFITS*** & $\begin{array}{l}\text { Total benefits received by a household at } \\
\text { baseline }\end{array}$ & .328 & 3.053 \\
\hline CUMULIPR & $\begin{array}{l}\text { Attainment and maintenance of economic } \\
\text { self-sufficiency (Dependent Variable) }\end{array}$ & N/A & N/A \\
\hline $\begin{array}{l}* \text { Covariates } \\
* * \text { Predictor 1 (Independent variable for Hypothesis 1) } \\
* * * \text { Predictor 2 (Independent variable for Hypothesis 2) } \\
\wedge \text { Variance Inflation Factor }\end{array}$
\end{tabular}

\section{Binomial Logistic Regression}

Because the outcome variable is binary, the researcher used logistic regression to test the study hypotheses. Using IBM SPSS Statistics Version 23.0, the researcher performed the hierarchical entry of blocks method to control for the covariates. Since there were two hypotheses to be tested in this research, the investigator proceeded by running two separate analyses. In each analysis the researcher took into consideration all the control variables and the relevant independent variable, and left out the other independent variable. The following 17 control variables were entered in block 1 of each analysis: age, gender, nativity, citizenship, ethnicity, race, education, metro status, geographical location, average state unemployment rate, average state minimum wage, average state poverty rate, household type, presence of children under 18 in the household, number of people in the household, financial capability, and work status. In block 2 of each analysis, one of the independent variables - welfare benefits receipt per household or number of welfare benefits per household-was entered into the equation. Such hierarchical technique allowed to compare the $\mathrm{R}^{2}$-change associated with entering the second block, and the additional variance explained by the independent variable after 
accounting for the control variables. Finally, because SIPP used a sample design in which different households are sampled at different rates, the use of weights is generally essential to generate unbiased estimates of population characteristics. The inclusion of the weights variable WHFNWGT in the analysis was thus used to obtain point estimates that are representative of the survey population. Please refer to the codebook in Appendix 1 for a complete description of the study variables. 


\section{CHAPTER VIII: RESULTS}

\section{Descriptive Statistics}

Before moving into the regressions, the frequency distributions of all the variables for the full sample as well as the intervention and the comparison groups will be examined. Table 7 below summarizes the frequency distributions for the full sample. Descriptive statistics for the intervention group and the comparison group are presented in Table 8. As highlighted in Table 7, the racial/ethnic makeup of the sample was mostly White (74.1 percent) compared to its non-White proportion (25.9 percent). 21.3 percent of respondents identified themselves as Hispanic. If the 25.9 percent of non-Whites are combined with the proportion of Hispanics, the sample then appears to have slightly higher percentages of minority participants than the general population. Nonetheless, these percentages are consistent with the over-representation of lower income Americans selected for this project. More than three-quarters (77.6 percent) of the study participants identified themselves as US-born citizens, as compared to less than one quarter (22.4 percent) immigrants. As mentioned in the methodology section, the participants in the sample ranged from 18 to 65 years old, with a mean age of 39.77. Just over half of the survey respondents (52.2 percent) were under 40 years old, while nearly half of them (47.8 percent) reported to be 40 years old and over. About two-thirds of the respondents (62.8 percent) were female, as opposed to just 37.2 percent male. With respect to educational attainment, roughly half of the sample (52.0 percent) did not pursue or complete postsecondary education, whereas the remaining half (48.0 percent) did. In terms of financial capability, just over one-third of the survey respondents (34.7 percent) indicated high financial capability, whereas the remaining two-thirds (65.3 percent) 
reported low financial capability. As pertains to employment status, one-third of the survey respondents (33.6 percent) worked less than 35 hours per week; almost another third of them (32.1 percent) carried full-time employment, while the remaining third (34.3 percent) was not working or looking for work.

Regarding household structure, slightly over forty percent of the informants (41.7 percent) were married couples, as opposed to 58.3 percent who identified themselves as single. Closely similar percentages, 44.0 percent and 56.0 percent, were reported in reference to the presence or absence of children in the households, respectively. Yet closely similar proportions were also found with regard to the number of people per household. Indeed, 43.4 percent of the participants lived in households with less than three people, while 56.6 percent of them lived in households with three or more people.

From a geographical standpoint, roughly one-fifth of the informants $(20.4$ percent) lived in non-metropolitan areas, as opposed to the vast majority of them (79.6 percent) who lived in metropolitan areas. In addition, a plurality of the participants (42.1 percent) lived in the South, while others resided in the Northeast (14.6 percent), the West (21.1 percent), and the Midwest (21.1 percent). Moreover, over half of the participants (56.3 percent) lived in states that had very low-to-moderate average rates of poverty for the 2008-2012 period, while the remaining 43.7 percent of them resided in states with high-to-very high average poverty levels for the same timeframe. Furthermore, over half of the sample (57.7 percent) lived in states where the average minimum wage rates were less than 7 dollars per week, in contrast of 42.3 percent of them who lived in states with average minimum wage rates of 7 dollars or more per week. Finally, the participants were split almost evenly— 48.0 percent and 52.0 percent—over states with average 
unemployment rates of less than 6 percent and states where these rates were 6 percent or more, respectively.

\begin{tabular}{|c|c|c|c|c|}
\hline Variable & $\mathbf{N}$ & $\%$ & Mean & SD* \\
\hline Age & & & 1.52 & .500 \\
\hline Less than 40 & 2,201 & 52.2 & - & - \\
\hline 40 and over & 2,015 & 47.8 & - & - \\
\hline US Nativity & & & 1.22 & .417 \\
\hline No & 946 & 22.4 & - & - \\
\hline Yes & 3,270 & 77.6 & - & - \\
\hline Hispanic Ethnicity & & & 1.79 & .410 \\
\hline No & 3,316 & 78.7 & - & - \\
\hline Yes & 900 & 21.3 & - & - \\
\hline Education & & & 1.48 & .500 \\
\hline No post-secondary & 2,193 & 52.0 & - & - \\
\hline Post-secondary & 2,023 & 48.0 & - & - \\
\hline Household Type & & & 1.58 & .493 \\
\hline Single & 2,458 & 58.3 & - & - \\
\hline Married & 1,758 & 41.7 & - & - \\
\hline Children in the Home & & & 1.44 & .497 \\
\hline No & 1,857 & 44.0 & - & - \\
\hline Yes & 2,359 & 56.0 & - & - \\
\hline $\begin{array}{c}\text { Average State } \\
\text { Unemployment Rate }\end{array}$ & & & 1.48 & .500 \\
\hline Less than 6 percent & 2,191 & 48.0 & - & - \\
\hline 6 percent or more & 2,025 & 52.0 & - & - \\
\hline Work Status & & & 2.01 & .824 \\
\hline Less than 35 hrs./week & 1,415 & 33.6 & - & - \\
\hline $35 \mathrm{hrs} . /$ week or more & 1,355 & 32.1 & - & - \\
\hline Not working/looking & 1,446 & 34.3 & - & - \\
\hline Welfare Receipt & & & 1.42 & .494 \\
\hline No & 1,780 & 42.2 & - & - \\
\hline Yes & 2,436 & 57.8 & - & - \\
\hline Total Benefits & & & 1.79 & .770 \\
\hline
\end{tabular}




\begin{tabular}{|c|c|c|c|c|}
\hline None & 1,780 & 42.2 & - & - \\
\hline One or Two & 1,536 & 36.4 & - & - \\
\hline Three to Seven & 900 & 21.3 & - & - \\
\hline Gender & & & 1.63 & .483 \\
\hline Male & 1,568 & 37.2 & - & - \\
\hline Female & 2,648 & 62.8 & - & - \\
\hline US Citizenship & & & 1.14 & .346 \\
\hline No & 587 & 13.9 & - & - \\
\hline Yes & 3,629 & 86.1 & - & - \\
\hline Race & & & 1.26 & .438 \\
\hline Non-White & 1,090 & 25.9 & - & - \\
\hline White & 3,126 & 74.1 & - & - \\
\hline Metro & & & 1.20 & .403 \\
\hline Non-Metro & 862 & 20.4 & - & - \\
\hline Metro & 3,354 & 79.6 & - & - \\
\hline People in the Home & & & 1.57 & .496 \\
\hline Less than three & 1,828 & 43.4 & - & - \\
\hline Three or more & 2,388 & 56.6 & - & - \\
\hline Financial Capability & & & 1.65 & .476 \\
\hline High & 1,464 & 34.7 & - & - \\
\hline Low & 2,752 & 65.3 & - & - \\
\hline $\begin{array}{c}\text { Average State Minimum } \\
\text { Wage }\end{array}$ & & & 1.58 & .494 \\
\hline Less than $\$ 7$ / week & 2,434 & 57.7 & - & - \\
\hline$\$ 7 /$ week or more & 1,782 & 42.3 & - & - \\
\hline Regions & & & 2.51 & .992 \\
\hline Northeast & 615 & 14.6 & - & - \\
\hline South & 1,777 & 42.1 & - & - \\
\hline West & 891 & 21.1 & - & - \\
\hline Midwest & 933 & 21.1 & - & - \\
\hline Poverty Level & & & 1.56 & .496 \\
\hline High-Very high & 1,843 & 43.7 & - & - \\
\hline Very Low-Moderate & 2,373 & 56.3 & - & - \\
\hline Self-Sufficiency & & & .32 & .468 \\
\hline No & 2,846 & 67.5 & - & - \\
\hline Yes & 1,370 & 32.5 & - & - \\
\hline \multicolumn{5}{|l|}{ * Standard Deviation } \\
\hline
\end{tabular}


Based on the frequency distributions depicted in Table 8, there were some major discrepancies between the intervention group and the comparison group on certain variables, including age, household type, education, presence of children, and number of people in the household. Notable - but less drastic - preexisting differences between the two groups were also observed for the variables race, Hispanic ethnicity, gender, US citizenship, nativity, and financial behavior. Yet, both groups shared similar frequency distribution patterns with respect to work status and geographical location which includes metro status, US regions, average state poverty levels, average state unemployment rates and average state minimum wage rates. All these aforementioned differences were controlled in the analyses.

\begin{tabular}{|c|c|c|c|c|c|c|c|c|}
\hline \multicolumn{9}{|c|}{$\begin{array}{l}\text { Table 8. Frequency Distributions of Variables for } \\
\text { Intervention Group and Comparison Group }\end{array}$} \\
\hline \multirow{2}{*}{ Variable } & \multicolumn{4}{|c|}{ Intervention Group } & \multicolumn{4}{|c|}{ Comparison Group } \\
\hline & $\mathbf{N}$ & $\%$ & $\mathbf{M}$ & SD* & $\mathbf{N}$ & $\%$ & $\mathbf{M}$ & SD* \\
\hline Age & 2,436 & 100 & 1.63 & .483 & 1,780 & 100 & 1.37 & .484 \\
\hline Less than 40 & 1,537 & 63.1 & - & - & 664 & 37.3 & - & - \\
\hline 40 and over & 899 & 36.9 & - & - & 1,116 & 62.7 & - & - \\
\hline Gender & 2,436 & 100 & 1.69 & .461 & 1,780 & 100 & 1.54 & .499 \\
\hline Male & 743 & 30.5 & - & - & 825 & 46.3 & - & - \\
\hline Female & 1,693 & 69.5 & - & - & 955 & 53.7 & - & - \\
\hline US Nativity & 2,436 & 100 & 1.27 & .445 & 1,780 & 100 & 1.16 & .367 \\
\hline No & 660 & 27.1 & - & - & 286 & 16.1 & - & - \\
\hline Yes & 1,776 & 72.9 & - & - & 1,494 & 83.9 & - & - \\
\hline US Citizenship & 2,436 & 100 & 1.19 & .390 & 1,780 & 100 & 1.07 & .262 \\
\hline No & 455 & 18.7 & - & - & 132 & 7.4 & - & - \\
\hline Yes & 1,981 & 81.3 & - & - & 1,648 & 92.6 & - & - \\
\hline Hispanic Ethnicity & 2,436 & 100 & 1.71 & .456 & 1,780 & 100 & 1.90 & .304 \\
\hline No & 1,719 & 70.6 & - & - & 1,597 & 89.7 & - & - \\
\hline Yes & 717 & 29.4 & - & - & 183 & 10.3 & - & - \\
\hline
\end{tabular}




\begin{tabular}{|c|c|c|c|c|c|c|c|c|}
\hline Race & 2,436 & 100 & 1.31 & .462 & 1,780 & 100 & 1.19 & .393 \\
\hline Non-White & 750 & 30.8 & - & - & 340 & 19.1 & - & - \\
\hline White & 1,686 & 69.2 & - & - & 1,440 & 80.9 & - & - \\
\hline Education & 2,436 & 100 & 1.39 & .487 & 1,780 & 100 & 1.61 & .488 \\
\hline $\begin{array}{c}\text { No post-secondary } \\
\text { education }\end{array}$ & 1,498 & 61.5 & - & - & 695 & 39.0 & - & - \\
\hline $\begin{array}{l}\text { Post-secondary } \\
\text { education }\end{array}$ & 936 & 38.5 & - & - & 1,085 & 61.0 & - & - \\
\hline Metro & 2,436 & 100 & 1.21 & .408 & 1,780 & 100 & 1.19 & .396 \\
\hline Non-metro area & 515 & 21.1 & - & - & 347 & 19.5 & - & - \\
\hline Metro area & 1,921 & 78.9 & - & - & 1,433 & 80.5 & - & - \\
\hline Region & 2,436 & 100 & 2.50 & .990 & 1,780 & 100 & 2.52 & .996 \\
\hline Northeast & 364 & 14.9 & - & - & 251 & 14.1 & - & - \\
\hline South & 1,017 & 41.7 & - & - & 760 & 42.7 & - & - \\
\hline West & 531 & 21.8 & - & - & 360 & 20.2 & - & - \\
\hline Midwest & 524 & 21.5 & - & - & 409 & 23.0 & - & - \\
\hline $\begin{array}{c}\text { State Unemployment } \\
\text { Rate }\end{array}$ & 2,436 & 100 & 1.48 & .500 & 1,780 & 100 & 1.48 & .500 \\
\hline Less than 6 percent & 1,170 & 48.0 & - & - & 855 & 48.0 & - & - \\
\hline 6 percent or more & 1,266 & 52.0 & - & - & 925 & 52.0 & - & - \\
\hline $\begin{array}{c}\text { Average State Minimum } \\
\text { Wage }\end{array}$ & 2,436 & 100 & 1.57 & .496 & 1,780 & 100 & 1.59 & .491 \\
\hline Less than $\$ 7$ per hour & 1,378 & 56.6 & - & - & 1,056 & 59.3 & - & - \\
\hline$\$ 7$ or more per hour & 1,058 & 43.4 & - & - & 724 & 40.7 & - & - \\
\hline $\begin{array}{c}\text { Average State Poverty } \\
\text { Level }\end{array}$ & 2,436 & 100 & 1.55 & .497 & 1,780 & 100 & 1.57 & .495 \\
\hline $\begin{array}{c}\text { Very low-to-moderate } \\
\text { poverty }\end{array}$ & 1,350 & 55.4 & - & - & 1,023 & 57.5 & - & - \\
\hline $\begin{array}{l}\text { High and very high } \\
\text { poverty }\end{array}$ & 1,086 & 44.6 & - & - & 757 & 42.5 & - & - \\
\hline Household Type & 2,436 & 100 & 1.56 & .496 & 1,780 & 100 & 1.61 & .488 \\
\hline Single & 1,375 & 56.4 & - & - & 1,083 & 39.2 & - & - \\
\hline Married couples & 1,061 & 43.6 & - & - & 697 & 60.8 & - & - \\
\hline Presence of Children & 2,436 & 100 & 1.21 & .407 & 1,780 & 100 & 1.76 & .430 \\
\hline No & 511 & 21.0 & - & - & 1,346 & 75.6 & - & - \\
\hline Yes & 1,925 & 79.0 & - & - & 434 & 24.4 & - & - \\
\hline People in Household & 2,436 & 100 & 1.77 & .420 & 1,780 & 100 & 1.29 & .452 \\
\hline Less than three & 558 & 22.9 & - & - & 1,270 & 71.3 & - & - \\
\hline
\end{tabular}




\begin{tabular}{|c|c|c|c|c|c|c|c|c|}
\hline Three or more & 1,878 & 77.1 & - & - & 510 & 28.7 & - & - \\
\hline Financial capability & 2,436 & 100 & 1.75 & .432 & 1,780 & 100 & 1.52 & .500 \\
\hline High & 604 & 24.8 & - & - & 860 & 48.3 & - & - \\
\hline Low & 1,832 & 75.2 & - & - & 920 & 51.7 & - & - \\
\hline Work Status & 2,436 & 100 & 2.02 & .827 & 1,780 & 100 & 2.00 & .819 \\
\hline $\begin{array}{c}\text { Less than } 35 \text { hours per } \\
\text { week }\end{array}$ & 815 & 33.5 & - & - & 600 & 33.7 & - & - \\
\hline $\begin{array}{l}35 \text { hours or more per } \\
\text { week }\end{array}$ & 769 & 31.6 & - & - & 586 & 32.9 & - & - \\
\hline $\begin{array}{l}\text { Not working, not } \\
\text { looking }\end{array}$ & 852 & 35.0 & - & - & 594 & 33.4 & - & - \\
\hline Welfare Receipt & 2,436 & 100 & 1.00 & .000 & 1,780 & 100 & 2.00 & .000 \\
\hline No & 0 & 0.0 & - & - & 1,780 & 100.0 & - & - \\
\hline Yes & 2,436 & 100.0 & - & - & 0 & 0.0 & - & - \\
\hline Total benefits & 2,436 & 100 & 2.21 & 1.122 & 1,780 & 100 & .00 & .000 \\
\hline One benefits & 861 & 35.3 & - & - & 0 & 0.0 & - & - \\
\hline Two benefits & 675 & 27.7 & - & - & 0 & 0.0 & - & - \\
\hline Three benefits & 429 & 17.6 & - & - & 0 & 0.0 & - & - \\
\hline Four benefits & 471 & 19.3 & - & - & 0 & 0.0 & - & - \\
\hline Self-Sufficiency & 2,436 & 100 & .22 & .413 & 1,780 & 100 & 1.53 & .499 \\
\hline No & 1,906 & 78.2 & - & - & 940 & 52.8 & - & - \\
\hline Yes & 530 & 21.8 & - & - & 840 & 47.2 & - & - \\
\hline \multicolumn{9}{|l|}{$\begin{array}{l}* \mathrm{SD}=\text { Standard deviation } \\
\mathrm{M}=\text { Mean }\end{array}$} \\
\hline
\end{tabular}

\section{Regressions}

In the regression output of each analysis, the researcher first looked at the between-block proportion of variance change. To ascertain the proximity of the regression line with respect to the data points, the researcher considered Nagelkerke Rsquare as the coefficient of determination. The researcher also looked at any improvement in percent classification between the blocks, as well as the odds ratio. It was expected that due to the large sample size, even small effects would be statistically significant. Therefore, it was important to assess effect sizes, namely the odds ratios 
associated with the independent variable in each hypothesis. According to Bonett and Price (2015), odds ratios (OR) are a useful way to interpret the magnitude of effects in studies that involve binary outcome variables. Odds ratios vary from 0 to $+\infty$ with a score of 1 indicating no difference in the odds of the occurrence of an outcome (i.e., economic self-sufficiency in this study) between two group conditions (i.e., households that participated in federal welfare programs and those that did not in this study). Values that are below 1 mean a decrease in likelihood of an event occurrence relative to the reference group, while values above 1 indicate just the opposite (Osteen \& Bright, 2010). Standard tables of interpretation of OR in intervention research provide the following parameters to assess the magnitude of effects: small $=1.44$, medium $=2.47$, and large $=4.25$. These effect sizes imply that the OR is greater than 1 . When the OR is less than 1 , however, the following sizes apply: small $=.69$, medium $=.40$, and large $=.24($ Buchholz, Linton, Courtney, \& Schoeny, 2016, p. 57). In this research, the odds ratio is the likelihood of economic self-sufficiency if a household received one or more welfare benefits in relation to the likelihood of economic self-sufficiency if a household did not receive any of these benefits.

Multivariate Analysis for Hypothesis 1: Low-income households that receive one or more lower-tier federal means-tested benefits will be less likely to attain and maintain economic self-sufficiency than will their counterparts who do not participate in federal welfare programs after controlling for the identified covariates.

Proportion of variance explained. As seen in the model summary (Table 9) below, block 1 - which controlled for all the covariates-explained 14 percent of the variance in attainment and maintenance of economic self-sufficiency (Nagelkerke R- 
square), $-2 \mathrm{LL}=13625218.1, \chi 2(20)=1249835.8, p<.05$. With the addition of the independent variable (household welfare benefits receipt), there was a 3 percentage point R-square change from 14.1 percent in block 1 to 16.6 percent in block 2 (Nagelkerke Rsquare), $-2 \mathrm{LL}=13387293.9, \chi 2(21)=1487759.9, p<.05$. In other words, the 3 percentage point improvement in Nagelkerke R-square indicates an increase in the variance accounted for with the addition of the independent variable after controlling for all the covariates in block 1 .

\begin{tabular}{|c|c|c|c|c|c|}
\hline \multicolumn{6}{|c|}{ Table 9. Model Summaries, Hypothesis 1} \\
\hline \multicolumn{6}{|c|}{ Block 1 Model Summary } \\
\hline Step & \multicolumn{2}{|c|}{$\begin{array}{c}-2 \log \\
\text { likelihood }\end{array}$} & \multicolumn{2}{|c|}{$\begin{array}{c}\text { Cox \& Snell R } \\
\text { Square }\end{array}$} & $\begin{array}{c}\text { Nagelkerke R } \\
\text { Square }\end{array}$ \\
\hline 1 & \multicolumn{2}{|c|}{13625218.1} & \multicolumn{2}{|r|}{.102} & .141 \\
\hline \multicolumn{6}{|c|}{ Omnibus Tests of Model Coefficients } \\
\hline & & \multicolumn{2}{|c|}{ Chi-square } & df & Sig. \\
\hline \multirow[t]{3}{*}{ Step 1} & Step & \multicolumn{2}{|c|}{1249835.770} & 20 & .000 \\
\hline & Block & \multicolumn{2}{|c|}{1249835.770} & 20 & .000 \\
\hline & Model & \multicolumn{2}{|c|}{1249835.770} & 20 & .000 \\
\hline \multicolumn{6}{|c|}{ Block 2 Model Summary } \\
\hline Step & \multicolumn{2}{|c|}{$\begin{array}{c}-2 \log \\
\text { likelihood }\end{array}$} & \multicolumn{2}{|c|}{$\begin{array}{c}\text { Cox \& Snell R } \\
\text { Square }\end{array}$} & $\begin{array}{c}\text { Nagelkerke R } \\
\text { Square }\end{array}$ \\
\hline 1 & 1338 & 293.9 & & .120 & .166 \\
\hline \multicolumn{6}{|c|}{ Omnibus Tests of Model Coefficients } \\
\hline & & \multicolumn{2}{|c|}{ Chi-square } & $\mathrm{df}$ & Sig. \\
\hline \multirow[t]{3}{*}{ Step 1} & Step & \multicolumn{2}{|c|}{237924.161} & 1 & .000 \\
\hline & Block & \multicolumn{2}{|c|}{237924.161} & 1 & .000 \\
\hline & Model & \multicolumn{2}{|c|}{1487759.931} & 21 & .000 \\
\hline
\end{tabular}

Observed and predicted classifications. Based on the following classification table (Table 10), each block contributed to the improvement of the overall predictive ability of the model in a statistically significant way. As depicted in the aforementioned 
table, the correct classification in the initial model (beginning block) was 66 percent. This block represented the null hypothesis which explains the contribution of a model absent any predictors (independent variable and covariates). The predictors in block 1 increased the correct classification of the model to 68 percent. Finally, there was an additional 1 percentage point improvement in percent correct classification associated with welfare receipt in block 2 , leading to a 69 percent predictive power of the final model (model fit).

\begin{tabular}{|c|c|c|c|c|c|}
\hline \multicolumn{6}{|c|}{ Table 10. Classification Distributions, Hypothesis 1} \\
\hline \multicolumn{6}{|c|}{ Classification for Initial Model or Beginning Block (Null Hypothesis) } \\
\hline \multirow{3}{*}{\multicolumn{3}{|c|}{ Observed }} & \multicolumn{3}{|c|}{ Predicted } \\
\hline & & & \multicolumn{2}{|c|}{\begin{tabular}{|c|} 
Attainment and maintenance of \\
economic self-sufficiency
\end{tabular}} & \multirow{2}{*}{$\begin{array}{l}\text { Percentage } \\
\text { Correct }\end{array}$} \\
\hline & & & No & Yes & \\
\hline \multirow[t]{3}{*}{ Step 0} & Attainment and & No & 7705693 & 0 & 100.0 \\
\hline & $\begin{array}{l}\text { maintenance of economic } \\
\text { self-sufficiency }\end{array}$ & Yes & 3926409 & 0 & .0 \\
\hline & Overall Percentage & & & & 66.2 \\
\hline \multicolumn{6}{|c|}{ Classification for Block 1} \\
\hline \multirow{3}{*}{\multicolumn{3}{|c|}{ Observed }} & \multicolumn{3}{|c|}{ Predicted } \\
\hline & & & \multicolumn{2}{|c|}{$\begin{array}{c}\text { Attainment and maintenance of } \\
\text { economic self-sufficiency }\end{array}$} & \multirow{2}{*}{$\begin{array}{l}\text { Percentage } \\
\text { Correct }\end{array}$} \\
\hline & & & No & Yes & \\
\hline \multirow[t]{3}{*}{ Step 1} & Attainment and & No & 6828408 & 877285 & 88.6 \\
\hline & $\begin{array}{l}\text { maintenance of economic } \\
\text { self-sufficiency }\end{array}$ & Yes & 2800583 & 1125826 & 28.7 \\
\hline & Overall Percentage & & & & 68.4 \\
\hline \multicolumn{6}{|c|}{ Classification for Final Model (Model Fit) } \\
\hline \multirow{3}{*}{\multicolumn{3}{|c|}{ Observed }} & \multicolumn{3}{|c|}{ Predicted } \\
\hline & & & \multicolumn{2}{|c|}{$\begin{array}{c}\text { Attainment and maintenance of } \\
\text { economic self-sufficiency }\end{array}$} & \multirow{2}{*}{$\begin{array}{l}\text { Percentage } \\
\text { Correct }\end{array}$} \\
\hline & & & No & Yes & \\
\hline \multirow[t]{3}{*}{ Step 1} & Attainment and & No & 6681909 & 1023784 & 86.7 \\
\hline & $\begin{array}{l}\text { maintenance of economic } \\
\text { self-sufficiency }\end{array}$ & Yes & 2567063 & 1359346 & 34.6 \\
\hline & Overall Percentage & & & & 69.1 \\
\hline
\end{tabular}

Odds ratio. Table 11 below displays the regression coefficients (B) and odds ratios $(\operatorname{Exp}(B))$ of economic self-sufficiency with regard to all the 18 predictor variables 
included in the equation (model). The next-to-last line in the table shows the effect of the independent variable, welfare receipt, on the outcome, attainment and maintenance of self-sufficiency, while controlling for all the other predictors of the model. As seen, the odds ratio for this variable is .443 , indicating that participants in the intervention group (i.e., those coded " 1 " on the independent variable) had less than half the odds of attaining and maintain self-sufficiency than those in the comparison group (those coded "0" on the independent variable). In other words, those in the intervention group were 2.3 times (1/.443) less likely to attain and maintain economic self-sufficiency than those in the comparison group. This is a medium effect size. Therefore, hypothesis 1 was supported.

Table 11. Logistic Regression of Self-Sufficiency: Variables in the Equation, Hypothesis 1

\begin{tabular}{|l|r|r|r|r|r|r|r|r|}
\hline & & & & & & & \multicolumn{2}{|c|}{$95 \%$ C.I.for EXP(B) } \\
\cline { 7 - 8 } & \multicolumn{1}{c|}{$\mathrm{B}$} & S.E. & Wald & df & Sig. & Exp(B) & Lower & Upper \\
\hline State unemployment & .136 & .002 & 7264.697 & 1 & .000 & 1.146 & 1.142 & 1.150 \\
State minimum wage & -.003 & .002 & 1.671 & 1 & .196 & .997 & .993 & 1.001 \\
Age range & .066 & .001 & 2193.969 & 1 & .000 & 1.069 & 1.066 & 1.072 \\
Gender & .061 & .001 & 1839.984 & 1 & .000 & 1.063 & 1.060 & 1.066 \\
Nativity & .002 & .002 & .455 & 1 & .500 & 1.002 & .997 & 1.006 \\
US citizenship & .409 & .003 & 18875.528 & 1 & .000 & 1.505 & 1.497 & 1.514 \\
Hispanic ethnicity & -.109 & .002 & 2851.193 & 1 & .000 & .897 & .893 & .900 \\
Race & .204 & .002 & 13802.139 & 1 & .000 & 1.226 & 1.222 & 1.231 \\
Education level & -.503 & .001 & 122208.561 & 1 & .000 & .605 & .603 & .606 \\
Metro status & .380 & .002 & 40019.567 & 1 & .000 & 1.462 & 1.457 & 1.467 \\
State poverty rate & -.016 & .002 & 44.508 & 1 & .000 & .984 & .980 & .989 \\
Marital status & .524 & .002 & 114513.119 & 1 & .000 & 1.689 & 1.684 & 1.694 \\
Children in the home & -.237 & .002 & 11285.550 & 1 & .000 & .789 & .785 & .792 \\
People in the home & -.087 & .002 & 1562.665 & 1 & .000 & .917 & .913 & .921 \\
Financial capability & .391 & .001 & 73768.901 & 1 & .000 & 1.478 & 1.474 & 1.482 \\
Northeast region & -.098 & .003 & 1302.683 & 1 & .000 & .906 & .901 & .911 \\
South region & -.061 & .003 & 479.011 & 1 & .000 & .941 & .936 & .946
\end{tabular}




\begin{tabular}{l|r|r|r|r|r|r|r|r|} 
West region & .022 & .002 & 101.939 & 1 & .000 & 1.022 & 1.018 & 1.027 \\
Part-time work & -.065 & .002 & 1501.094 & 1 & .000 & .937 & .934 & .940 \\
Full-time work & -.452 & .002 & 72351.665 & 1 & .000 & .636 & .634 & .638 \\
Welfare receipt & -.815 & .002 & 234212.207 & 1 & .000 & .443 & .441 & .444 \\
Constant & -.709 & .007 & 9868.815 & 1 & .000 & .492 & & \\
\hline
\end{tabular}

Although presence of children was included as a covariate and thus presumably controlled during the analysis, the researcher still remained unsure about the possibility that the difference in self-sufficiency may have been due to the presence of children in the household. In fact, as shown in the frequency distributions of the variables, there was a major difference between the intervention group and the comparison group in reference to presence of children in the households. Hence, the researcher thought that it would be worthwhile to perform a follow-up analysis of only households with children $(n=2359)$. This follow-up analysis was to determine whether self-sufficiency outcomes differ between these two groups, using a sample where the playing field was more or less leveled.

The tables below (Tables 12-14) present the explained variance, the correct classification, and the odds ratios for households with children $(n=2,359)$. As demonstrated in the tables, the results were quite similar to those found in the analysis of the full sample with (a) a 3 percentage point $\mathrm{R}$-square change in the explained variance in attainment and maintenance of self-sufficiency from 15 percent in block 1 (Nagelkerke R-square), $-2 \mathrm{LL}=6795872.3, \chi 2(19)=717935.3, p<.05$ to 18 percent in block 2 (Nagelkerke R-square), $-2 \mathrm{LL}=6668813.8, \chi 2(20)=844993.7, p<.05,(\mathrm{~b})$ a predictive capability of 72.5 percent in block 0 to 73.4 percent in block 1 to 75.1 percent in block 2 , 
and (c) an odds ratio of .431 for the independent variable (welfare receipt). These

findings corroborated those found for the full sample. That is, the presence or absence of children in the household was already controlled for in the analysis and thus cannot be used in the interpretation of the differences between the two groups.

Table 12. Model Summaries, Hypothesis 1, Households with Children Only

\begin{tabular}{|c|c|c|c|c|c|}
\hline \multicolumn{6}{|c|}{ Block 1 Model Summary } \\
\hline Step & \multicolumn{2}{|c|}{$\begin{array}{c}-2 \text { Log } \\
\text { likelihood }\end{array}$} & \multicolumn{2}{|c|}{$\begin{array}{c}\text { Cox \& Snell R } \\
\text { Square }\end{array}$} & $\begin{array}{c}\text { Nagelkerke R } \\
\text { Square }\end{array}$ \\
\hline 1 & \multicolumn{2}{|c|}{6795872.3} & & 106 & .154 \\
\hline \multicolumn{6}{|c|}{ Omnibus Tests of Model Coefficients } \\
\hline & & \multicolumn{2}{|c|}{ Chi-square } & df & Sig. \\
\hline \multirow[t]{3}{*}{ Step 1} & Step & \multicolumn{2}{|c|}{717935.297} & 19 & .000 \\
\hline & Block & \multicolumn{2}{|c|}{717935.297} & 19 & .000 \\
\hline & Model & \multicolumn{2}{|c|}{717935.297} & 19 & .000 \\
\hline \multicolumn{6}{|c|}{ Block 2 Model Summary } \\
\hline Step & \multicolumn{2}{|c|}{$\begin{array}{c}-2 \log \\
\text { likelihood }\end{array}$} & \multicolumn{2}{|c|}{$\begin{array}{c}\text { Cox \& Snell R } \\
\text { Square }\end{array}$} & $\begin{array}{c}\text { Nagelkerke R } \\
\text { Square }\end{array}$ \\
\hline 1 & \multicolumn{2}{|c|}{6668813.8} & & 124 & .179 \\
\hline \multicolumn{6}{|c|}{ Omnibus Tests of Model Coefficients } \\
\hline & & \multicolumn{2}{|c|}{ Chi-square } & $\mathrm{df}$ & Sig. \\
\hline \multirow[t]{3}{*}{ Step 1} & Step & \multicolumn{2}{|c|}{127058.437} & 1 & .000 \\
\hline & Block & \multicolumn{2}{|c|}{127058.437} & 1 & .000 \\
\hline & Model & \multicolumn{2}{|c|}{844993.734} & 20 & .000 \\
\hline
\end{tabular}

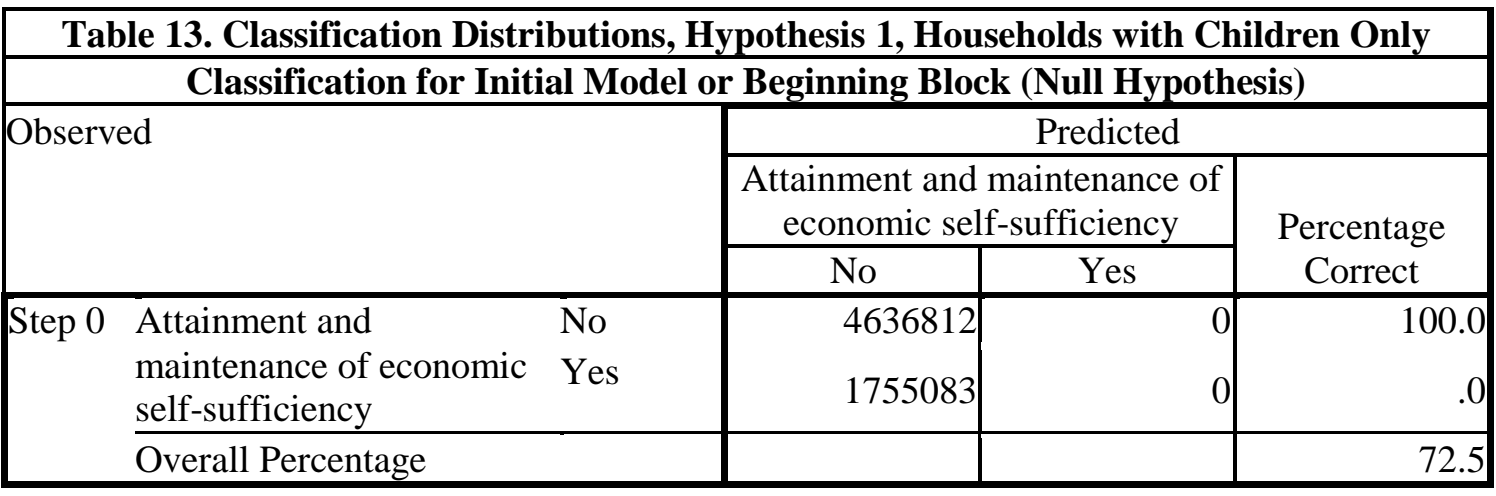




\begin{tabular}{|c|c|c|c|c|c|}
\hline \multicolumn{6}{|c|}{ Classification for Block 1} \\
\hline \multirow{3}{*}{\multicolumn{3}{|c|}{ Observed }} & \multicolumn{3}{|c|}{ Predicted } \\
\hline & & & \multicolumn{2}{|c|}{$\begin{array}{c}\text { Attainment and maintenance of } \\
\text { economic self-sufficiency }\end{array}$} & \multirow{2}{*}{$\begin{array}{l}\text { Percentage } \\
\text { Correct }\end{array}$} \\
\hline & & & No & Yes & \\
\hline \multirow[t]{3}{*}{$\overline{\text { Step } 1}$} & \multirow{2}{*}{$\begin{array}{l}\text { Attainment and } \\
\text { maintenance of economic } \\
\text { self-sufficiency }\end{array}$} & No & 4332236 & 304577 & 93.4 \\
\hline & & Yes & 1396481 & 358602 & 20.4 \\
\hline & \multicolumn{2}{|l|}{ Overall Percentage } & & & 73.4 \\
\hline \multicolumn{6}{|c|}{ Classification for Final Model (Model Fit) } \\
\hline \multirow{3}{*}{\multicolumn{3}{|c|}{ Observed }} & \multicolumn{3}{|c|}{ Predicted } \\
\hline & & & \multicolumn{2}{|c|}{$\begin{array}{l}\text { Attainment and maintenance of } \\
\text { economic self-sufficiency }\end{array}$} & \multirow{2}{*}{$\begin{array}{l}\text { Percentage } \\
\text { Correct }\end{array}$} \\
\hline & & & No & Yes & \\
\hline \multirow[t]{3}{*}{ Step 1} & Attainment and & No & 4347323 & 289489 & 93.8 \\
\hline & $\begin{array}{l}\text { maintenance of economic } \\
\text { self-sufficiency }\end{array}$ & Yes & 1299657 & 455426 & 25.9 \\
\hline & Overall Percentage & & & & 75.1 \\
\hline
\end{tabular}

Table 14. Logistic Regression of Self-Sufficiency: Variables in the Equation, Hypothesis 1, Households with Children Only

\begin{tabular}{|c|c|c|c|c|c|c|c|c|}
\hline & \multirow[b]{2}{*}{$\mathrm{B}$} & \multirow[b]{2}{*}{ S.E. } & \multirow[b]{2}{*}{ Wald } & \multirow[b]{2}{*}{ df } & \multirow[b]{2}{*}{ Sig. } & \multirow[b]{2}{*}{$\operatorname{Exp}(B)$} & \multicolumn{2}{|c|}{ 95\% C.I.for $\operatorname{EXP}(\mathrm{B})$} \\
\hline & & & & & & & Lower & Upper \\
\hline State unemployment & .132 & .002 & 3159.482 & 1 & .000 & 1.141 & 1.135 & 1.146 \\
\hline State minimum wage & -.098 & .003 & 953.862 & 1 & .000 & .906 & .901 & .912 \\
\hline Age range & .389 & .002 & 37381.165 & 1 & .000 & 1.475 & 1.469 & 1.481 \\
\hline Gender & .191 & .002 & 7174.375 & 1 & .000 & 1.211 & 1.205 & 1.216 \\
\hline Nativity & .040 & .003 & 144.676 & 1 & .000 & 1.041 & 1.034 & 1.048 \\
\hline US citizenship & .492 & .004 & 15475.881 & 1 & .000 & 1.636 & 1.623 & 1.648 \\
\hline Hispanic ethnicity & -.054 & .003 & 423.136 & 1 & .000 & .947 & .942 & .952 \\
\hline Race & .320 & .003 & 15520.912 & 1 & .000 & 1.377 & 1.370 & 1.384 \\
\hline Education level & -.603 & .002 & 87632.206 & 1 & .000 & .547 & .545 & .549 \\
\hline Metro status & .274 & .003 & 10467.285 & 1 & .000 & 1.315 & 1.308 & 1.322 \\
\hline State poverty rate & .169 & .003 & 2495.930 & 1 & .000 & 1.185 & 1.177 & 1.193 \\
\hline Marital status & .392 & .002 & 28493.975 & 1 & .000 & 1.480 & 1.474 & 1.487 \\
\hline People in the home & .172 & .003 & 2681.953 & 1 & .000 & 1.188 & 1.180 & 1.196 \\
\hline Financial capability & .474 & .002 & 51909.222 & 1 & .000 & 1.606 & 1.600 & 1.613 \\
\hline North region & -.370 & .004 & 8506.157 & 1 & .000 & .691 & .686 & .696 \\
\hline
\end{tabular}




\begin{tabular}{l|r|r|r|r|r|r|r|r|} 
South region & -.092 & .004 & 528.257 & 1 & .000 & .912 & .905 & .919 \\
West region & -.030 & .003 & 85.484 & 1 & .000 & .970 & .964 & .977 \\
Part-time work & .103 & .003 & 1648.519 & 1 & .000 & 1.109 & 1.103 & 1.114 \\
Full-time work & -.319 & .002 & 16783.637 & 1 & .000 & .727 & .723 & .730 \\
Welfare receipt & -.841 & .002 & 129026.810 & 1 & .000 & .431 & .429 & .433 \\
Constant & -1.096 & .010 & 12217.294 & 1 & .000 & .334 & & \\
\hline
\end{tabular}

\section{Multivariate Analysis for Hypothesis 2: Low-income households who enrolled in} more programs will have worse self-sufficiency outcomes than will their counterparts who participate in fewer services after controlling for the identified covariates.

Proportion of variance explained. In the second analysis, the covariates in block 1 explained 9 percent of the variance in attainment and maintenance of economic selfsufficiency (Nagelkerke R-square), -2 LL $=6536998.8, \chi 2(20)=412455.1, p<.05$ (Table 15). It should be noted that this proportion of explained variance was different from that registered in multivariate analysis I. This difference can be explained by the fact that significance levels were reduced and error variances enlarged by smaller sample sizes. In fact, households that did not participate in welfare programs at baseline (comparison group) were incompatible with the purpose of this analysis. These households were therefore removed for the final sample $(n=2,436)$.

With the entry of the independent variable (number of welfare benefits per household) in block 2, the model explained 12 percent of the variance in economic selfsufficiency (Nagelkerke R-square), $-2 \mathrm{LL}=6412273.6, \chi 2(21)=537180.4, p<.05$. This three percentage point R-square change between the two blocks was incrementally associated with the impact of the independent variable. Please see model summary below for more details. 


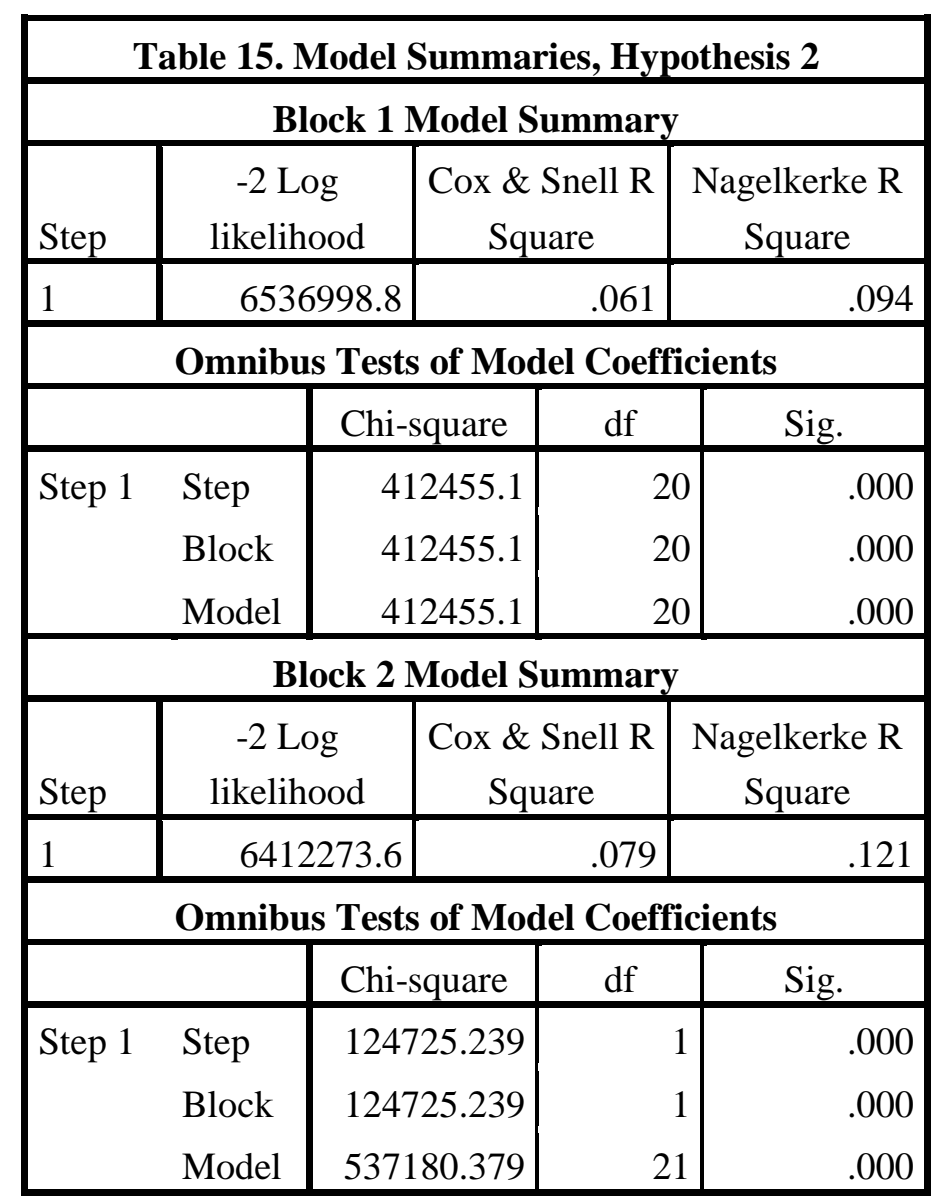

Observed and predicted classifications. As seen in Table 16, the correct classification of 77.1 percent in block 1 did not improve the 77.4 percent prior correct classification (block 0). The model predictive capacity was basically unchanged from one block to another. A similar scenario occurred in block 2 (model fit) where the percentage accuracy in classification knew no statistical improvement from the previous blocks. In short, the model correctly predicted 77 percent of the cases, the same percentage as for the null hypothesis. Please see model classification table below for more details. 


\begin{tabular}{|c|c|c|c|c|c|}
\hline \multicolumn{6}{|c|}{ Table 16. Classification Distributions, Hypothesis 2} \\
\hline \multicolumn{6}{|c|}{ Classification for Initial Model or Beginning Block (Null Hypothesis) } \\
\hline \multirow{3}{*}{\multicolumn{3}{|c|}{ Observed }} & \multicolumn{3}{|c|}{ Predicted } \\
\hline & & & \multicolumn{2}{|c|}{$\begin{array}{c}\text { Attainment and maintenance of } \\
\text { economic self-sufficiency }\end{array}$} & \multirow{2}{*}{$\begin{array}{l}\text { Percentage } \\
\text { Correct }\end{array}$} \\
\hline & & & No & Yes & \\
\hline \multirow[t]{3}{*}{ Step 0} & Attainment and & No & 5033516 & 0 & 100.0 \\
\hline & $\begin{array}{l}\text { maintenance of economic } \\
\text { self-sufficiency }\end{array}$ & Yes & 1469334 & 0 & .0 \\
\hline & Overall Percentage & & & & 77.4 \\
\hline \multicolumn{6}{|c|}{ Classification for Block 1} \\
\hline \multirow{3}{*}{\multicolumn{3}{|c|}{ Observed }} & \multicolumn{3}{|c|}{ Predicted } \\
\hline & & & \multicolumn{2}{|c|}{$\begin{array}{c}\text { Attainment and maintenance of } \\
\text { economic self-sufficiency }\end{array}$} & \multirow{2}{*}{$\begin{array}{l}\text { Percentage } \\
\text { Correct }\end{array}$} \\
\hline & & & No & Yes & \\
\hline \multirow[t]{3}{*}{ Step 1} & Attainment and & No & 4957440 & 76076 & 98.5 \\
\hline & $\begin{array}{l}\text { maintenance of economic } \\
\text { self-sufficiency }\end{array}$ & Yes & 1412704 & 56630 & 3.9 \\
\hline & Overall Percentage & & & & 77.1 \\
\hline \multicolumn{6}{|c|}{ Classification for Final Model (Model Fit) } \\
\hline \multirow{3}{*}{\multicolumn{3}{|c|}{ Observed }} & \multicolumn{3}{|c|}{ Predicted } \\
\hline & & & \multicolumn{2}{|c|}{$\begin{array}{c}\text { Attainment and maintenance of } \\
\text { economic self-sufficiency }\end{array}$} & \multirow{2}{*}{$\begin{array}{l}\text { Percentage } \\
\text { Correct }\end{array}$} \\
\hline & & & No & Yes & \\
\hline \multirow[t]{3}{*}{ Step 1} & \multirow{2}{*}{\multicolumn{2}{|c|}{$\begin{array}{l}\text { Attainment and } \\
\text { maintenance of economic } \\
\text { self-sufficiency }\end{array}$}} & 4919479 & 114037 & 97.7 \\
\hline & & & 1377346 & 91988 & 6.3 \\
\hline & Overall Percentage & & & & 77.1 \\
\hline
\end{tabular}

Odds ratio. Table 17 exhibits the regression equation for the logistic regression of self-sufficiency on all the covariates and the independent variable. The next-to-last line shows an odds ratio $(\operatorname{Exp}(B))$ of .685 for attainment and maintenance of economic selfsufficiency as a function of number of benefits received per household. This means, while controlling for all the other predictors in the model, the odds of attaining and maintaining economic self-sufficiency decreased by approximately one-third for each additional benefit received. In other words, households were 1.4 (1/.691) times less likely to become and remain economically self-sufficient with each additional benefit received. 
Although small, this effect is exponential: a household receiving two benefits was 1.4 times less likely to attain and maintain self-sufficiency compared to a household receiving one benefit; a household receiving three benefits was 2.0 times less likely $\left(1.4^{2}\right)$, and a household receiving four benefits was almost 3.0 times less likely $\left(1.4^{3}\right)$.

Thus, hypothesis 2 was supported.

\begin{tabular}{|c|c|c|c|c|c|c|c|c|}
\hline \multicolumn{9}{|c|}{$\begin{array}{l}\text { Table 17. Logistic Regression of Self-Sufficiency: Variables in the Equation, } \\
\text { Hypothesis } 2\end{array}$} \\
\hline & \multirow[b]{2}{*}{$\mathrm{B}$} & \multirow[b]{2}{*}{ S.E. } & \multirow[b]{2}{*}{ Wald } & \multirow[b]{2}{*}{$\mathrm{df}$} & \multirow[b]{2}{*}{ Sig. } & \multirow[b]{2}{*}{$\operatorname{Exp}(B)$} & \multicolumn{2}{|c|}{ 95\% C.I.for $\operatorname{EXP}(B)$} \\
\hline & & & & & & & Lower & Upper \\
\hline State unemployment & .053 & .002 & 487.685 & 1 & .000 & 1.055 & 1.050 & 1.060 \\
\hline State minimum wage & -.376 & .003 & 12513.129 & 1 & .000 & 687 & .682 & .691 \\
\hline Age range & .254 & .002 & 14731.379 & 1 & .000 & 1.289 & 1.284 & 1.294 \\
\hline Gender & .059 & .002 & 724.726 & 1 & .000 & 1.061 & 1.057 & 1.066 \\
\hline Nativity & -.147 & .003 & 1827.555 & 1 & .000 & .863 & .857 & .869 \\
\hline US citizenship & .608 & .004 & 23477.183 & 1 & .000 & 1.836 & 1.822 & 1.850 \\
\hline Hispanic ethnicity & -.160 & .003 & 3326.349 & 1 & .000 & .852 & .848 & .857 \\
\hline Race & .290 & .002 & 13569.654 & 1 & .000 & 1.336 & 1.330 & 1.343 \\
\hline Education level & -.477 & .002 & 52788.761 & 1 & .000 & .621 & .618 & .623 \\
\hline Metro status & .357 & .003 & 16912.286 & 1 & .000 & 1.429 & 1.421 & 1.436 \\
\hline State poverty rate & -.051 & .004 & 201.683 & 1 & .000 & .950 & .944 & .957 \\
\hline Marital status & .145 & .002 & 3999.750 & 1 & .000 & 1.156 & 1.150 & 1.161 \\
\hline Children in the home & .032 & .003 & 108.140 & 1 & .000 & 1.033 & 1.027 & 1.039 \\
\hline People in the home & -.171 & .003 & 3273.036 & 1 & .000 & .843 & .838 & .848 \\
\hline Financial capability & .523 & .002 & 57281.048 & 1 & .000 & 1.687 & 1.679 & 1.694 \\
\hline North region & -.243 & .004 & 3310.230 & 1 & .000 & .784 & .778 & .791 \\
\hline South region & -.091 & .004 & 473.439 & 1 & .000 & .913 & .905 & .920 \\
\hline West region & -.145 & .003 & 1846.663 & 1 & .000 & .865 & .860 & .871 \\
\hline Part-time work & .013 & .003 & 28.308 & 1 & .000 & 1.014 & 1.009 & 1.019 \\
\hline Full-time work & -.271 & .003 & 11575.981 & 1 & .000 & .763 & .759 & .767 \\
\hline Number of benefits & -.369 & .001 & 118688.613 & 1 & .000 & .691 & .690 & .693 \\
\hline Constant & -.682 & .011 & 4154.526 & 1 & .000 & .506 & & \\
\hline
\end{tabular}




\section{CHAPTER IX: DISCUSSION}

\section{Interpretation of Results}

This research tested two hypotheses in order to determine whether participation in federal welfare programs galvanizes low-income households toward economic selfsufficiency. Both hypotheses forecast a negative correlation between welfare participation and household income. Hypothesis 1 predicted lower odds of attaining and maintaining self-sufficiency following receipt of welfare benefits compared to households not receiving such benefits. Hypothesis 2 anticipated a reduction in household income based on the number of welfare benefits received. Results from binary logistic regression corroborated both hypotheses, given that (a) households on welfare were two times less likely to attain and maintain economic self-sufficiency as compared to those not on welfare and (b) self-sufficiency was negatively related to the number of benefits received by a household. These results can be interpreted in light of potential preexisting differences between the intervention group and the comparison group, which were not accounted for in the analysis. Access to services and social support are two facets of social capital that could explain the natural sorting mechanism of study participants into groups.

Access to services. Accessibility to federal welfare programs can arguably be a byzantine process for low-income families. There exist labyrinths and entanglements in the American welfare system intended to prevent people from applying. Williamson (1999) used the term "bureaucratic transaction costs" to describe obstacles faced in transacting. Under a welfare system set up to prevent people from accessing programs in the first place, the costs of the transaction make it difficult for some people to receive 
benefits. Under Williamson's (1999) bureaucratic transaction hypothesis, the government practically plays a game against its citizens who, for the most part, are limited in the transaction.

This dovetails perfectly with von Neumann and Morgenstern's (1944) Game Theory which describes rational decisions between competitive entities. In this case, the government intends to limit welfare seekers in the transaction. When prevented from engaging in free transactions, people are basically captives and counterproductive results of programs are produced. That is, the lack of bona fide intent on the part of the government in the design of antipoverty policies would make beneficiaries struggle to meet program expectations. For instance, the intended goal of TANF is to keep people off welfare by turning to the workforce for basic support. Unintended results, however, occur when recipients are disconnected from both welfare and work (Blank \& Kovak, 2008, 2009; Loprest, 2011; Loprest \& Nichols, 2011). Because poor people tend to lack the necessary skills to navigate the complexity of the welfare system by themselves, social capital, in the form of experienced or professional people who can advise them, is critical in applying for and accessing social services. For example, in the Affordable Care Act, these experienced people are called navigators. This is - or used to be - an important role for social workers, for whom linkage of people and programs was an important function.

Hence, as compared to those in the comparison group, households in the intervention group were perhaps more able to navigate and overcome the public assistance bureaucracy aimed at repelling applicants. In other words, participants in the intervention group may have had assistance from social workers or other navigators than 
their counterparts in the comparison group. As a result, these household members may have balanced work and welfare in such a way to avoid falling into the benefits cliff. In welfare, benefits cliffs take place when a household income is far from being adequate yet is just high enough to prevent enrollment in fundamental programs (Kaz, 2015). In other words, by earning just a couple of dollars above the income eligibility thresholds, householders may have to make out-of-pocket payments for key goods and services such as food, healthcare, or housing. It would have therefore been wise for these householders to circumvent any benefits cliff at all costs.

Indeed, Edin and Lein (1996) found little self-sufficiency differences between single mothers who worked and those on welfare who did not work. Those on welfare understood the costs associated with work in terms of fatigue, clothing, transportation and childcare. Therefore, the single mothers used welfare a coping mechanism against lowpaying jobs in the labor market. Their work ethic has never been in question as countless studies found that the poor have similar work aspirations as other people from the middle class (Schiller, 1973). Instead, this is a rational choice to break even with a welfare system that is rigged against them in the first place. Since earnings from work are similar to — or less than—what was provided in multiple welfare programs (Edin \& Lein, 1996), it is likely that recipients may decide to remain on welfare as long as possible or just work part-time to avoid the benefits cliff. Such coping mechanisms do not apply to participants in the comparison group.

Social support. It is possible that participating households that did not apply for welfare benefits but were eligible for these benefits perhaps were more likely to use their informal safety net, whereas those that did apply may not have had that safety net option 
or have had exhausted it. Stack (1974) wrote about informal support networks used by single mothers in a Midwestern city. These included childcare assistance, exchange of goods and services, and temporary shelter assistance. In some cultures, it is a reflection on the entire family for household members to let one of theirs go to public assistance. So family members seek welfare not as first resort but as last resort. Conceivably, households whose informal social support network was intact remained in the comparison group. By contrast, those whose informal social network support failed or was nonexistent were classified into the intervention group. Hardcastle, Powers, and Wenocur (2011) wrote that social support networks include family members, kinship and social acquaintances (primary group); churches, unions, social clubs (secondary); and support groups (tertiary) (p. 293). Any support received by households in the comparison group — whether in the form of childcare, transportation, money, or linkage to employment-would give them the edge over those in the intervention group that did not receive such help. Social capital, especially in the form of childcare, transportation, and linkage to employment would allow participants in the comparison group to seek, find, and maintain work. This would not be the case for those in the intervention group, provided that there was a lack of social capital.

\section{Theoretical Inferences}

In view of the foregoing interpretation, the findings are consistent with the claims of the theory of policy design and social construction and the racial classification model which point out "foul play" in the design and implementation of welfare policies at national and subnational levels. Legislatively, policymakers set welfare recipients (minorities, in particular) up for failure. The predetermined twists and turns in the 
policymaking process are impeding factors for self-sufficiency. On the other hand, the present findings neither refute nor substantiate the claims of the culture of poverty theory that welfare receipt creates dependence on the government. While it is true that the intervention group had less self-sufficiency than the comparison group and that more benefits were associated with lower household income, the quasi-experimental nature of this research design does not allow for causal inference; indeed, as discussed above, these findings may be a result of pre-existing group differences.

\section{Consistency with Prior Research}

The results are consistent with a line of previous research findings that, contrary to their ultimate goals, federally-funded means-tested welfare programs actually correlate with a decrease in labor participation, a sine qua non condition of economic selfsufficiency. Indeed, researchers have found negative associations between several welfare programs and the labor supply, including Medicaid (Baicker, Finkelstein, Song, \& Taubman, 2014; Moffitt \& Wolfe, 1990; Winkler, 1991), food stamps/SNAP (Fraker \& Moffitt, 1988; Hoynes \& Schanzenbach, 2012), and housing assistance (Jacob \& Ludwig, 2012; Owens \& Baum, 2009). However, the present findings are different from the work of several other researchers, including Loeb and Corcoran (2001), Hall et al. (2010), Schoeni and Blank (2000), McKernan, Lerman, Pindus, and Valente (2000), and O'Neill and Hill (2001).

Hall et al. (2010) found that female immigrants leaving welfare were as likely to find and maintain employment as their eligible counterparts who did not receive welfare. These TANF leavers were also more likely to work than poor immigrant females who were not eligible for welfare due to residency issues. Meanwhile, comparing female 
welfare recipients to their counterparts not on welfare, Loeb and Corcoran (2001) found no differences in earnings between the two groups. Finally, McKernan et al. (2000), O'Neill \& Hill (2001) and Schoeni \& Blank (2000) all conducted large-scale studies that showed the instrumental role of welfare in raising employment among disadvantaged women, especially minority single mothers.

There are two possible explanations for such inconsistency with this line of prior research. First, all the aforementioned studies focused on a single program (TANF), whereas this research was about enrollment in multiple welfare programs. In other words, TANF input in the current investigation is comprised of less than 10 percent. Second, researchers also worked on data collected during times of economic growth, while the current investigator used data gathered during and after economic downturn. The enforcement of labor participation under TANF, coupled with the economic boom of the late 1990s, is arguably the main reason behind the discrepancies in the findings.

\section{Implications}

Implications for research. By their nature, the findings hold implications for research. Although parallel, to some extent, with previous investigative efforts, these findings represent a new line of research. In fact, no previous studies investigate concurrent participation in as many means-tested welfare benefits. Moreover, the current literature focuses primarily on the effectiveness of single programs. Researchers have also demonstrated a preference for the study of female-headed households with children. Social scientists' tendency to recruit samples made of single-gender participants leave behind married couples. Furthermore, the current body of research on social welfare is based on relatively old data that might not be relevant to current social welfare policies 
(Slack et al., 2014). The findings of this research contribute to fill all the aforementioned existing gaps in the literature. By identifying the number of benefits received by a household as an exponential factor of economic self-sufficiency, the findings contribute to the expansion of the body of research on poverty and social welfare.

Implications for policy. The findings represent a wake-up call for policymakers to reassess current welfare interventions and ensure that those at the bottom of society are not left behind. With only 33 percent of the total sample $(n=4,216)$ attaining and maintaining economic self-sufficiency, it is evident that the labor market as well as the benefit programs woefully fail to galvanize low-income households toward financial independence. So it is time for policymakers to act accordingly. Policymakers should adopt the policy of a strong labor market and/or that of a holistic approach toward welfare. The former involves the creation of good-paying jobs, while the latter implies the perception of welfare as entitlement.

Strong labor market. Since welfare recipients are expected to reach economic self-sufficiency through the workforce (Peck \& Theodore, 2000), it would be important to assess the relationship between the supply side and the demand side of the labor market. Although the federal government responded to the Great Recession with the enactment and implementation of the $\$ 789$ billion American Recovery and Reinvestment Act (ARRA), America still struggles to cope with the lasting effects of the 2008 recession. In 2009, when Congress enacted the ARRA, the national unemployment rate reached 8.3 percent. Three years later, in February 2012, the nation still faced the same rate of unemployment, prompting talks of a jobless recovery (Carter \& Tippins, 2012). Given the fact that welfare recipients are low-income individuals, the likelihood for them 
to be competitive in today's economy is thin. Therefore, in America's current slack labor market (where there are more job seekers than positions available), welfare recipients struggle to secure and maintain any decent employment due notably to lack of skills (Derr \& Brown, 2015; Dworsky \& Courtney, 2007; Siegel, 2004). The slow-moving economy in the United States over the past near-decade has triggered a dichotomy between the supply side and the demand side of the labor force. This disequilibrium in the workforce represents an enormous barrier to employment among welfare enrollees (Derr \& Brown, 2015; Siegel, 2004). A strong labor market constitutes the availability of job opportunities that provide health and retirement benefits, good working conditions and living wages. Under such a labor market, welfare would be provided only as last resort.

Welfare as entitlement. In the absence of a strong labor market, a holistic approach toward welfare as entitlement deserves consideration. This consists in the expansion of welfare programs to assist low-income households and the reduction of stigmatizing rhetoric toward the poor. In this context, expansion of welfare means a considerable investment in human capital by improving the living conditions of the poor and preparing them for better job opportunities (McKeen, 2006; Peck, 2001). In other words, the entitlement approach implies the empowerment of the poor toward economic self-sufficiency through the acquisition of the skillset needed to enter the workforce. On a long run, this could be seen as a win-win scenario for both the recipients of benefits and the government. In fact, under normal circumstances these recipients would eventually rely less on public assistance but become productive members of society. The entitlement 
approach toward self-sufficiency has been adopted in the Scandinavia as well as several countries across mainland Europe (Peck \& Theodore, 2000).

Another key element under the entitlement approach is stigma removal. Research has revealed that stigma prevents participation in federal means-tested programs. Indeed, only about 30 percent of the poor who are eligible for welfare in the United States take the option of applying for benefits. So the vast majority of the needy people in this country opts against participating in welfare programs due to stigma (Blank \& Ruggles, 1996; Moffitt, 1983; Stuber \& Kronebusch, 2004; Stuber \& Schlesinger, 2006). Considering how vital the welfare programs are to the economic well-being of disadvantaged individuals and families, the effects of stigma should not be taken lightly. According to Titmuss (1968), the means-tested notion in welfare policies is itself a stigmatizing and demeaning measure which contributes to negative stigma. For example, the public might have a more favorable view attitude toward Medicare (not means tested), as opposed to Medicaid (means-tested). Kerbo (1976) argued that stigma can create a state of passivity in recipients of public assistance which may result in the preclusion of efforts toward self-efficacy. Therefore, Congress should find ways to lessen stigma in the design and implementation of the welfare policies.

One simple yet significant way the U.S. Congress can act is by benchmarking its own success with SNAP. SNAP moved toward Electronic Benefit Transfer (EBT) cards to prevent frauds and remove stigma associated with paper food stamps. The adoption of a new name, "SNAP," in lieu of "Food Stamps" in 2008 was another smart move from the U.S. Congress to further reduce stigma around the program (US Department of Agriculture, 2014). Before that change, the 
SNAP take-up rate was unsatisfactory, with 32.6 percent, 50.2 percent and 65.5 percent of participants in 1976, 2003, and 2007, respectively. By 2011, 83.3 percent of eligible families received SNAP (USDHHS, n. d.).

Some would argue that the higher SNAP take-up rate over the past decade has been influenced by the 2008 recession which resulted in much more widespread need. Indeed, ARRA substantially increased SNAP benefits between 2009 and 2013. However, in a comparative analysis of participation change in SNAP and TANF programs over the latest recession, Derr and Brown (2015) found that SNAP had a 89.4 percent change between 2007 and 2012, while TANF only managed to record a 7.0 percent increase for the same time period. In other words, the SNAP participation rate grew from $11,789,594$ average monthly cases in 2007 to $22,329,713$ average monthly cases in 2012 , while the average monthly cases for TANF varied only slightly from 1,753,891 in 2007 to $1,876,426$ in 2012 . Thus, how a program is shaped and portrayed by Congress and by states conveys a message to end-users. A positive message is likely to increase participation, while a negative view implies diversion toward program selection or nonparticipation altogether (Stuber \& Kronebusch, 2004, 2006).

Stigma removal in the US welfare state cannot be achieved by Congress alone, given the fact that the stigmatization of the poor has been found to come from various sources. These stem from landlords and local housing authorities (Teater, 2011) to the media, employers, and caseworkers (Jarrett, 1996). Therefore, any effort toward addressing this issue should be broad-based. The media in particular could play a paramount role in conveying positive stories about welfare, thereby decreasing stigma (Gans, 1995; Jarrett; 1996). For instance, journalism played a crucial role in paving the 
path to the War on Poverty (WOP) agenda (Keefe, 2010; Skidmore, 2009). This began in 1962 with the publication of The Other America: Poverty in the United States by political activist and radio commentator Michael Harrington. Harrington's (1962) work focused on dilapidated communities in which 40 to 50 million Americans lived. In 1963, influential journalist Dwight Macdonald put Harrington's (1962) work in the political spotlight through a review of the book in The New Yorker. By reading this popular periodical, President Kennedy came across Harrington’s (1962) work and the deplorable living conditions for almost half of the nation.

Although Kennedy had also observed poverty first-hand in West Virginia during a 1960 campaign event, it was Macdonald's review of Harrington's work that prompted the president to act (Keefe, 2010). President Kennedy ordered members of his government to start drafting a plan to address poverty in America - a plan that his successor Lyndon Johnson expanded under the "Great Society" project. Hence, the media was instrumental in raising awareness about poverty, an indispensable step for the passage of the WOP programs in the 1960s (Keefe, 2010; Skidmore, 2009).

Under the entitlement approach, the federal government will also have to invest more on antipoverty interventions and assert more control over their implementation. More important, the government should adopt a new measure of poverty which agglomerates all anti-poverty programs. This is arguably the most direct way to measure the full impact of these programs on poverty reduction. The current official poverty measure does not account for the federal welfare programs, both cash and in-kind. It is time for policymakers to choose a more reflective tool. For example, when taken into consideration in poverty calculation, three lower-tier means-tested programs - SNAP, 
HCV, and TANF - lifted 15.6 million Americans out of poverty in 2012, including 7.1 million children. For the same fiscal year, these programs also raised 7 million people out of deep poverty, including 2.8 million children (Sherman \& Trisi, 2015).

By all accounts, the federal government seems to fully adopt neither a strong labor market nor a system of entitlement programs. In other words, the federal government is just adopting parts of each of these two approaches. If the government continuously attempts to win both ways by misfiring on both the labor market and the welfare state, then low-income households will continue to find themselves in economic limbo. Indeed, these households will lose both ways. So it is important for the government to define how the problem of poverty should be addressed. The current research proposes a strong labor market and/or a welfare state as solution. Anything in between could be detrimental to the very people that policymakers claim to help.

In fact, claiming to help people and actually helping them are two different things. There had not been much social mobility for the welfare recipients over the 5-year span of the current study. Could this be a result of the ruling class regulating the poor? Through their social control thesis described earlier, Piven and Cloward (1971) argued that welfare programs, despite their claims, are not really intended to help the poor. Rather, the architects of these programs want to assert control over the poor, shaping their behavior, and keeping them down. The current state of the welfare system seems to support the regulating the poor theory advanced by Piven and Cloward in 1971. After all, Moffitt (2015) found that the existing American welfare system is more beneficial to households with higher income than those with lower income. The government can always redeem itself by adopting one of the two policy recommendations mentioned in 
this research. This way, the government would send the right signal that its goal is to help the poor progress through the social pipeline.

Implications for practice. Human services workers can learn from these findings in serving poor individuals and families. More specifically, the findings could help social welfare organizations and workers better understand why welfare clients sometimes fail to meet some expectations with respect to employment. The findings compel workers to conclude that the system does not provide all the ingredients necessary for low-income people to become financially independent. Public assistance itself is disempowering for beneficiaries, staff, and organizations. From a participant's perspective, the mechanisms of the welfare programs prevent clients from developing a sense of worth and personal agency (Kerbo, 1976). Instead, the requirements for participation in these programs tend to diminish participants' conceptions about their own capabilities. These clients usually develop mistrust toward the government because of the tiring and devaluing process of merely getting services. This process of disempowerment is consistent with the letter and spirit of the culture of poverty theory upon which most welfare programs are crafted and implemented. As mentioned earlier, the culture of poverty theory seeks to shift the blame on the poor, making them look lazy in the eyes of the public. As Ryan (1976) would argue, however, the poor should not bear the blame for situations that are above and beyond their power.

Disempowerment takes place when people make several attempts to secure employment that turn out to be unsuccessful. Disempowerment also occurs when a welfare recipient working for a landscaping company cuts grass for the whole day under blistering sunrays only to earn a wage of 9 or 10 dollars per hour. Such a wage is not 
enough for workers to bring food on the table or put a roof over the heads of their families. Disempowerment also happens when a poor client on welfare has to settle for part-time jobs. Part-time jobs with no fringe benefits are tough to keep. With a decline in the adjusted value of the federal minimum wage, hardworking individuals may end up not having enough to support their families. In other words, as jobs in the current labor market provide no decent wages and fringe benefits, it could be said that the workplace has left hard-working individuals and their families and not the reverse. Breitkreuz and Williamson (2012) used the term "self-sufficiency trap" to lament the lack of sustainable workforce conditions for the poor to achieve the work-centered goal of social welfare policies.

From a caseworker's perspective, there is usually not enough time devoted to the assessment and reassessment of clients' situations. Usually, eligibility workers abide by the requirements of the job by completing applications for as many welfare clients as possible. That is, their jobs may be constrained by requirements to act on a given number of applications in a day.

From an organization perspective, the situation is not different. There happens to be a lack of efforts from human service organizations directed at empowering staff for a better relationship with clients. The business-minded approach adopted by social service organizations precludes them from considering welfare recipients as an equally important element of the equation. During the late 1960s/early 1970s services and payments were separated in AFDC. TANF with its emphasis on services to promote employment would seem to provide an opportunity to increase the attention to service. The emphasis, however, has been on compliance rather than an effort to understand the client. Hence, 
the main purpose of human service agencies is to satisfy the requirements imposed by the funders. Antipoverty foundations should bring the cause of the poor to the front stage, forging relevant discussions and providing funding for research on economic selfsufficiency.

Thus, the findings call upon human services workers to mobilize for advocacy on behalf of the poor. Since the Reagan administration, advocacy on behalf of the poor has seemed to enter an era of muteness (Hasenfeld \& Garrow, 2012). This era is characterized by a sense of powerlessness which prevents public assistance recipients, social workers, and human services administrators from making their voices heard. If the goal of the Reagan administration was to eventually extinguish the advocacy flame among social policy practitioners, there is no doubt that this administration was successful in doing so. In effect, social advocacy on behalf of disadvantaged populations is no longer supported by famous advocacy groups who once championed their cause. Indeed, some leaders of these nonprofit organizations decided to abandon the fight or simply change their focus (Baumgartner et al. 2009, p. 256). These findings call for a concerted effort from clients, caseworkers and program administrators and all other stakeholders toward bettering the conditions of the poor through empowerment and advocacy.

As a concept, advocacy has been at the center of the social work field. Since its inception a century ago, the social work profession has pledged a long-term commitment to social justice. In fact, the core values and principles of the profession as well as its Code of Ethics compel social workers to advocate with and on behalf of oppressed populations (National Association of Social Workers [NASW], 2008). Defending the 
cause of socio-economically disadvantaged groups has been the hallmark of social work throughout history. This has been what sets the field apart from other disciplines. Social workers are trained to become advocates for the poor and are expected to play that role whenever possible. Social workers need to stand up and speak out against social policies that cause prejudice to clients, staff, organizations and the greater society.

Elsewhere, it would be beneficial for the country to adopt preventive measures and a more client-centered approach in social welfare. Hawkins (2006) recommended that social workers embrace a preventive approach toward social problems. This approach should be based on collaborative efforts between social workers and community leaders at all levels of governance and target the well-being of individuals. The Unites States takes credit for implementing Social Security in 1935, which has since prevented most elders from dropping into poverty. There are still poor older people, but far less than in earlier decades. The Old Age Insurance (OAI) Program has been credited with reducing poverty among older people, as a result of a half century of expanding coverage and benefits after 1935. It should be noted that OAI is a universal, not means-tested, program.

What stood alone in the 1935 law was its purpose. It is a poverty-prevention approach among the elderly population. So the nation can look for inspiration in its own past to counteract poverty though preventive measures. Meanwhile, in order to increase the probability for employment among welfare recipients, there should be a more client-centered approach where individuals can be guided towards their own areas of interest. In addition, social workers should use their person-in-environment assessment skills to detect potential barriers to employment. With adequate support, 
recipients will eventually overcome these barriers to join the labor market (Banerjee \& Damman, 2013).

Implications for social work education. The findings can be used in classroom environments to prepare social work students for inevitable encounters with poor welfare recipients. Students should learn not to be a priori judgmental toward clients who struggle economically. Given the level of unpopularity of welfare in the mainstream media, some social work students may harbor preconceived ideologies against welfare recipients. Thus the results of this research can be utilized by students to debunk stigma in their quest to empower and advocate on behalf of their clients. The findings also resonate with KrumerNevo, Weiss-Gal, and Monnickendam's (2009) plea for poverty-aware courses in social work education. The findings provide empirical evidence which can be utilized to corroborate or refute certain welfare-related claims within the classroom. For example, as mandated by the Council on Social Work Education (CSWE), social policy courses cover several areas of poverty, namely theoretical perspectives and historical development of welfare programs. When discussing these topics, policy instructors can bring the findings of this research to stimulate critical thinking within the classroom. The findings can also be brought into legislative advocacy classrooms where the focus is usually on raising awareness about public policies that adversely impact people, primarily at macro levels. Moreover, schools can also organize poverty-related symposiums, colloquiums, and conferences. Hence, social work professors and field instructors can build on these findings to raise awareness about the plight of the poor as recommended by the profession's values and ethics. 


\section{Limitations}

As is true for all studies, this research investigation is not exempt from limitations. Underreporting and seam bias were two major shortcomings associated with this study. These were of methodological sources and therefore beyond the researcher's ability to control them. Indeed, researchers using secondary data may often find themselves powerless vis-à-vis some methodological limitations related to the data collected in the first place. In addition to the two limitations above, which are inherent to the original data collection, this study is limited in terms of its timeframe, model, variable, and lack of randomization. These limitations pertain to model specification and research design. All limitations in this study are described below.

Underreporting. According to Gundersen and Kreider (2008), self-reported data may contain inaccurate information, as interviewees may choose to underreport benefits, assets and earnings. Indeed, there is a tendency or a belief on the part of many respondents that doing so would jeopardize their eligibility for benefits. The social safety net in America does not encourage savings and accumulation of assets because of its counterproductive program eligibility requirements (Hurst \& Ziliak, 2001; Sherraden, 1991). Hence, households in the intervention group were probably more likely to underreport their income, especially to a government surveyor. This has to do with the fear of losing benefits due to too much income, a concern not applicable to households who opted against receiving welfare. The latter group of households arguably would be comfortable reporting their income in a comparatively more accurate fashion. Therefore, intervention group respondents may have earned as much income as or even more 
income than their counterparts in the control group, but all this may have been undermined with underreporting.

Seam bias. Seam bias has been identified as the greatest weakness of the SIPP longitudinal data (Burkhead \& Coder, 1985; Coder, Burkhead, Feldman-Harkins, \& McNeil, 1987; Hill, 1994; Kalton \& Miller, 1991; Martini, 1989; Moore, 2008;

Ryscavage, 1993; Weidman, 1986; Young, 1989; Weinberg, 2002). By definition, seam bias refers to "a pronounced tendency for reported program turnover to occur between waves more often than within waves" (Czajka, 1983, p. 93). That is, longitudinal survey estimates tend to display striking inaccuracies mostly between the last month of a wave and the beginning of the next one. As of the 2004 panel, however, SIPP has improved the interview questionnaires in an attempt to address its seam bias. SIPP surveyors used dependent interviewing techniques to prompt respondents toward recalling and reviewing pertinent responses provided during a previous wave in order elicit more accurate answers. Dependent interviewing strategies have significantly improved the 2004 and 2008 SIPP Panels, but could not eliminate the seam bias completely (Moore et al., 2008).

Study timeframe. Arguably, the five-year timeframe within which this research was conducted is too short to determine whether self-sufficiency was maintained or not. That is, participating households that did not attain and maintain economic selfsufficiency during this five-year period are not necessarily condemned in their current situation. These households may well have become economically self-reliable shortly after the end of the study. Similarly, households that have reached and maintained economic independence over the course of the study may have relapsed in the months or years that followed the predetermined termination of the study. Therefore, the results of 
this research could have been different had the timeframe been ten or twenty years instead of just five years.

Model limitation. Although accepted as the appropriate data analysis model for this particular investigation, binary logistic regression sacrificed the precision of the data. For example, participating households with a monthly income of 0 were classified within the same "non-self-sufficient" bracket as those with a monthly income of 150 percent of the FPL. In the same vein, respondents whose monthly household income was 151 percent of the FPL were grouped together with those whose monthly income way exceeded that threshold to form the self-sufficient bracket. In other words, by limiting the outcome variable to just two categories, binary logistic regression excludes crucial information that could be used to differentiate sub-groups of survey respondents and scrutinize multiple layers of self-sufficiency.

Variable limitation. This study is limited by the fact that the selection of variables is limited to those available in the SIPP dataset; thus other potential predictors of self-sufficiency could not be investigated. For example, the 2008 SIPP Panel did not include key welfare programs such as the EITC — one of the nation's biggest and most direct weapons against poverty. The EITC dispatched about 67 billion dollars to more than 27 million working families and individuals in 2015, lifting 6.5 million people out of poverty in the process, including 3.3 million children (Center on Budget and Policy Priorities, 2016; US Internal Revenue Service, 2017). So it would be interesting to know whether the inclusion of EITC would make a difference in self-sufficiency outcomes for welfare recipients. Further, the survey data collection method does not allow for rich, indepth analysis of respondents' perspectives and perceptions. 
Lack of randomization. Because the participants were not randomly assigned into the intervention group and the control group, this study does not have the legs to withstand inferential scrutiny. Hence, the quasi-experimental design limits the ability to draw causal conclusions.

\section{Recommendations for Future Research}

Future research endeavors should attempt to address the limitations raised in the current study. In particular, the use of administrative data can be helpful in thwarting or counteracting possible biases associated with underreporting. It is worth noting that experimental designs might not be suitable for large-scale welfare studies on ethical grounds. That is, it would unethical to voluntarily withhold benefits from participants in the control group for a considerable period of time. Thus, quasi-experimental studies are highly encouraged. Finally, researchers interested in replicating this study could consider using the upcoming 2014 SIPP Panel. 


\section{REERENCES}

Aber, J. L., Bennett, N. G., Conley, D. C., \& Li, J. (1997). The effects of poverty on child health and development. Annual Review of Public Health, 18(1), 463-483.

Administration for Children and Families (2014). AFDC caseload data 1960 - 1995. Retrieved from https://www.acf.hhs.gov/ofa/resource/afdc-caseload-data-19601995

Aigner, S. M. (1982). Social development and mass society: Iowa. Social Service Review, 56(3), 375-392.

Albritton, R. B. (1979). Social amelioration through mass insurgency? A reexamination of the Piven and Cloward thesis. American Political Science Review, 73(04), 1003-1011.

Almond, D., Hoynes, H. W., \& Schanzenbach, D. W. (2011). Inside the war on poverty: The impact of food stamps on birth outcomes. The Review of Economics and Statistics, 93(2), 387-403.

Amenta, E. (1998). Bold relief: Institutional politics and the origins of modern American social policy. Princeton, NJ: Princeton University Press.

Anderson, S., Leventhal, T., \& Dupéré, V. (2014). Exposure to neighborhood affluence and poverty in childhood and adolescence and academic achievement and behavior. Applied Developmental Science, 18(3), 123-138. doi:10.1080/10888 691.2014.924355

Ansalone, G. (2001). Schooling, tracking, and inequality. Journal of Children and Poverty, 7(1), 33-47.

Apel, R. J., \& Sweeten, G. (2010). Propensity score matching in criminology and criminal justice. In A. R. Piquero \& D. Weisburd (Eds.), Handbook of quantitative criminology (pp. 543-562). New York, NY: Springer.

Aratani, Y., Lu, H., \& Aber, J. L. (2014). Shrinking the public safety net or helping the poor play by the rules? The changes in the state-level policies that affected lowincome families with children in the welfare reform era: 1994-2002. American Journal of Evaluation, 35(2), 189-213.

Ashmore, S. Y. (2008). Carry it on: The war on poverty and the civil rights movement in Alabama, 1964-1972. Athens: University of Georgia Press.

Ashraf, N., Camerer, C. F., \& Loewenstein, G. (2005). Adam Smith, behavioral economist. The Journal of Economic Perspectives, 19(3), 131-145. 
Attree, P. (2006). The social costs of child poverty: A systematic review of the qualitative evidence. Children \& Society, 20(1), 54-66.

Baicker, K., \& Finkelstein, A. (2011). The effects of Medicaid coverage-Learning from the Oregon experiment. New England Journal of Medicine, 365(8), 683-685.

Baicker, K., Finkelstein, A., Song, J., \& Taubman, S. (2014). The impact of Medicaid on labor market activity and program participation: Evidence from the Oregon health insurance experiment. The American Economic Review, 104(5), 322-328.

Ballou, J. (2014). Work incentive policies: An evaluation of their effects on welfare women's choice. Journal of Sociology \& Social Welfare, 4(6), 850-863.

Bamberger Jr, E. C. (1965). Legal Services Program of the Office of Economic Opportunity. Notre Dame Law Review, 41 (6), 847-852.

Bamfield, L. (2007) Born unequal: Why we need a progressive pre-birth agenda. London: Fabian Society.

Banerjee, M. M., \& Damman, J. L. (2013). The capabilities approach: A framework to understand and enhance TANF recipients' employability. Journal of Poverty, 17(4), 414-436. doi:10.1080/10875549.2013.833162

Banovcinova, A., Levicka, J., \& Veres, M. (2014). The impact of poverty on the family system functioning. Procedia-Social and Behavioral Sciences, 132, 148-153.

Baraldi, A. N., \& Enders, C. K. (2010). An introduction to modern missing data analyses. Journal of School Psychology, 48(1), 5-37.

Barth, R. P., Wildfire, J., \& Green, R. L. (2006). Placement into foster care and the interplay of urbanicity, child behavior problems, and poverty. American Journal of Orthopsychiatry, 76(3), 358-366.

Bauman, K. J. (1999a). Extended measures of well-being: Meeting basic needs. Retrieved from https://www.census.gov/prod/99pubs/p70-67.pdf

Bauman, K. J. (1999b). Shifting family definitions: The effect of cohabitation and other nonfamily household relationships on measures of poverty. Demography, 36(3), 315-325.

Bauman, R. (2008). Race and the war on poverty: From Watts to East L.A. Norman: University of Oklahoma Press. 
Baumgartner, F. R., Berry, J. M., Hojnacki, M., Leech, B. L., \& Kimball, D. C. (2009). Lobbying and policy change: Who wins, who loses, and why. Chicago, IL: University of Chicago Press.

Beardwood, R. (1968). The southern roots of the urban crisis. Fortune, 78(2) 80-87.

Belsley, D. A., Kuh, E. \& Welsch, R. E. (1980). Regression diagnostics: Identifying influential data and sources of collinearity. New York, NY: John Wiley.

Bennett, D. A. (2001). How can I deal with missing data in my study? Australian and New Zealand Journal of Public Health, 25(5), 464-469.

Bertrand, M., Mullainathan, S., \& Shafir, E. (2004). A behavioral-economics view of poverty. The American Economic Review, 94(2), 419-423.

Besharov, D. J., \& Laumann, L. A. (1997). Don't call it child abuse if it's really poverty. Journal of Children and Poverty, 3(1), 5-36.

Betz, M. (1974). Riots and welfare: Are they related? Social Problems, 21(3), 345-55.

Betzelt, S., Bothfeld, S., \& Béraud, M. (2011). Activation and labour market reforms in Europe: Challenges to social citizenship. Work and welfare in Europe. Houndmills: Palgrave Macmillan.

Beverly, S. G. (2001). Material hardship in the United States: Evidence from the survey of income and program participation. Social Work Research, 25(3), 143-151.

Bhaskaran, K., \& Smeeth, L. (2014). What is the difference between missing completely at random and missing at random? International Journal of Epidemiology, 43(4), 1336-1339.

Bielby, W. T., \& Baron, J. N. (1986). Men and women at work: Sex segregation and statistical discrimination. American Journal of Sociology, 91(4), 759-799.

Bilenkisi, F., Gungor, M. S., \& Tapsin, G. (2015). The impact of household heads' education levels on the poverty risk: The evidence from Turkey. Educational Sciences: Theory \& Practice, 15(2), 337-348.

Bishaw, A., \& Glassman, B. (2016). Poverty 2014 and 2015. Retrieved from https://www.census.gov/content/dam/Census/library/publications/2016/demo/acsb r15-01.pdf

Bitler, M. P., \& Currie, J. (2005). Does WIC work? The effects of WIC on pregnancy and birth outcomes. Journal of Policy Analysis and Management, 24(1), 73-91. 
Bitler, M., Hoynes, H., \& Kuka, E. (2014). Child poverty and the great recession in the United States. Retrieved from http://www.unicef-irc.org/publications/pdf liwp_2014_11.pdf

Bjelland, M. J., Bruyère, S. M., von Schrader, S., Houtenville, A. J., Ruiz-Quintanilla, A., \& Webber, D. A. (2010). Age and disability employment discrimination: Occupational rehabilitation implications. Journal of Occupational Rehabilitation, 20(4), 456-471.

Blank, R. M. (1997). It takes a nation: A new agenda for fighting poverty. Princeton, NJ: Princeton University Press.

Blank, R. M., \& Kovak, B. (2008). Policy brief: Helping disconnected single mothers. Ann Arbor, MI: National Poverty Center.

Blank, R. M., \& Kovak, B. (2009). The growing problem of disconnected single mothers. In C. J. Heinrich \& J. K. Scholz (Eds.), Making the work-based safety net work better: Forward-looking policies to help low-income families (pp. 227-252). New York: Russell Sage Foundation.

Blank, R., \& Ruggles, P. (1996). When do women use AFDC and food stamps? The dynamics of eligibility vs. participation. Journal of Human Resources, 24(1), 5487.

Bloom, D., Loprest, P. J., \& Zedlewski, S. R. (2011). TANF recipients with barriers to employment. Retrieved from https://www.acf.hhs.gov/sites/default/files/opre/ barries_employ.pdf

Boland, B. (1973). Participation in the aid to families with dependent children program $(A F D C)$. Washington, D.C.: GPO.

Bollinger, C. R., \& Hirsch, B. T. (2013). Is earnings nonresponse ignorable? Review of Economics and Statistics, 95(2), 407-416.

Bonett, D. G., \& Price, R. M. (2015). Varying coefficient meta-analysis methods for odds ratios and risk ratios. Psychological methods, 20(3), 394-406.

Boushey, H. (2014). A new agenda for American families and the economy. Dissent, 61(3), 49-53.

Bowen, G. L., Desimone, L. M., \& McKay, J. K. (1995). Poverty and the single mother family: A macroeconomic perspective. Marriage and Family Review, 20(1-2), $115-142$. 
Bradley, R. H., \& Corwyn, R. F. (2002). Socioeconomic status and child development. Annual Review of Psychology, 53(1), 371-399.

Bradshaw, J. (2002). Child poverty and child outcomes. Children \& Society, 16(2), 131140.

Breitkreuz, R. S., \& Williamson, D. L. (2012). The self-sufficiency trap: A critical examination of welfare-to-work. Social Service Review, 86(4), 660-689.

Bremner, R. H. (1956). The discovery of poverty in the United States. New York, NY: New York University Press.

Brooks-Gunn, J. (1997). Neighborhood poverty: Context and consequences for children. New York, NY: Russell Sage Foundation.

Buchholz, S. W., Linton, D. M., Courtney, M. R., \& Schoeny, M. E. (2016). Systematic reviews. In J. R. Bloch, M. R. Courtney, \& M. L. Clark (Eds.), Practice-based clinical inquiry in nursing: Looking beyond traditional methods for PhD and DNP research (45-66). New York, NY: Springer Publishing Company.

Buchmann, C., \& DiPrete, T. A. (2006). The growing female advantage in college completion: The role of family background and academic achievement. American sociological review, 71(4), 515-541.

Burkhead, D., \& Coder, J. (1985). Gross changes in income recipiency from the survey of income and program participation. Washington, DC: American Statistical Association.

Butterfield, A. K. J., Rocha, C. J., \& Butterfield, W. H. (2010). The dynamics of family policy. Chicago, IL: Lyceum Books.

Buvinic, M., \& Gupta Rao, G. (1997). Female-headed households and female-maintained families: Are they worth targeting to reduce poverty in developing countries? Economic Development \& Cultural Change, 45(2), 258-280.

Campbell, A. L. (2014). Trapped in America's safety net: One family's struggle. Chicago, IL: University of Chicago Press.

Campbell, D., \& Wright, J. (2005). Rethinking welfare school attendance policies. Social Service Review, 79(1), 2-28.

Campbell, F. A., Pungello, E. P., Miller-Johnson, S., Burchinal, M., \& Ramey, C. T. (2001). The development of cognitive and academic abilities: Growth curves from an early childhood educational experiment. Developmental Psychology, $37(2), 231-242$. 
Campbell, T. D. (1971). Adam Smith's science of morals. Glasgow, Scotland: University of Glasgow Social and Economic Studies, New Series, no. 21.

Campbell, T. D., \& Ross, I. S. (1981). The utilitarianism of Smith's policy advice. Journal of the History of Ideas, 42, 73-92.

Cancian, M. \& Meyer, D. R. (2004). Alternative measures of economic success among TANF participants: Avoiding poverty, hardship, and dependence on public assistance. Journal of Policy Analysis \& Management, 23(3), 531-548.

Cancian, M., Han, E., \& Noyes, J. L. (2014). From multiple program participation to disconnection: Changing trajectories of TANF and SNAP beneficiaries in Wisconsin. Children and Youth Services Review, 42, 91-102.

Caputo, R. K. (1997). Escaping poverty and becoming self-sufficient. Journal of Sociology and Social Welfare, 24(3), 5-23.

Carter, R., \& Tippins, S. (2012). American recovery and reinvestment act of 2009: A historical perspective. Insights to a Changing World Journal, (3), 43-62.

Center on Budget \& Policy Priorities (2011). Poverty and financial distress would have been substantially worse in 2010 without government action, new census data show. Retrieved from http://www.cbpp.org/files/11-7-11pov.pdf

Center on budget and Policy Priorities (2015). Where do our federal tax dollars go? Retrieved from http://www.cbpp.org/sites/default/files/atoms/files/4-14-08tax.pdf

Cepeda, M. S., Boston, R., Farrar, J. T., \& Strom, B. L. (2003). Comparison of logistic regression versus propensity score when the number of events is low and there are multiple confounders. American Journal of Epidemiology, 158(3), 280-287.

Chamlin, M. (1992). Intergroup threat and social control: Welfare expansion among states during the 1960s and 1970s. In A. Liska (Ed.), Social threat and social control (pp. 151-164). Albany, NY: State University of New York Press.

Chamlin, M. B., Burek, M. W., \& Cochran, J. K. (2007). Welfare policy as social control: A specific test of the Piven and Cloward thesis. Criminal Justice Policy Review, $18(2), 132-152$.

Chang, C. (2015). Seven lessons about child poverty. Challenge, 58(3), 262-282.

Chapin, F. S. (1947). Experimental designs in sociological research. Harper, New York. 
Cheng, H. G., \& Phillips, M. R. (2014). Secondary analysis of existing data:

Opportunities and implementation. Shanghai Archives of Psychiatry, 26(6), 371375. doi:10.11919/j.issn.1002-0829.214171

Clampet-Lundquist, S., \& Massey, D. S. (2008). Neighborhood effects on economic selfsufficiency: A reconsideration of the moving to opportunity experiment 1. American Journal of Sociology, 114(1), 107-143.

Clinton, Bill (1994). State of the Union address (January 25, 1994). Retrieved from http://millercenter.org/president/clinton/ speeches/speech-3437

Clinton, Bill (2006). How we ended welfare, together. Retrieved from http://www.nytimes. com/2006/08/22/opinion/22clinton.html?_r=0

Cochran, T. C. (1985). Challenges to American values: Society, business, and religion. New York, NY: Oxford University Press.

Coder, J., Burkhead, D., Feldman-Harkins, A., \& McNeil J. (1987). Preliminary data from the SIPP 1983-84 longitudinal research file. Washington, DC: United States Census Bureau.

Conger, R. D., Conger, K. J., Elder Jr., G. H., Lorenz, F. O., \& Simons, R. L. (1994). Economic stress, coercive family process and developmental problems of adolescents, Child Development, 65: 541-561.

Conger, R. D., Wallace, L. E., Sun, Y., Simons, R. L., McLoyd, V. C., \& Brody, G. H. (2002). Economic pressure in African American families: A replication and extension of the family stress model. Developmental Psychology, 38(2), 179-193.

Conlan, T. J. (2010). From new federalism to devolution: Twenty-five years of intergovernmental reform. Washington, DC: Brookings Institution Press.

Correll, S. J., \& Benard, S. (2007). Getting a job: Is there a motherhood penalty? American Journal of Sociology, 112(5), 1297-1339.

Czajka, J. (1983). Subannual income estimation. In M. David (Ed.), Technical, conceptual, and administrative lessons of the income survey development program (ISDP). New York, NY: Social Science Research Council.

Czajka, J. L., \& Denmead, G. (2008). Income data for policy analysis: A comparative assessment of eight surveys. Washington, DC: Mathematica Policy Research.

Dahl, G. B., \& Lochner, L. (2012). The impact of family income on child achievement: Evidence from the earned income tax credit. American Economic Review, 102(5), 1927-1956. 
Danziger, S. K., \& Danziger, S. (1995). Child poverty, public policy and welfare reform. Children and Youth Services Review, 17(1-2), 1-10.

Danziger, S. K., \& Seefeldt, K. S. (2003). Barriers to employment and the 'hard to serve:' Implications for services, sanctions, and time limits. Social Policy \& Society, 2(2), 151-160. doi: 10.1017/S1474746403001210

Daugherty, R. H., \& Barber, G. M. (2001). Self-sufficiency, ecology of work, and welfare reform. Social Service Review, 75(4), 662-675.

Davis, K. S. (1969). The paradox of poverty in America. New York, NY: H. W. Wilson Company.

De Silva, I., \& Sumarto, S. (2015). Dynamics of growth, poverty and human capital: Evidence from Indonesian sub-national data. Journal of Economic

Development, 40(2), 1-33.

Dehejia, R. H., \& Wahba, S. (2002). Propensity score-matching methods for nonexperimental causal studies. Review of Economics \& Statistics, 84(1), 151161.

DeNavas-Walt, C., \& Proctor, B. D. (2014). Income and poverty in the United States: 2013. Retrieved from http://www.census.gov/content/dam/Census/library/ publications /2014/ demo/p60-249.pdf

DeNavas-Walt, C., \& Proctor, B. D. (2014). Income, poverty, and health insurance coverage in the United States: 2013. Retrieved from http://www.census.gov/ content /dam/Census/ library/publications/2014/demo/p60-249.pdf

DeNavas-Walt, C., \& Proctor, B. D. (2015). Income, poverty, and health insurance coverage in the United States: 2014. Retrieved from https://www.census.gov/ content/dam/ Census/ library/publications/2015/demo/p60-252.pdf

DeNavas-Walt, C., Proctor, B. D., \& Lee, C. H. (2006). Income, poverty, and health insurance coverage in the United States: 2005. Retrieved from http://www. census.gov/ prod/2006pubs/p60-231.pdf

DeNavas-Walt, C., Proctor, B. D., \& Smith, J. C. (2008). Income, poverty, and health insurance coverage in the United States: 2007. Retrieved from https://www. census.gov/prod/ 2008pubs/p60-235.pdf

DeNavas-Walt, C., Proctor, B. D., \& Smith, J. C. (2009). Income, poverty, and health insurance coverage in the United States: 2008. Retrieved from https://www.census.gov/ prod/2009pubs/p60-236.pdf 
DeNavas-Walt, C., Proctor, B. D., \& Smith, J. C. (2010). Income, poverty, and health insurance coverage in the United States: 2009. Retrieved from https://www.census.gov/ prod/2010pubs/p60-238.pdf

DeNavas-Walt, C., Proctor, B. D., \& Smith, J. C. (2011). Income, poverty, and health insurance coverage in the United States: 2010. Retrieved from http://www.census.gov/prod/2011 pubs/p60-239.pdf

DeNavas-Walt, C., Proctor, B. D., \& Smith, J. C. (2012). Income, poverty, and health insurance coverage in the United States: 2011. Retrieved from https://www.census.gov/prod/ 2012pubs/p60-243.pdf

DeNavas-Walt, C., Proctor, B. D., \& Smith, J. C. (2013). Income, poverty, and health insurance coverage in the United States: 2012. Retrieved from https://www.census.gov/prod /2013pubs/p60-245.pdf

Derr, M. K., \& Brown, E. (2015). Improving program engagement of TANF families: Understanding participation and those with reported zero hours of participation in work activities. Washington, DC: Office of Planning, Research and Evaluation.

Diggle, P. J., Liang, K. Y., \& Zeger, S. L. (1995). Analysis of longitudinal data. New York, NY: Oxford University Press.

Doar, R., Bowman, K., \& O’Neil, E. (2016). Poverty survey: Attitudes toward the poor, poverty, and welfare in the United States. Retrieved from http://www.aei.org/publication/2016-poverty-survey/

Dohmen, T. J. (2005). Housing, mobility and unemployment. Regional Science and Urban Economics, 35(3), 305-325.

Dong, Y., \& Peng, C. Y. J. (2013). Principled missing data methods for researchers. SpringerPlus, 2(1), 1-17. doi:10.1186/2193-1801-2-222.

Duflo, E. (2006). Poor but rational? In A. V. Banerjee, R. Benabou, \& D. Mookherjee, Understanding poverty (pp. 367-378). New York, NY: New York University Press.

Duncan, G. J., \& Brooks-Gunn, J. (2000). Family poverty, welfare reform, and child development. Child Development, 71(1), 188-196.

Durkheim, E. (1897, 1951). Suicide: A study in sociology. Glencoe, IL: Free Press.

Durman, E. (1973). Have the poor been regulated? Toward a multivariate understanding of welfare growth. Social Service Review, 47(3), 339-359. 
Dworsky, A., \& Courtney, M. E. (2007). Barriers to employment among TANF applicants and their consequences for self-sufficiency. Families in Society: The Journal of Contemporary Social Services, 88(3), 379-389. doi:10.1606/10443894.3647

Edin, K., \& Lein, L. (1996). Work, welfare, and single mothers' economic survival strategies. American Sociological Review, 62(2), 253-266.

Edin, K., \& Lein, L. (1997). Making ends meet: How single mothers survive welfare and low-wage work. New York, NY: Russell Sage Foundation.

Eissa, N., \& Hoynes, H. W. (2006). Behavioral responses to taxes: Lessons from the EITC and labor supply. In J. M. Poterba (Ed.), Tax policy and the economy (pp. 73-110). Cambridge, MA: MIT Press.

Enders, C., Dietz, S., Montague, M., \& Dixon, J. (2006). Modern alternatives for dealing with missing data in special education research. In T. E. Scruggs \& M. A. Mastropieri (Eds.), Advances in learning and behavioral disorders (pp. 101-130). New York, NY: Elsevier.

Ermisch, J., Francesconi, M., \& Pevalin, D. J. (2001). Outcomes for children of poverty. Retrieved from https:/www.researchgate.net/profile/David_Pevalin/publication/ 265149837_Outcomes_for_Children_in_Poverty/links/54191a470cf2218008bf50 44.pdf

Evans, G. W., \& Fuller-Rowell, T. E. (2013). Childhood poverty, chronic stress, and young adult working memory: the protective role of self-regulatory capacity. Developmental Science, 16(5), 688-696. doi:10.1111/desc.12082

Evans, W. N., \& Garthwaite, C. L. (2014). Giving mom a break: The impact of higher EITC payments on maternal health. American Economic Journal: Economic Policy, 6(2), 258-290.

Farley, O. W., Smith, L. L., \& Boyle, S. W. (2012). Introduction to social work (12 ed.). Boston, MA: Pearson Education.

Farmbry, K. (2014). The war on poverty: A retrospective. London, UK: Lexington Books.

Farrar, D. E., \& Glauber, R. R. (1967). Multicollinearity in regression analysis: The problem revisited. The Review of Economic and Statistics, 49(1), 92-107.

Feagin, J., \& Hahn, H. (1973). Ghetto revolts: The politics of violence in American cities. New York, NY: Macmillan. 
Fellowes, M. C., \& Rowe, G. (2004). Politics and the new American welfare states. American Journal of Political Science, 48(2), 362-373.

Figlio, D., Hamersma, S., \& Roth, J. (2009). Does prenatal WIC participation improve birth outcomes? New evidence from Florida. Journal of Public Economics, 93(1), 235-245.

Finegold, K., Wherry, L., \& Schardin, S. (2004). Block grants: Historical overview and lessons learned. Retrieved from file://C:/Users/user/Downloads/Finegold\%20et\% 20al\%202004\%20(1).pdf

Fisher, G. M. (1992). Poverty guidelines for 1992. Social Security Bulletin, 55(1), 43-46.

Fisher, I. (1930. The theory of interest. New York, NY: Macmillan.

Fleckenstein, T. (2012). The politics of labour market reforms and social citizenship in Germany. West European Politics, 35(4), 847-868. doi:10.1080/01402382.2012. 682348

Flouri, E., Midouhas, E., \& Joshi, H. (2014). Family poverty and trajectories of children's emotional and behavioural problems: The moderating roles of self-regulation and verbal cognitive ability. Journal of Abnormal Child Psychology, 42(6), 10431056. doi:10.10 07/s10802-013-9848-3

Fraker, T., \& Moffitt, R. (1988). The effect of food stamps on labor supply: A bivariate selection model. Journal of Public Economics, 35(1), 25-56.

Fraser, N., \& Gordon, L. (1994). A genealogy of dependency: Tracing a keyword of the US welfare state. Signs: Journal of Women in Culture and Society, 19(2), 309336.

Fuligni, A. J. (1997). The academic achievement of adolescents from immigrant families: The role of family background, attitudes, and behavior. Child Development, 68(2), 351-363.

Galster, G. (2002). An economic efficiency analysis of deconcentrating poverty populations. Journal of Housing Economics, 11(4), 303-329.

Gans, H. J. (1995). The war against the poor: The underclass and antipoverty policy. New York, NY: Basic Books.

García-Gómez, P., Jones, A. M., \& Rice, N. (2010). Health effects on labour market exits and entries. Labour Economics, 17(1), 62-76. 
Gassman-Pines, A., \& Hill, Z. (2013). How social safety net programs affect family economic well-being, family functioning, and children's development. Child Development Perspectives, 7(3), 172-181.

Germany, K. B. (2007). New Orleans after the promises: Poverty, citizenship, and the search for the great society. Athens: University of Georgia Press.

Gilbert, C. E. (1966). Policy-making in public welfare: The 1962 amendments. Political Science Quarterly, 81(2), 196-224.

Gowdy, E. \& Pearlmutter, S. (1993). Economic self-sufficiency: It's not just the money. Affilia, 8(4), 368-387.

Graham, J. W., Hofer, S. M., Donaldson, S. I., MacKinnon, D. P., \& Schafer, J. L. (1997). Analysis with missing data in prevention research. In K. J. Bryant, M. Windle \& S. G. West (Eds.), The science of prevention: Methodological advances from alcohol and substance abuse research (pp. 325-366). Washington, DC: American Psychological Association.

Grant, K. E., O'Koon, J. H., Davis, T. H., Roache, N. A., Poindexter, L. M., Armstrong, M. L., et al. (2000). Protective factors affecting low-income urban African American youth exposed to stress. Journal of Early Adolescence, 20, 388-417.

Gregory, C. A., \& Deb, P. (2015). Does SNAP improve your health? Food Policy, 50, 11-19.

Grinstein-Weiss, M., Lee, J., Greeson, J. K. P., Han, C., Yeo, Y. H., \& Irish, K. (2008). Fostering low-income homeownership through individual development accounts: A longitudinal, randomized experiment. Housing Policy Debate, 19(4), 711-739.

Grinstein-Weiss, M., Sherraden, M., Gale, W. G., Rohe, W. M., Schreiner, M., \& Key, C. (2013). Long-term impacts of individual development accounts on homeownership among baseline renters: Follow-up evidence from a randomized experiment. American Economic Journal: Economic Policy, 5(1), 122-145.

Grønbjerg, K. A. (1977). Mass society and the extension of welfare, 1960-1970. Chicago, IL: University of Chicago Press.

Grubb, W. N. (1984). The price of local discretion: Inequalities for children's programs in Texas. Journal of Policy Analysis and Management 3(3), 359-372.

Gu, X. S., \& Rosenbaum, P. R. (1993). Comparison of multivariate matching methods: Structures, distances, and algorithms. Journal of Computational and Graphical Statistics, 2(4), 405-420. 
Gundersen, C., \& Kreider, B. (2008). Food stamps and food insecurity what can be learned in the presence of nonclassical measurement error? Journal of Human Resources, 43(2), 352-382.

Haitovsky, Y. (1969). Multicollinearity in regression analysis: Comment. The Review of Economics and Statistics, 51(4), 486-489.

Hall, C. C. (2008). Decisions under poverty: A behavioral perspective on the decision making of the poor. New York, NY: Princeton University.

Hall, M., Graefe, D. R., \& De Jong, G. F. (2010). Economic self-sufficiency among immigrant TANF-leavers: Welfare eligibility as a natural experiment. Social Science Research, 39(1), 78-91.

Han, C., Grinstein-Weiss, M., \& Sherraden, M. (2009). Assets beyond savings in individual development accounts. Social Service Review, 83(2), 221-244.

Hanson, J. L., Hair, N., Shen, D. G., Shi, F., Gilmore, J. H., Wolfe, B. L., \& Pollak, S. D. (2013). Family poverty affects the rate of human infant brain growth. Plos ONE, 8(12), 1-9. doi:10.1371/journal.pone.0080954

Hardcastle, D. A., Powers, P. R., \& Wenocur, S. (2011). Community practice: Theories and skills for social workers ( ${ }^{\text {rd }}$ ed.). Oxford, NY: Oxford University Press.

Harrington, M. (1962). The other America: Poverty in the United States. New York, NY: Touchstone Rockefeller Center.

Hasenfeld, Y. \& Garrow, E. E. (2012). Nonprofit human-service organizations, social rights, and advocacy in a neoliberal welfare state. Social Service Review, 86(2), 295-322.

Hasenfeld, Y. (2009). Human services administration and organizational theory. In R. J. Patti (Ed.) The handbook of human services management, $2^{\text {nd }}$ ed., (pp.53-80). Thousand Oaks, CA: Sage.

Hawkins, J. D. (2006). Science, social work, prevention: Finding the intersections. Social Work Research, 30(3), 137-152.

Hawkins, R. L. (2005). From self-sufficiency to personal and family sustainability: A new paradigm for social policy. Journal of Sociology \& Social Welfare, 32(4), 7792.

Henninger, W. \& Luze, G. (2014). Poverty, caregiver depression and stress as predictors of children's externalizing behaviours in a low-income sample. Child \& Family Social Work, 19(4), 467-479. 
Hernandez, D. C., \& Pressler, E. (2014). Accumulation of childhood poverty on young adult overweight or obese status: race/ethnicity and gender disparities. Journal of Epidemiology \& Community Health, 68(5), 478-484. doi:10.1136/jech-2013203062

Hetling, A., Hoge, G. L., \& Postmus, J. L. (2016). What is economic self-sufficiency? Validating a measurement scale for policy, practice, and research. Journal of Poverty, 20(2), 214-235.

Hicks, A., \& Swank, D. H. (1983). Civil disorder, relief mobilization, and AFDC caseloads: A reexamination of the Piven and Cloward thesis. American Journal of Political Science, 27(4), 695-716.

Hill, D. (1994). The relative empirical validity of dependent and independent data collection in a panel survey. Journal of Official Statistics, 10, 359-380.

Hofferth, S. L. (2005). Secondary data analysis in family research. Journal of Marriage and Family, 67(4), 891-907.

Holzer, H. J., Schanzenbach, D. W., Duncan, G. J., \& Ludwig, J. (2008). The economic costs of childhood poverty in the United States. Journal of Children \& Poverty, 14 (1), 41-61.

Holzer, H. J., Stoll, M. A., \& Wissoker, D. (2004). Job performance and retention among welfare recipients. Social Service Review, 78(3), 343-369.

Hong, P. Y. P., Sheriff, V. A., \& Naeger, S. R. (2009). A Bottom-up definition of selfsufficiency voices from low-income jobseekers. Qualitative Social Work, 8(3), 357-376.

Horgan, G. (2007). The impact of poverty on young children's experience of school. Layerthorpe, York: Joseph Rowntree Foundation.

Horton, N. J., \& Kleinman, K. P. (2007). Much ado about nothing: A comparison of missing data methods and software to fit incomplete data regression models. The American Statistician, 61(1):79-90. doi:10.1198/000313007X172556

Horwath, J. (2007). Child neglect: Identification and assessment. New York, NY: Palgrave Macmillan.

Howard, C. (1999). The American welfare state, or states? Political Research Quarterly, 52(2), 421-442. 
Howell, E. M., \& Kenney, G. M. (2012). The impact of the Medicaid/CHIP expansions on children a synthesis of the evidence. Medical Care Research and Review, 69(4), 372-396.

Hoynes, H. W., \& Schanzenbach, D. W. (2012). Work incentives and the food stamp program. Journal of Public Economics, 96(1), 151-162.

Hoynes, H., Miller, D., \& Simon, D. (2015). Income, the earned income tax credit, and infant health. American Economic Journal: Economic Policy, 7(1), 172-211.

Hoynes, H., Page, M., \& Stevens, A. H. (2011). Can targeted transfers improve birth outcomes? Evidence from the introduction of the WIC program. Journal of Public Economics, 95(7), 813-827.

Huber, J. (1974). Poverty, stratification and ideology. In J. Huber \& P. Chalfant (Eds.), The sociology of American poverty (pp. 1-16). Cambridge, MA: Schenkman.

Huber, J., \& Form, W. H. (1973). Income and ideology. New York, NY: Free Press.

Huffman, M. L., \& Cohen, P. N. (2004). Racial wage inequality: Job segregation and devaluation across us labor markets1. American Journal of Sociology, 109(4), 902-936.

Hurst, E., \& Ziliak, J. P. (2001). Welfare reform and household saving. Madison, WI: Institute for Research on Poverty.

Huston, A. C. (1991). Children in poverty: Child development and public policy. Cambridge: University Press.

Ibrahim, J. G., \& Molenberghs, G. (2009). Missing data methods in longitudinal studies: A Review. Test, 18(1), 1-43.

Indiana Institute for Working Families (2012). The cliff effect: One step forward, two steps back. Retrieved from http://www.incap.org/cliffeffect.html\#.WRNGXOX yuM9

Ingram, H., Schneider, A. L., \& DeLeon, P. (2007). Social construction and policy design. Theories of the Policy Process, 2, 93-126.

Irving, S. (2013). Program participation and child well-being. Washington, DC: US Census Bureau.

Isaac, L. \& Kelly, W. R. (1981). Racial insurgency, the state, and welfare expansion: Local and national level evidence from the postwar United States. American Journal of Sociology, 86(6), 1348-1386. 
Jacob, B. A., \& Ludwig, J. (2012). The effects of housing assistance on labor supply: Evidence from a voucher lottery. The American Economic Review, 102(1), 272304.

Janjua, P. Z., \& Kamal, U. A. (2011). The role of education and income in poverty alleviation: A cross-country analysis. The Lahore Journal of Economics, 16(1), 143-172.

Jarrett, R. L. (1996). Welfare stigma among low-income, African American single mothers. Family Relations, 45(4), 368-374.

Jencks, C. (1996). Can we replace welfare with work? In M. R. Darby (Ed.), Reducing poverty in America (pp. 69-81). Thousand Oaks, CA: Sage.

Jennings, E. T. (1979). Civil turmoil and the growth of welfare rolls: A comparative state policy analysis. Policy Studies Journal, 7(4), 739-745.

Johnson, E., \& Sherraden, M. S. (2007). From financial literacy to financial capability among youth. Journal of Sociology \& Social Welfare, 34(3), 119-146.

Johnson, L. B. (1964). Annual message to the congress on the state of the union. Retrieved from http://www.pbs.org/wgbh/americanexperience/features/primaryresources/lbj-union64/

Johnson, R. C. \& Corcoran, M. E. (2003). The road to economic self-sufficiency: Job quality and job transition patterns after welfare reform. Journal of Policy Analysis \& Management, 22(4), 615-639.

Joyce, T., \& Racine, A. (2005). CHIP shots: Association between the State Children's Health Insurance Programs and immunization rates. Pediatrics, 115(5), 526-534.

Joyce, T., Racine, A., \& Yunzal-Butler, C. (2008). Reassessing the WIC effect: Evidence from the pregnancy nutrition surveillance system. Journal of Policy Analysis and Management, 27(2), $277-303$.

Kahneman, D., \& Tversky, A. (1979). Prospect theory: An analysis of decision under risk. Econometrica: Journal of the Econometric Society, 47(2), 263-291.

Kaida, L. (2015). Ethnic variations in immigrant poverty exit and female employment: The missing link. Demography, 52(2), 485-511. doi:10.1007/s13524-015-0371-8

Kalton, G., \& Miller, M. (1991). The seam effect with social security income in the survey of income and program participation. Journal of Official Statistics, 7, 235245. 
Kang, H. (2013). The prevention and handling of the missing data. Korean Journal of Anesthesiology, 64(5), 402-406.

Karger, H. (2014). The bitter pill: Austerity, debt, and the attack on Europe's welfare states. Journal of Sociology \& Social Welfare, 41(2), 33-53.

Katz, M. B. (2008). The price of citizenship: Redefining the American welfare state. Philadelphia, PA: University of Pennsylvania Press.

Kaz, D. (2015). Understanding "benefits cliffs:" Implications for helping Washingtonians advance to self-sufficiency through workforce strategies. Retrieved from http://www.seattlejobsinitiative.com/wp-content/uploads/SJI_BenefitsCliffs _Report_MAR2015.pdf

Keefe, L. M. (2010). Dwight Macdonald and poverty discourse, 1960-1965: The art and power of a seminal book review. Poverty \& Public Policy, 2(2), 145-188.

Kennedy, J. F. (1962). Special message to the Congress on public welfare programs. Retrieved from http://www.presidency.ucsb.edu/ws/?pid=8758

Kerbo, H. (1976). The stigma of welfare and a passive poor. Sociology and Social Research, 60(2), 173-187.

Keynes, J. M. (1936) The General theory of employment, interest and money. London: Macmillan.

Kildal, N. \& Nilssen, E. (2011). Norwegian welfare reforms: Social contracts and activation policies. Houndmills: Palgrave Macmillan.

Kincaid, J. (1998). The devolution tortoise and the centralization hare. New England Economic Review, 13-44.

King, G., \& Nielsen, R. (2016). Why propensity scores should not be used for matching. Retrieved from http://gking.harvard.edu/files/gking/files/psnot.pdf? $\mathrm{m}=1456683191$

Kling, J. R., Liebman, J. B., \& Katz, L. F. (2007). Experimental analysis of neighborhood effects. Econometrica, 75(1), 83-119.

Kling, J. R., Liebman, J. B., Katz, L. F., \& Sanbonmatsu, L. (2004). Moving to opportunity and tranquility: Neighborhood effects on adult economic selfsufficiency and health from a randomized housing voucher experiment. Retrieved from https://papers.ssrn.com/sol3/ papers.cfm?abstract_id=588942 
Kluegel, J. R., \& Smith, E. R. (1986). Beliefs about inequality: Americans' views of what is and what ought to be. Hawthorne, NY: Aldine de Gruyter.

Knowlton, W., \& Zeckhauser, R. (1986). American society: Public and private responsibilities. Cambridge, MA: Ballinger Publishing Company.

Krumer-Nevo, M., Weiss-Gal, I., \& Monnickendam, M. (2009). Poverty-aware social work practice: A conceptual framework for social work education. Journal of Social Work Education, 45(2), 225-243.

Lee, B. J., \& Mackey-Bilaver, L. (2007). Effects of WIC and food stamp program participation on child outcomes. Children and Youth Services Review, 29(4), 501517.

Lee, H., Andrew, M., Gebremariam, A., Lumeng, J. C., \& Lee, J. M. (2014). Longitudinal associations between poverty and obesity from birth through adolescence. American Journal of Public Health, 104(5), 70-76. doi:10.2105/AJPH.2013.301806

Leicht, K. T. (2008). Broken down by race and gender? Sociological explanations of new sources of earnings inequality. Annual Review of Sociology, 34, 237-255.

Levine, P. B., \& Schanzenbach, D. W. (2009). The impact of children's public health insurance expansions on educational outcomes. Forum for Health Economics and Policy, 12(1), 1-26. doi:10.2202/ 1558-9544.1137

Levitan, S. A., Mangum, G. L., Mangum, S. L., \& Sum, A. M. (2003). Programs in aid of the poor. Baltimore, MD: Johns Hopkins University Press.

Lewis, I. A, \& Schneider, W. (1985, June/July). Hard times: The public on poverty. Public Opinion, 1-7, 59-60.

Lewis, O. (1966). La vida: A Puerto Rican family in the culture of poverty-San Juan and New York (Vol. 13). New York, NY: Random House.

Lieberman, R. (1998). Shifting the color line: Race and the American welfare state. Cambridge, MA: Harvard University Press.

Light, R., Roscigno, V. J., \& Kalev, A. (2011). Racial discrimination, interpretation, and legitimation at work. The Annals of the American Academy of Political and Social Science, 634(1), 39-59.

Lindrooth, R. C., \& McCullough, J. S. (2007). The effect of Medicaid family planning expansions on unplanned births. Women's Health Issues, 17(2), 66-74. 
Lipina, S., Segretin, S., Hermida, J., Prats, L., Fracchia, C., Camelo, J. L., \& Colombo, J. (2013). Linking childhood poverty and cognition: Environmental mediators of non-verbal executive control in an Argentine sample. Developmental Science, 16(5), 697-707. doi:10.1111/desc. 12080

Lippmann, S. (2008). Rethinking risk in the new economy: Age and cohort effects on unemployment and re-employment. Human Relations, 61(9), 1259-1292.

Little, R. J. (1988). A test of missing completely at random for multivariate data with missing values. Journal of the American Statistical Association, 83(404), 11981202.

Little, R. J. A., \& Rubin, D. B. (2002). Statistical analysis with missing data (2nd ed.). Hoboken, NJ: Wiley.

Loeb, S., \& Corcoran, M. (2001). Welfare, work experience, and economic selfsufficiency. Journal of Policy Analysis and Management, 20(1), 1-20.

Loprest, P. J. (2011). Disconnected families in TANF. Washington, DC: Urban Institute.

Loprest, P., \& Nichols, A. (2011). Dynamics of being disconnected from work and TANF. Washington, DC: Urban Institute.

Lowi, T. J. (1998). Think globally, lose locally. In G. Lachapelle \& J. E. Trent (Eds), Globalization, governance and identity: The emergence of new partnerships (1738). Montreal: University of Montreal Press.

Ludwig, J., \& Miller, M. (2005). Interpreting the WIC debate. Journal of Policy Analysis and Management, 24(4), 691-701.

Ludwig, J., Duncan, G. J., Gennetian, L. A., Katz, L. F., Kessler, R. C., Kling, J. R., \& Sanbonmatsu, L. (2012). Neighborhood effects on the long-term well-being of low-income adults. Science, 337(6101), 1505-1510.

Luhby, T. (2014). U.S. poverty rate drops for first time since 2006. Retrieved from http://money. cnn.com/2014/09/16/news/economy/median-income-poverty-ratedown-census/

Marshall, T. H. (1992). Citizenship and social class. London: Pluto Press.

Martini, A. (1989). Seam effect, recall bias, and the estimation of labor force transition rates from SIPP. Washington, DC: American Statistical Association.

Maskovsky, J. (2001). Afterword: Beyond the privatist consensus. In J. G. Goode \& J. Maskovsky (Eds.), The new poverty studies: The ethnography of power, politics, 
and impoverished people in the United States (pp. 470-482). New York, NY: New York University Press.

McCarthy, J. D., \& Zald, M. N. (1973). The trend of social movements in America: Professionalization and resource mobilization. Morristown, NY: General Learning Press.

McDonald, S., Lin, N., \& Ao, D. (2009). Networks of opportunity: Gender, race, and job leads. Social Problems, 56(3), 385-402.

McGuinness, T. M., \& Schneider, K. (2007). Poverty, child maltreatment, and foster care. Journal of the American Psychiatric Nurses Association, 13(5), 296-303.

McKeen, W. (2006). Diminishing the concept of social policy: The shifting conceptual ground of social policy debate in Canada. Critical Social Policy, 26(4), 865-887.

McKernan, S. M., Lerman, R., Pindus, N., \& Valente, J. (2000). The relationship between metropolitan and non-metropolitan locations, changing welfare policies, and the employment of single mothers. Washington, DC: Joint Center for Poverty Research.

Menard, S. (1995). Applied logistic regression analysis. Thousand Oaks, CA: Sage Publications.

Meyer, B. D. (2008). The US earned income tax credit, its effects, and possible reforms. Retrieved from https://www.econstor.eu/bitstream/10419/45762/1/573610983.pdf

Meyer, B. D., Mok, W. K., \& Sullivan, J. X. (2009). The under-reporting of transfers in household surveys: Its nature and consequences. Washington, DC: National Bureau of Economic Research.

Meyers, M. K. (2014). Are we asking the right questions about poverty in America? Social Service Review, 88(4), 728-744.

Moffitt, R. (1987). Historical growth in participation in aid to families with dependent children: Was there a structural shift? Journal of Post Keynesian Economics, 9(3), 347-363.

Moffitt, R. A. (2015). The deserving poor, the family, and the US welfare system. Demography, 52(3), 729-749.

Moffitt, R., \& Wolfe, B. (1990). The effect of the Medicaid program on welfare participation and labor supply. Washington, DC: National Bureau of Economic Research. 
Moore, J. C. (2008). Seam bias in the 2004 SIPP panel: Much improved, but much bias still remains. Washington, DC: US Census Bureau Statistical Research Division.

Moraes, S., Durrant, J. E., Brownridge, D., \& Reid, G. (2006). Professionals' decisionmaking in cases of physical punishment reported to child welfare authorities: Does family poverty matter? Child \& Family Social Work, 11(2), 157-169.

Morgan, K. J., \& Campbell, A. L. (2011). The delegated welfare state: Medicare, markets, and the governance of social policy. New York, NY: Oxford University Press.

Moynihan, D. P. (1965a). The Negro family: The case for national action. Washington, D.C.: Department of Labor, Office of Planning and Research.

Moynihan, D. P. (1965b). The professionalization of reform. The Public Interest, 1, 6-16.

Mullainathan, S., \& Shafir, E. (2009). Savings policy and decision-making in low-income households. In M. Barr \& R. Blank (Eds.), Insufficient funds: Savings, assets, credit, and banking among low-income households (pp. 121-145). New York, NY: Russell Sage Foundation Press.

Murray, C. (1984). Losing ground: American social policy, 1950-1980. New York, NY: Basic Books.

Murray, C. (1990). The emerging British underclass. London: Institute of Economic Affairs.

Murray, K. O., \& Primus, W. E. (2005). Recent data trends show welfare reform to be a mixed success: Significant policy changes should accompany reauthorization. Review of policy Research, 22(3), 301-324.

Murray, M. G., \& Pancoast, E. (1945). Trends in Old-Age Insurance and Old-Age Assistance. Social Security Bulletin, 8, 12-15.

Myers, R. H. (1990). Classical and modern regression with applications. Boston, MA: PWS \& Kent Publishing Company.

Mykerezi, E., \& Mills, B. (2010). The impact of Food Stamp Program participation on household food insecurity. American Journal of Agricultural Economics, 92(5), 1379-1391.

National Association of Social Workers (2008). Code of Ethics of the National Association of social Workers. Washington, DC: NASW

New York Times (1989, August 20). Did the war on poverty fail? Retrieved from http://www. nytimes.com/1989/08/20/opinion/did-the-war-on-poverty-fail.html? 
Newman, S. J., \& Harkness, J. M. (2002). The long-term effects of public housing on self-sufficiency. Journal of Policy Analysis \& Management, 21(1), 21-43.

Noble, K. G., Norman, M. F., \& Farah, M. J. (2005). Neurocognitive correlates of socioeconomic status in kindergarten children. Developmental Science, 8(1), 7487.

Nord, M. (2012). How much does the supplemental nutrition assistance program alleviate food insecurity? Evidence from recent programme leavers. Public Health Nutrition, 15(5), 811-817.

Nussbaum, M. (2000). Women and human development: The capabilities approach. Cambridge University Press: Cambridge, MA.

O'Brien, J. (2014). Too big to fail or too hard to remember? Lessons from the new deal on dealing with systemically important institutions. Law \& Financial Markets Review, 8(3), 249-259.

O'Connor, A. (2001). Poverty knowledge. Princeton, NJ: Princeton University Press.

Okech, D. (2011). Enrollment decisions in a child development accounts program for low-income families. Journal of Family and Economic Issues, 32(3), 400-410.

O'Neill, J. E., \& Hill, A. M. (2001). Gaining ground? Measuring the impact of welfare reform on welfare and work. New York, NY: Manhattan Institute.

Orleck, A. (2005) Storming Caesars palace: How Black mothers fought their own war on poverty. Boston, MA: Beacon Press.

Orloff, A. (1996). Gender in the welfare state. Annual Review of Sociology, 22(1), 51-78.

Osmond, C., Barker, D. J., Winter, P. D., Fall, C. H., \& Simmonds, S. J. (1993). Early growth and death from cardiovascular disease in women. British Medical Journal, 307(6918), 1519-1524.

Osteen, P., \& Bright, C. (2010, January). Effect sizes and intervention research. Workshop delivered at 2010 Society for Social Work and Research (SSWR) Conference, San Francisco, CA.

Otteson, J. (2002). Adam Smith's marketplace of life. Cambridge, UK: Cambridge University Press. 
Owens, M. F., \& Baum, C. L. (2009). The effects of federal housing assistance on exiting welfare and becoming employed for welfare recipients. Journal of Poverty, 13(2), 130-151.

Ozawa, M. N., \& Yoon, H. (2005). "Leavers" from TANF and AFDC: How do they fare economically? Social Work, 50(3), 239-249.

Parker, L. A. (1994).The role of workplace support in facilitating self-sufficiency among single mothers on welfare. Family Relations, 43(2), 168-173.

Patterson, J. T. (1981). The welfare state in America, 1930-1960. Durham, UK: British Association of American Studies.

Patterson, J. T. (2000). America's struggle against poverty in the twentieth century. Cambridge, MA: Harvard University Press.

Pavetti, L. (2002). Helping the hard-to-employ. In I. V. Sawhill, R. K. Weaver, R. Haskins, \& A. Kane (Eds.), Welfare reform and beyond: The future of the safety net (pp. 135-142). Washington, DC: Brookings Institution Press.

Peck, J. (2001). Workfare states. New York, NY: Guilford Publications.

Peck, J., \& Theodore, N. (2000). "Work first": Workfare and the regulation of contingent labour markets. Cambridge Journal of Economics, 24(1), 119-138.

Peikes, D. N., Moreno, L., \& Orzol, S. M. (2012). Propensity score matching. The American Statistician, 62(3), 222-231. doi:10.1198/000313008X332016

Pelkowski, J. M., \& Berger, M. C. (2004). The impact of health on employment, wages, and hours worked over the life cycle. The Quarterly Review of Economics \& Finance, 44(1), 102-121.

Perry-Burney, G. D., \& Jennings, A. (2003). Welfare to what? A policy agenda. Journal of Health \& Social Policy, 16(4), 85-99.

Peterson, P. E. (1991). The urban underclass and the poverty paradox. Political Science Quarterly, 106(4), 617-637.

Pierce, J. J., Siddiki, S., Jones, M. D., Schumacher, K., Pattison, A., \& Peterson, H. (2014). Social construction and policy design: A review of past applications. Policy Studies Journal, 42(1), 1-29.

Pigott, T. D. (2001). A review of methods for missing data. Educational Research \& Evaluation, 7(4), 353-383. 
Piven, F. F., \& Cloward, R. A. (1971, 1993). Regulating the poor: The functions of public welfare. New York, NY: Vintage Books.

Prasad, M. (2012). The land of too much: American abundance and the paradox of poverty. Cambridge, MA: Harvard University Press.

Prentice, S. (2007). Less access, worse quality: New evidence about poor children and regulated child care in Canada. Journal of Children and Poverty, 13(1), 57-73.

Proctor, B. D., Semega, J. L., \& Kollar, M. A. (2016). Income and poverty in the United States: 2015. Retrieved from https://www.census.gov/content/dam/Census/library/ publications/2016/demo/p60-256.pdf

Rainwater, L. (1970). Neutralizing the disinherited: Some psychological aspects of understanding the poor. In V. L. Allen (Ed.), Psychological factors in poverty (pp. 9-28). Chicago, IL: Markham.

Rank, M. R. (2004). One nation, underprivileged: Why American poverty affects us all. New York, NY: Oxford University Press.

Ratcliffe, C., McKernan, S. M., \& Zhang, S. (2011). How much does the Supplemental Nutrition Assistance Program reduce food insecurity? American Journal of Agricultural Economics, 93(4), 1082-1098.

Raymo, J. M., \& Zhou, Y. (2012). Living arrangements and the well-being of single mothers in Japan. Population Research \& Policy Review, 31(5), 727-749.

Reagan, R. (1986, February 15). Radio address to the nation on welfare reform. Retrieved from http://www.presidency.ucsb.edu/ws/?pid=36875

Robeyns, I. (2005). The capability approach: A theoretical survey. Journal of Human Development, 6(1), 93-117.

Rochefort, D. A. (1981). Progressive and social control perspectives on social welfare. Social Service Review, 55(4), 568-592.

Rodgers, H. R. Jr. (1982). The cost of human neglect: America's welfare failure. Armok, N.Y.: M. E. Sharpe, Inc.

Rodgers, H. R., \& Tedin, K. L. (2006). State TANF spending: Predictors of state tax effort to support welfare reform. Review of Policy Research, 23(3), 745-759.

Rolleston, C. (2011). Educational access and poverty reduction: The case of Ghana 1991-2006. International Journal of Educational Development, 31(4), 338-349. 
Roscigno, V. J., Garcia, L. M., \& Bobbitt-Zeher, D. (2007). Social closure and processes of race/sex employment discrimination. The Annals of the American Academy of Political and Social Science, 609(1), 16-48.

Roscigno, V. J., Mong, S., Byron, R., \& Tester, G. (2007). Age discrimination, social closure and employment. Social Forces, 86(1), 313-334.

Rose, N. E. (2009). Lessons from the new deal public employment programs. Monthly Review: An Independent Socialist Magazine, 61(5), 21-32.

Rosenbaum, P. R., \& Rubin, D. B. (1983). The central role of the propensity score in observational studies for causal effects. Biometrika, 70(1), 41-55.

Rubin, D. B. (1976). Inference and missing data. Biometrika, 63(3), 581-92.

Ryan, W. (1976). Blaming the victim. New York, NY: Vintage.

Ryscavage, P. (1993). The seam effect in SIPP's labor force data: Did the recession make it worse? Washington, DC: United States Census Bureau.

Sacks, V., Murphey, D., \& Moore, K. (2014). Adverse childhood experiences: national and state-level prevalence. Retrieved from https://www.childtrends.org/wpcontent/uploads/2014/07/Brief-adverse-childhood-experiences_FINAL.pdf

Sandfort, J. R., \& Hill, M. S. (1996). Assisting young, unmarried mothers to become selfsufficient: The effects of different types of early economic support. Journal of Marriage \& the Family, 58(2), 311-326.

Sandstrom, H., Seefeldt, K., Huerta, S., \& Loprest, P. (2014). Understanding the dynamics of disconnection from employment and assistance. Washington, DC: Office of Planning, Research and Evaluation (OPRE).

Schafer, J. L., \& Graham, J. W. (2002). Missing data: our view of the state of the art. Psychological methods, 7(2), 147-177.

Schiller, B. R. (1973). Empirical studies of welfare dependency: A survey. Journal of Human Resources, 8, 19-32.

Schneider, A. L., \& Ingram, H. M. (1997). Policy design for democracy. Kansas City, KS: University Press of Kansas.

Schneider, A., \& Sidney, M. (2009). What is next for policy design and social construction theory? Policy Studies Journal, 37(1), 103-119. 
Schoeni, R. F., \& Blank, R. M. (2000). What has welfare reform accomplished? Impacts on welfare participation, employment, income, poverty and family structure. Washington, DC: National Bureau of Economic Research.

Schram, S. F., \& Turbett, J. B. (1983a). The welfare explosion: Mass society versus social control. Social Service Review, 57(4), 614-625.

Schram, S. F., \& Turbett, J. P. (1983b). Civil disorder and the welfare explosion: a twostep process. American Sociological Review, 48(3), 408-414.

Sen, A. (1987). The standard of living: Lecture II, lives and capabilities. In G. Hawthorn (Ed.), The standard of living (pp. 20-38). Cambridge: Cambridge University Press.

Sen, A. (1993). Capability and well-being. In M. Nussbaum \& A. Sen (Eds.), The quality of life (pp. 30-53). New York, NY: Oxford University Press.

Shaefer, H. L., \& Edin, K. (2013). Rising extreme poverty in the United States and the response of federal means-tested transfer programs. Social Service Review, 87(2), 250-268.

Shaefer, H. L., \& Gutierrez, I. A. (2013). The supplemental nutrition assistance program and material hardships among low-income households with children. Social Service Review, 87(4), 753-779.

Shain, B. A. (1994). The myth of American individualism: The Protestant origins of American political thought. Princeton, NY: Princeton University Press.

Sheely, A. (2012). Devolution and welfare reform: Re-evaluating "success." Social Work, 57(4), 321-331. doi:10.1093/sw/sws022

Shefrin, H. M., \& Thaler, R. H. (1988). The behavioral life-cycle hypothesis. Economic Inquiry, 26(4), 609-643.

Sherman, A., \& Trisi, D. (2015). Safety net more effective against poverty than previously thought: Correcting for underreporting of benefits reveals stronger reductions in poverty and deep poverty in all states. Retrieved from http://www.cbpp.org/sites/ default/files/atoms/files/5-6-15pov.pdf

Sherraden M., Barth, R. P., Brekke, J., Fraser, M.., Madershied, R.., \& Padgett, D., (2014). Social is fundamental: Introduction and context for grand challenges for social work. Baltimore, MD: American Academy of Social Work and Social Welfare.

Sherraden, M. (1991). Asset and the poor: A new American welfare policy. Armonk, NY: M. E. Sharpe. 
Siegel, D. I., Green, J., Abbott, A., Mogul, M., \& Patacsil, M. (2004). Barriers to employment: Returners to welfare and those who have left the welfare and employment rolls. The Social Policy Journal, 3(4), 19-37. doi:10.1300/J185v03 n04_03

Silver, H. (1994). Social exclusion and social solidarity: Three paradigms. International Labour Review, 133, 531-578.

Simpson, N., Tiefenthaler, J., \& Hyde, J. (2010). The impact of the earned income tax credit on economic well-being: A comparison across household types. Population Research and Policy Review, 29(6), 843 -864. doi:10.1007/s11113-009-9170-5

Skidmore, M. S. (2009). Revisiting a classic after nearly a half century. Poverty \& Public Policy, 1(2), 1-5.

Slack, K. S., Kim, B., Yang, M. Y., \& Berger, L. M. (2014). The economic safety net for low-income families with children. Children and Youth Services Review, 46, 213 219.

Smith, A. (1759, 1976). The theory of moral sentiments. Glasgow, Scotland: Glasgow Edition of the Works and Correspondence of Adam Smith.

Snohomish County Self-Sufficiency Taskforce (2004). Self-sufficiency matrix: An assessment and measurement tool created through a collaborative partnership of the human services community in Snohomish County. Retrieved from http://www.performwell.org/index.php? option=com_mtree\&task=att _download\&link_id=48\&cf_id=24

Snyder, A. R., McLaughlin, D. K., \& Findeis, J. (2006). Household composition and poverty among female-headed households with children: Differences by race and residence. Rural Sociology, 71(4), 597-624.

Soss, J., Fording, R. C., \& Schram, S. F. (2008). The color of devolution: Race, federalism, and the politics of social control. American Journal of Political Science, 52(3), 536-553.

Soss, J., Schram, S. F., Vartanian, T., \& O'Brien, E. (2001). Setting the terms of relief: Explaining state policy choices in the devolution revolution. American Journal of Political Science 45(2), 378-395.

Stack, C. B (1974). All our kin: Strategies for survival in an urban Black community. Ney York, New York. Basic Books.

Stigler, G. J. (1950). The development of utility theory I. Journal of Political Economy, 58(4), 307-327. 
Stone, D. (2002). Policy paradox: The art of political decision making. New York, NY: Norton.

Stuber, J., \& Kronebusch, K. (2004). Stigma and other determinants of participation in TANF and Medicaid. Journal of Policy Analysis and Management, 23(3), 509530.

Stuber, J., \& Schlesinger, M. (2006). Sources of stigma for means-tested government programs. Social Science \& Medicine, 63(4), 933-945.

Tabachnick, B. G., \& Fidell, L. S. (2012). Using multivariate statistics (6th ed.). Needham Heights, MA: Allyn \& Bacon.

Teater, B. A. (2011). A qualitative evaluation of the Section 8 housing choice voucher program: The recipients' perspectives. Qualitative Social Work, 10(4), 503-519.

Thaler, R. H. (1994). Psychology and savings policies. The American Economic Review, 84(2), 186-192.

The Roosevelt Institute (2014). The new deal. Retrieved from http://rooseveltinstitute.org/policy-and-ideasroosevelt-historyfdr/new-deal

Tiehen, L., Jolliffe, D., \& Gunderson, C. (2012). Alleviating povety in the United States: The critical role of SNAP benefits. Retrieved from http://safsf.org/documents/ repository/ 74_04-15-13_err132_1_.pdf

Titmuss, R. M. (1968). Commitment to welfare. New York, NY: Pantheon Books.

Tobin, J. (1994). Poverty in relation to macroeconomic trends, cycles, policies. New Haven, CT: Cowles Foundation.

Torres, J., \& Wong, R. (2013). Childhood poverty and depressive symptoms for older adults in Mexico: A life-course analysis. Journal of Cross-Cultural Gerontology, 28(3), 317-337. doi:10.1007/s10823-013-9198-1

United Nations (2013). The Millennium Development Goals report 2013. New York, NY: United Nations.

United States Bureau of Labor Statistics (2014). Labor forces statistics. Retrieved from http://data.bls. gov/timeseries/LNS14000000

United States Census Bureau (2015a). Geographic terms and concepts: Census divisions and census regions. Retrieved from https://www.census.gov/geo/reference/ gtc/gtc_census_divreg.html 
United States Census Bureau (2015b). Annual estimates of the resident population by sex, age, race, and Hispanic origin for the united states and states: April 1, 2010 to July 1, 2014. Retrieved from http://factfinder.census.gov/ faces/tableservices/ jsf/pages/productview.xhtml? src=bkmk

United States Census Bureau (2015c). Quick facts: Wisconsin. Retrieved from http://www.census. gov/quickfacts/table/LND110210/55

United States Census Bureau (2016). How the Census Bureau measures poverty. Retrieved from https:/www.census.gov/topics/income-poverty/poverty/ guidance/poverty-measures.html

United States Congress. (1912). Children's Bureau Act. Public Law, 62-116.

United States Congress. (1933). Child abuse prevention and treatment act of 1933. Public Law, 73-66.

United States Congress. (1935). Social Security Act. Public Law, 74-271.

United States Congress. (1962). Public Welfare Amendments of 1962. Public Law, 87543.

United States Congress. (1964). Economic Opportunity Act. Public Law, 88-452.

United States Congress. (1964). Food Stamps Act. Public Law, 88-525.

United States Congress. (1965). Older Americans Act. Public Law, 89-73.

United States Congress. (1967). Social Security Amendments. Public Law, 90-248.

United States Congress. (1972). Social Security Amendments. Public Law, 92-603.

United States Congress. (1974). Housing and Community Development Act. Public Law, 93-383.

United States Congress. (1975). Social Services Amendments. Public Law, 93-647.

United States Congress. (1981). Omnibus Budget Reconciliation Act. Public Law, 97-35.

United States Congress. (1996). Personal Responsibility and Work Opportunity Reconciliation Act. Public Law, 104-193. 
United States Congress. (1998). Community Opportunities, Accountability, and Training and Educational Services Human Services Reauthorization Act. Public Law, 105285.

United States Congress. (2008). Food, Conservation, and Energy Act. Public Law, 110246.

United States Department of Agriculture. (2014). Supplemental nutrition assistance program (SNAP): A short history of SNAP. Retrieved from http://www.fns.usda. gov/snap/short-history-snap

United States Department of Health \& Human Services. (2014). Welfare indicators and risks factors: Thirteen report to Congress. Retrieved from https://aspe.hhs.gov/pdf -report/welfare-indicators-and-risk-factors-thirteenth-report-congress

United States Department of Health \& Human Services. (2014b). AFI fact sheet. Retrieved from http://www.acf.hhs.gov/programs/ocs/resource/assets-forindependence-program-summary

United States House of Representatives, House Budget Committee Majority Staff. (2014). The war on poverty: 50 years later. Retrieved from http://budget.house. gov/uploadedfiles/war_on_poverty.pdf

United States Internal Revenue Service. (2017). Statistics for tax returns with EITC. Retrieved from http://www.eitc.irs.gov/EITC-Central/eitcstats

United States Social Security Administration. (n. d.) History of SSA during the Johnson administration 1963-1968. Retrieved from http://www.ssa.gov/history/ssa/ lbjmedicare1.html

Valcarce, A. (2010). El utilitarismo y la teoría moral de Adam Smith. Empresa $Y$ Humanismo, 13(1), 269-296.

Vobejda, B., \& Havemann, J. (1996, September). 2 HHS officials quit over welfare changes. Washington Post, A01.

Von Neumann, J., \& Morgenstern, O. (1944). Theory of games and economic behavior. Princeton, NJ: University Press.

Wadsworth, M. E., \& Kuh, D. J. (1997). Childhood influences on adult health: A review of recent work from the British 1946 national birth cohort study, the MRC National Survey of Health and Development. Pediatric and Perinatal Epidemiology, 11(1), 2-20.

Wadsworth, M. E., Raviv, T., Reinhard, C., Wolff, B., Santiago, C., \& Einhorn, L. (2008). An indirect effects model of the association between poverty and child 
functioning: The role of children's poverty-related Stress. Journal of Loss \& Trauma, 13(2/3), 156-185.

Wager, F., Bailey, N., Day, R., Hamilton, D., Hill, M., \& King, C. (2007). Serving children: The impact of poverty on children's experiences of services. Retrieved from http://strathprints.strath.ac.uk/36734/1/serving_children_3.pdf

Washington Post (2014, May 17). The Great Society at 50. Retrieved from http://www. washingtonpost. com /sf/national/2014/05/17/the-great-society-at-50/

Waters, M. C., \& Eschbach, K. (1995). Immigration and ethnic and racial inequality in the United States. Annual Review of Sociology, 21(1), 419-446.

Weber, M. (1930, 2001). Protestant ethic and the spirit of capitalism. New York, NY: Rutledge.

Weidman, L. (1986). Investigation of gross changes in income recipiency from the survey of income and program participation. Washington, DC: American Statistical Association.

Weinberg, D. (2002). The survey of income and program participation - Recent history and future developments. Washington DC: United States Census Bureau.

Weisbrod, B. A. (1966). The economics of poverty: An American paradox. Englewood Cliffs, NJ: Prentice-Hall.

West's Encyclopedia of American Law (2005). Contract with America. Retrieved November 20, 2014 from Encyclopedia.com: http://www.encyclopedia.com/doc/1G2-3437701121. html

Wheeler, M. (1955). Self-sufficiency and the Greek city. Journal of the History of Ideas, 16(3), 416-420.

White, I. R., Royston, P., \& Wood, A. M. (2011). Multiple imputation using chained equations: Issues and guidance for practice. Statistics in Medicine, 30(4), 377399.

Wilensky, H. L. (1975). The welfare state and equality. Berkeley, CA: University of California Press.

Wilkie, J. R. (1991). The decline in men's labor force participation and income and the changing structure of family economic support. Journal of Marriage and the Family, 53(1), 111-122.

Williamson, O. E. (1999). Public and private bureaucracies: A transaction cost economics perspectives. Journal of Law, Economics, and Organization, 15(1), 306-342. 
Winkler, A. E. (1991). The incentive effects of Medicaid on women's labor supply. Journal of Human Resources, 26(2) 308-337.

Witztum, A., \& Young, J. T. (2013). Utilitarianism and the role of utility in Adam Smith. European Journal of The History Of Economic Thought, 20(4), 572-602. doi:10.1080/09672567.2011.592846

Wood, R. G., Moore, Q., \& Rangarajan, A. (2008). Two steps forward, one step back: The uneven economic progress of TANF recipients. Social Service Review, 82(1), 3-28.

Wu, C. F., \& Eamon, M. K. (2010). Does receipt of public benefits reduce material hardship in low-income families with children? Children and youth services review, 32(10), 1262-1270.

Yang, Z., \& Gaydos, L. M. (2010). Reasons for and challenges of recent increases in teen birth rates: a study of family planning service policies and demographic changes at the state level. Journal of Adolescent Health, 46(6), 517-524.

Young, N. (1989). Wave-seam effects in the SIPP. Washington, DC: American Statistical Association.

Young, R., \& Johnson, D. R. (2015). Handling missing values in longitudinal panel data with multiple imputation. Journal of Marriage and Family, 77(1), 277-294.

Ziliak, J. P. (2003). Income transfers and assets of the poor. Review of Economics and Statistics, 85(1), 63-76. 


\section{APPENDICES}

\begin{tabular}{|c|c|c|}
\hline \multicolumn{3}{|c|}{ Appendix 1. Codebook of Variables } \\
\hline $\begin{array}{l}\text { Variable } \\
\text { Codes }\end{array}$ & Description & Variable Values \\
\hline ID & Person longitudinal key & None \\
\hline WHFNWGT & Household weight & None \\
\hline AGERANGE & What is the respondent's age range? & $\begin{array}{l}0=\text { Less than } 40 \\
1=40 \text { and over }\end{array}$ \\
\hline ESEX & What is the sex of the respondent? & $\begin{array}{l}0=\text { Female } \\
1=\text { Male }\end{array}$ \\
\hline EBORNUS & $\begin{array}{l}\text { Immigration status. Was respondent } \\
\text { born in the United States? }\end{array}$ & $\begin{array}{l}0=\text { No } \\
1=\text { Yes }\end{array}$ \\
\hline ECITIZEN & $\begin{array}{l}\text { Citizenship. Is respondent a citizen of } \\
\text { the United States? }\end{array}$ & $\begin{array}{l}0=\mathrm{No} \\
1=\mathrm{Yes}\end{array}$ \\
\hline EORIGIN & $\begin{array}{l}\text { Hispanic or Latino ethnicity. Des the } \\
\text { respondent consider himself or herself } \\
\text { Hispanic? }\end{array}$ & $\begin{array}{l}0=\text { No } \\
1=\text { Yes }\end{array}$ \\
\hline RACECODE & $\begin{array}{l}\text { Does respondent consider } \\
\text { herself/himself to be White or non- } \\
\text { White? }\end{array}$ & $\begin{array}{l}0=\text { Non-White } \\
1=\text { White }\end{array}$ \\
\hline EDUCATE & $\begin{array}{l}\text { Education level. What is the highest } \\
\text { level of school has respondent } \\
\text { completed or received? }\end{array}$ & $\begin{array}{l}0=\text { No post-secondary } \\
\text { education } \\
1=\text { Post-secondary } \\
\text { education }\end{array}$ \\
\hline METRO & $\begin{array}{l}\text { Cumulative metro status. Does } \\
\text { respondent live in a metro area or non- } \\
\text { metro area? }\end{array}$ & $\begin{array}{l}0=\text { No } \\
1=\text { Yes }\end{array}$ \\
\hline SPORA & $\begin{array}{l}\text { Average state poverty rates. What is } \\
\text { the average poverty level for the past } \\
\text { five years in the state where } \\
\text { respondent had lived? }\end{array}$ & $\begin{array}{l}0=\text { States with high and } \\
\text { very high average rates } \\
\text { of poverty } \\
1=\text { States with very low } \\
\text { to moderate average rates } \\
\text { of poverty }\end{array}$ \\
\hline
\end{tabular}




\begin{tabular}{|c|c|c|}
\hline RHTYPE & $\begin{array}{l}\text { Household type or living arrangement. } \\
\text { What type of household does } \\
\text { respondent live in? }\end{array}$ & $\begin{array}{l}0=\text { Single } \\
1=\text { Married couple }\end{array}$ \\
\hline ETENURE & $\begin{array}{l}\text { Ownership status. Is the living quarter } \\
\text { owned by respondent (or someone in } \\
\text { the household), or rented or occupied } \\
\text { without payment of cash rent? }\end{array}$ & $\begin{array}{l}0=\text { Rented or occupied } \\
\text { without payment } \\
1=\text { Owned by respondent } \\
\text { or someone in the } \\
\text { household }\end{array}$ \\
\hline RFNKIDS & $\begin{array}{l}\text { Presence of children under } 18 \text { in the } \\
\text { household. Are there children under } \\
18 \text { in the household? }\end{array}$ & $\begin{array}{l}0=\text { No } \\
1=\text { Yes }\end{array}$ \\
\hline EHHNUMPP & $\begin{array}{l}\text { Number of people in household } \\
\text { (household size). What is the total } \\
\text { number of persons in this household? }\end{array}$ & $\begin{array}{l}1=\text { Less than three } \\
2=\text { Three or more }\end{array}$ \\
\hline EAST2A & $\begin{array}{l}\text { Interest earning checking account } \\
\text { owned. Does respondent own an } \\
\text { interest earning checking account? }\end{array}$ & $\begin{array}{l}0=\text { No } \\
1=\text { Yes }\end{array}$ \\
\hline EAST2B & $\begin{array}{l}\text { Savings account owned. Does } \\
\text { respondent own a savings account? }\end{array}$ & $\begin{array}{l}0=\text { No } \\
1=\text { Yes }\end{array}$ \\
\hline FINANBHV & $\begin{array}{l}\text { Financial capability as measured by } \\
\text { homeownership and possessions of } \\
\text { bank accounts. Does the respondent } \\
\text { own a home and possess bank } \\
\text { accounts? }\end{array}$ & $\begin{array}{l}0=\text { Low financial } \\
\text { capability (no possession } \\
\text { of homes and/or bank } \\
\text { accounts) } \\
1 \text { = High financial } \\
\text { capability (possession of } \\
\text { homes and/or bank } \\
\text { accounts) }\end{array}$ \\
\hline EPTWRK & $\begin{array}{l}\text { Work status. Has respondent worked } \\
\text { less than } 35 \text { hours some weeks? }\end{array}$ & $\begin{array}{l}1=\text { Yes } \\
2=\text { No } \\
3=\text { Not working, not } \\
\text { looking }\end{array}$ \\
\hline RHMTRF & $\begin{array}{l}\text { Household means-tested cash or } \\
\text { noncash receipt (dichotomous } \\
\text { independent variable). Does this } \\
\text { household receive means-tested cash } \\
\text { or noncash benefits? }\end{array}$ & $\begin{array}{l}0=\text { No } \\
1=\text { Yes }\end{array}$ \\
\hline
\end{tabular}




\begin{tabular}{|l|l|l|}
\hline BENEFITS* & $\begin{array}{l}\text { Total household means-tested cash } \\
\text { and noncash benefits. How many } \\
\text { benefits does the household receive at } \\
\text { baseline? This variable is a } \\
\text { combination of seven other variables } \\
\text { (see footnotes). }\end{array}$ & $\begin{array}{l}1=\text { One benefit } \\
2=\text { Two benefits } \\
3=\text { Three benefits } \\
4=\text { Four benefits }\end{array}$ \\
\hline CUMULIPR** & $\begin{array}{l}\text { Attainment and maintenance of } \\
\text { economic self-sufficiency } \\
\text { (dichotomous outcome variable). Has } \\
\text { the household attained economic self- } \\
\text { sufficiency on or before Wave 12 and } \\
\text { maintained it through the remainder of } \\
\text { the study (Wave 15)? }\end{array}$ & $\begin{array}{l}0=\text { No } \\
1=\text { Yes }\end{array}$ \\
* RCUTYP27 (receipt of food assistance) \\
RCUTYP57 (receipt of health assistance) \\
EHOTLUNC (receipt of free-or reduced price school lunch) \\
EBRKFST (receipt of free or reduced-price school breakfast) \\
EGVTRNT (receipt of subsidized housing) \\
EEGYAST (receipt of energy assistance) \\
RHCBRF (receipt of cash assistance) \\
** This variable is a cumulative ratio of household income (THTOTINC) and \\
household poverty level (RHPOV).
\end{tabular}




\begin{tabular}{|l|l|l|l|l|l|}
\hline \multicolumn{5}{|c|}{ Appendix 2. State Minimum Wages for 2008-2012 } \\
\hline States & \multicolumn{5}{|c|}{ Year } \\
\hline & 2008 & 2009 & 2010 & 2011 & 2012 \\
\hline Alabama & $\$ 6.55$ & $\$ 7.25$ & $\$ 7.25$ & $\$ 7.25$ & $\$ 7.25$ \\
\hline Alaska & $\$ 7.15$ & $\$ 7.25$ & $\$ 7.75$ & $\$ 7.75$ & $\$ 7.75$ \\
\hline Arizona & $\$ 6.90$ & $\$ 7.25$ & $\$ 7.25$ & $\$ 7.35$ & $\$ 7.65$ \\
\hline Arkansas & $\$ 6.25$ & $\$ 7.25$ & $\$ 7.25$ & $\$ 7.25$ & $\$ 7.25$ \\
\hline California & $\$ 8.00$ & $\$ 8.00$ & $\$ 8.00$ & $\$ 8.00$ & $\$ 8.00$ \\
\hline Colorado & $\$ 7.02$ & $\$ 7.28$ & $\$ 7.24$ & $\$ 7.36$ & $\$ 7.64$ \\
\hline Connecticut & $\$ 7.65$ & $\$ 8.00$ & $\$ 8.25$ & $\$ 8.25$ & $\$ 8.25$ \\
\hline Delaware & $\$ 7.15$ & $\$ 7.25$ & $\$ 7.25$ & $\$ 7.25$ & $\$ 7.25$ \\
\hline $\begin{array}{l}\text { District of } \\
\text { Columbia }\end{array}$ & $\$ 7.55$ & $\$ 8.25$ & $\$ 8.25$ & $\$ 8.25$ & $\$ 8.25$ \\
\hline Florida & $\$ 6.79$ & $\$ 7.25$ & $\$ 7.25$ & $\$ 7.31$ & $\$ 7.67$ \\
\hline Georgia & $\$ 6.55$ & $\$ 7.25$ & $\$ 7.25$ & $\$ 7.25$ & $\$ 7.25$ \\
\hline Hawaii & $\$ 6.55$ & $\$ 7.25$ & $\$ 7.25$ & $\$ 7.25$ & $\$ 7.25$ \\
\hline Idaho & $\$ 7.25$ & $\$ 7.25$ & $\$ 7.25$ & $\$ 7.25$ & $\$ 7.25$ \\
\hline Illinois & $\$ 6.55$ & $\$ 7.25$ & $\$ 7.25$ & $\$ 7.25$ & $\$ 7.25$ \\
\hline Indiana & $\$ 6.55$ & $\$ 7.25$ & $\$ 7.25$ & $\$ 7.25$ & $\$ 7.25$ \\
\hline Iowa & $\$ 7.25$ & $\$ 7.25$ & $\$ 7.25$ & $\$ 7.25$ & $\$ 7.25$ \\
\hline Kansas & $\$ 8.25$ & $\$ 8.25$ & $\$ 8.25$ \\
\hline Kentucky & $\$ 2.65$ & $\$ 7.25$ & $\$ 7.25$ & $\$ 7.25$ \\
\hline Louisiana & $\$ 7.25$ & $\$ 7.25$ & $\$ 7.25$ & $\$ 7.25$ \\
\hline
\end{tabular}




\begin{tabular}{|l|l|l|l|l|l|}
\hline Maine & $\$ 7.25$ & $\$ 7.25$ & $\$ 7.50$ & $\$ 7.50$ & $\$ 7.50$ \\
\hline Maryland & $\$ 6.55$ & $\$ 7.25$ & $\$ 7.25$ & $\$ 7.25$ & $\$ 7.25$ \\
\hline Massachusetts & $\$ 8.00$ & $\$ 8.00$ & $\$ 8.00$ & $\$ 8.00$ & $\$ 8.00$ \\
\hline Michigan & $\$ 7.40$ & $\$ 7.40$ & $\$ 7.40$ & $\$ 7.40$ & $\$ 7.40$ \\
\hline Minnesota & $\$ 6.15$ & $\$ 6.15$ & $\$ 6.15$ & $\$ 6.15$ & $\$ 6.15$ \\
\hline Mississippi & $\$ 6.55$ & $\$ 7.25$ & $\$ 7.25$ & $\$ 7.25$ & $\$ 7.25$ \\
\hline Missouri & $\$ 6.65$ & $\$ 7.25$ & $\$ 7.25$ & $\$ 7.25$ & $\$ 7.25$ \\
\hline Montana & $\$ 6.55$ & $\$ 7.25$ & $\$ 7.25$ & $\$ 7.35$ & $\$ 7.65$ \\
\hline Nebraska & $\$ 6.55$ & $\$ 7.25$ & $\$ 7.25$ & $\$ 7.25$ & $\$ 7.25$ \\
\hline Nevada & $\$ 6.85$ & $\$ 7.55$ & $\$ 8.25$ & $\$ 8.25$ & $\$ 8.25$ \\
\hline New Hampshire & $\$ 7.25$ & $\$ 7.25$ & $\$ 7.25$ & $\$ 7.25$ & $\$ 7.25$ \\
\hline New Jersey & $\$ 7.15$ & $\$ 7.25$ & $\$ 7.25$ & $\$ 7.25$ & $\$ 7.25$ \\
\hline New Mexico & $\$ 6.50$ & $\$ 7.50$ & $\$ 7.50$ & $\$ 7.50$ & $\$ 7.50$ \\
\hline New York & $\$ 7.15$ & $\$ 7.25$ & $\$ 7.25$ & $\$ 7.25$ & $\$ 7.25$ \\
\hline North Carolina & $\$ 6.55$ & $\$ 7.25$ & $\$ 7.25$ & $\$ 7.25$ & $\$ 7.25$ \\
\hline North Dakota & $\$ 6.55$ & $\$ 7.25$ & $\$ 7.25$ & $\$ 7.25$ & $\$ 7.25$ \\
\hline Ohio & $\$ 7.00$ & $\$ 7.30$ & $\$ 7.30$ & $\$ 7.40$ & $\$ 7.70$ \\
\hline Oklahoma & $\$ 6.55$ & $\$ 7.25$ & $\$ 7.25$ & $\$ 7.25$ & $\$ 7.25$ \\
\hline Oregon & $\$ 7.95$ & $\$ 8.40$ & $\$ 8.40$ & $\$ 8.50$ & $\$ 8.80$ \\
\hline Pennsylvania & $\$ 7.15$ & $\$ 7.25$ & $\$ 7.25$ & $\$ 7.25$ & $\$ 7.25$ \\
\hline Puerto Rico & $\$ 6.55$ & $\$ 6.55$ & $\$ 6.55$ & $\$ 6.55$ & $\$ 6.55$ \\
\hline Rhode Island & $\$ 7.40$ & $\$ 7.40$ & $\$ 7.40$ & $\$ 7.40$ & $\$ 7.40$ \\
\hline
\end{tabular}




\begin{tabular}{|c|c|c|c|c|c|}
\hline South Carolina & $\$ 6.55$ & $\$ 7.25$ & $\$ 7.25$ & $\$ 7.25$ & $\$ 7.25$ \\
\hline South Dakota & $\$ 6.55$ & $\$ 7.25$ & $\$ 7.25$ & $\$ 7.25$ & $\$ 7.25$ \\
\hline Tennessee & $\$ 5.58$ & $\$ 7.25$ & $\$ 7.25$ & $\$ 7.25$ & $\$ 7.25$ \\
\hline Texas & $\$ 6.55$ & $\$ 7.25$ & $\$ 7.25$ & $\$ 7.25$ & $\$ 7.25$ \\
\hline Utah & $\$ 6.55$ & $\$ 7.25$ & $\$ 7.25$ & $\$ 7.25$ & $\$ 7.25$ \\
\hline Vermont & $\$ 7.68$ & $\$ 8.06$ & $\$ 8.06$ & $\$ 8.15$ & $\$ 8.46$ \\
\hline Virginia & $\$ 6.55$ & $\$ 7.25$ & $\$ 7.25$ & $\$ 7.25$ & $\$ 7.25$ \\
\hline Washington & $\$ 8.07$ & $\$ 8.55$ & $\$ 8.55$ & $\$ 8.67$ & $\$ 9.04$ \\
\hline West Virginia & $\$ 7.25$ & $\$ 7.25$ & $\$ 7.25$ & $\$ 7.25$ & $\$ 7.25$ \\
\hline Wisconsin & $\$ 6.50$ & $\$ 7.25$ & $\$ 7.25$ & $\$ 7.25$ & $\$ 7.25$ \\
\hline Wyoming & $\$ 6.55$ & $\$ 7.25$ & $\$ 7.25$ & $\$ 7.25$ & $\$ 7.25$ \\
\hline \multicolumn{6}{|c|}{$\begin{array}{l}\text { Source: Based on Bureau of Labor Statistics data gathered by } \\
\text { Labor Law Center. }\end{array}$} \\
\hline
\end{tabular}


VITA

\section{RIGAUD JOSEPH}

Lauderhill, Florida

2011

B.S., Social Work

Florida Atlantic University

Boca Raton, Florida

2012

M.S. Social Work

Florida Atlantic University

Boca Raton, Florida

2012-2013

Functional Family Therapist

The Starting Place, Inc.

Plantation, Florida

2013-2014

Family Therapist

Family Central, Inc.

Miami, Florida

2014-2016

Research Assistant

Florida International University

Miami, Florida

2016-Present

Doctoral Candidate

Florida International University

Miami, Florida

Adjunct Professor

Florida International University

Miami, Florida

Fluency in written and spoken English

Fluency in written and spoken French

Fluency with written and spoken Haitian Creole

Working knowledge of Spanish 


\section{PUBLICATIONS AND PRESENTATIONS}

Joseph, R. (2017). The war on poverty then and now: A plan toward ultimate victory. Poverty \& Public Policy, 9(2), 209-223.

Joseph, R. (2016, June). Critical analysis of common social work theories of poverty and social welfare. Paper presented at the Third Annual Global WellBeing and Social Change Conference, Lancaster, PA.

Huang, H., Joseph, R., Fernandez, S., \& Rhoden, M. A. (2017, January). Early engagement in college support programs: The key to academic success among former child welfare youth and homeless students. Poster presented at the 2017 Society for Social Work and Research Conference, News Orleans, LA.

Joseph, R. (2017, February). Seeking educational justice for hard-to-reach populations: Emancipated foster youth and homeless college students. Paper presented at the Florida Atlantic University's Humanities and Social Justice Symposium, Boca Raton, FL.

Joseph, R. (2017, March). Factors associated with homeownership among lowincome families in America. Paper presented at the Florida International University's GSAW Scholarly Forum, Miami, FL.

Joseph, R. (2017, June). Concurrent enrollment in federally-funded welfare programs and empowerment toward economic self-sufficiency. Paper presented at the Influencing Social Policy's 2017 Conference 2.0, St. Louis, Missouri. 